\title{
NATHALIA SENGER
}

\section{AVALIAÇÃO DOS EFEITOS CARDÍACOS DA \\ ANGIOTENSINA 1-7 EM MODELO ANIMAL DE HIPERTIREOIDISMO}

\begin{abstract}
Dissertação apresentada ao Programa de Pós-Graduação em Ciências Morfofuncionais do Instituto de Ciências Biomédicas da Universidade de São Paulo, para obtenção do Título de Mestre em Ciências.
\end{abstract}

São Paulo 


\section{NATHALIA SENGER}

\section{AVALIAÇÃO DOS EFEITOS CARDÍACOS DA ANGIOTENSINA 1-7 EM MODELO ANIMAL DE HIPERTIREOIDISMO}

Dissertação apresentada ao Programa de Pós-Graduação em Ciências Morfofuncionais do Instituto de Ciências Biomédicas da Universidade de São Paulo, para obtenção do Título de Mestre em Ciências.

Área de concentração: Ciências Morfofuncionais.

Orientadora: Prof ${ }^{a}$ Dr $^{\mathrm{a}}$ Maria Luiza Morais Barreto de Chaves.

Versão Original

São Paulo 
DOOE DECATALOOACAO NA FUBLICAOHO IOIF) Benipo at ablideca e rfomspho alomedica do natht de cuncas B lambalcas de Lriversobde de Bbo Fuso

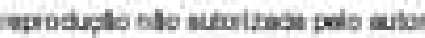

Benger, Nathala.

Aval acto dos etehos cardicos da angloteraina 1-7 em modelo animal de hipertireoldano / Nathala Senger. - S40 Paulo, 2015.

Orlentador. Prota. Dra. Mara Luza Moras Bareto de Chaves.

Disenaglo (Mestrado) - Unheraldade de SAo Paulo insturo de Clendas Blomed cas Departamento de Anatomla. Area de concentrafato clendas Mordotundonas. Linha de pesqulsa: Agto endosha na tslopatoogla cardovascular.

Versto do thilo para o ingles: Evaluation of cardac effects of angiotensin 1-7 in an arimai mode of hypertyryoidsn.

1. Hpetrofla cardaca 2. Funço cardaca 3. Homorio treduaro 4. Slstemb-Reilna-Angotensina 5. Angotensha 1-7 L. Chaves, Prota Dra. Marla Lulza Morals Bameto de II. Unversidade de Sto Paub. Instuto de Clenclas B omedcas. Programa de Pos-Graduacto en Clandas Mortofurdonals III. Thulo. 
Candidato(a): Nathalia Senger.

Título da Dissertação:- Avaliaçáo dos efeitos cardiacos da angiotensina 1-7 em modelo animal de hipert reoidismo.

Orientador(a):- $\quad$ Profa. Dra. Maria Luiza Morais Barreto de Chaves.

A Comissão Julgadora dos trabalhos de Defesa da Dissertaçăo de Mestrado, en sessảo pública realzada a $J$ considerou
(1) Aprovado(a)
( ) Reprovado(a)

Examinador(a): Assinatura:

Nome:

Instituip̧a:o:

Examinador(a): Assinatura:

Nome:

Instituipaso:

Presidente: Assinatura:

Nome:

Instituição: 


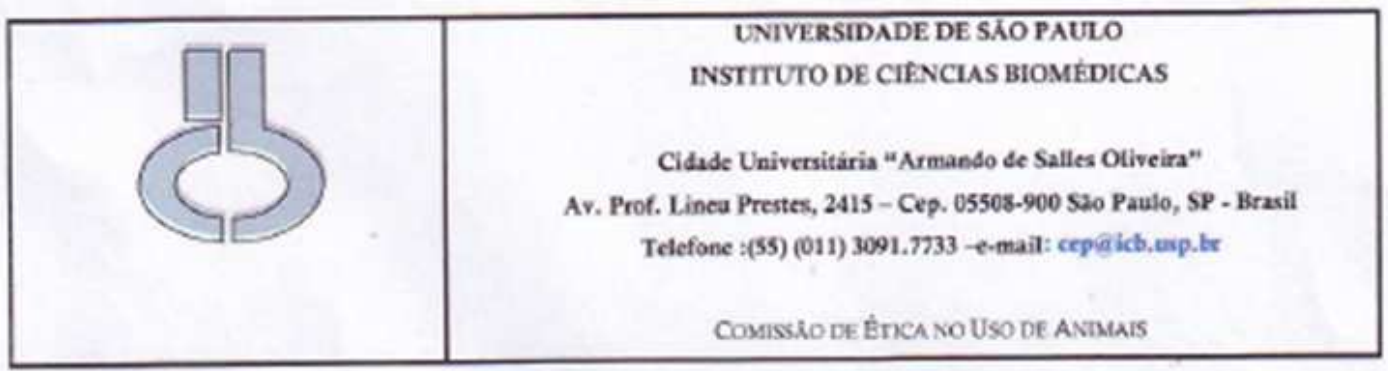

Decl. CEUA.027/2013.

Em adendo ao Certificado 030/12/CEUA, datado de 04.06 .12 e por solicitação da Profa. Dra. Maria Luiza Morais Barreto Chaves, responsável pela linha de Pesquisa, autorizo a inclusão da aluna Nathalia Senger ao Projeto de Pesquisa "Papel do sistema renina- angiotensina na hipentrofia cardiaca e/ou renal induzida pelos hormônios tiroideanos ", uma vez que se trata de utilização da mesma espécie animal e de métodos experimentais similares ao Projeto.

São Paulo, 05 de abril de 2013.

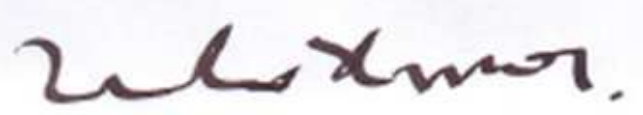

Prof. Dr. Wothan Tavares de Lima

Coordenador da CEUA

ICB/USP 
Aos meus pais,

Eduardo e Izilda, os quais são os responsáveis por todos os passos que dei em minha vida. 


\section{AGRADECIMENTOS}

À minha orientadora Profa . Dra . Maria Luiza Morais Barreto de Chaves por quem tenho muita admiração. Agradeço por me dar a oportunidade de trabalhar neste projeto e, sempre com muita dedicação e paciência, por contribuir para o meu crescimento científico e profissional.

Ao Prof. Dr. Robson Augusto dos Santos e à Profa. Dra. Maria José Campagnole pela intensa colaboração neste projeto, com 0 fornecimento dos animais geneticamente modificados e pela atenção e dedicação apresentada, por ambos, em todas as visitas que fiz ao Laboratório de Hipertensão.

A todos os colegas do laboratório LBCAF (Marina Fevereiro, Ana Paula Taniguchi, Ana Paula Takano, Caroline Lino, Ivson Bezerra, Camila Moreno, Denício Sousa, Elaine Castilho e Luana), os quais não só participaram diretamente da execução deste projeto, mas também, com muito companheirismo e amizade, tornaram todos os dias de trabalho muito mais prazerosos.

À Profa. Dra. Gabriela Placoná Diniz por toda ajuda fornecida durante todo o desenvolvimento do projeto.

Aos técnicos do laboratório do Prof. Dr. Robson Augusto dos Santos, José e Marilene, e a todos os seus alunos pela ajuda fornecida em diversos experimentos realizados em seu laboratório.

Ao Marcos Melo por aplicar toda a sua experiência e competência na realização dos exames ecocardiográficos.

Aos meus familiares, Eduardo, Izilda, Ana Paula e Ricardo pelo carinho e amor durante toda a minha trajetória. Sem vocês este dia não chegaria.

À Fundação de Amparo à Pesquisa do Estado de São Paulo pelo financiamento do projeto. 
Estudar é um privilégio e só o seu esforço pessoal o levará a conhecer pessoas e mundos que os acomodados jamais conhecerão. 


\section{Resumo}

SENGER, N. Avaliação dos efeitos cardíacos da Angiotensina 1-7 em modelo animal de hipertireoidismo. 2015. 92 f. Dissertação (Mestrado em Ciências Morfofuncionais) - Instituto de Ciências Biomédicas, Universidade de São Paulo, São Paulo, 2015.

Elevados níveis de hormônios tiroidianos (HT) promovem alterações no sistema cardiovascular, as quais culminam com a instalação de um processo hipertrófico e prejuízo na função cardíaca. Diversos trabalhos do nosso grupo demonstraram que um dos mecanismos para os HT levarem à hipertrofia e a outras manifestações cardiovasculares ocorre via ativação do Sistema Renina-Angiotensina (SRA), principalmente devido à ação do peptídeo Angiotensina II (Ang II). Por outro lado, a Angiotensina (1-7) (Ang 1-7), um peptídeo também sintetizado a partir do SRA, apresenta ações opostas às da Ang II correspondendo, portanto, a um importante braço contra-regulatório dentro do SRA. A hipótese do presente estudo é que a Ang 1-7 consiga atenuar ou prevenir os efeitos cardíacos induzidos pelos HT. Para testá-la, foram utilizados ratos transgênicos que superexpressam constitutivamente o peptídeo Ang 1-7 (TGR-L3292). Os animais foram induzidos ao hipertireoidismo por injeções intraperitoneais diárias de triiodotironina (T3) $(7 \mu \mathrm{g} / 100 \mathrm{~g}$ de peso corpóreo/dia) e/ou receberam infusão contínua do antagonista seletivo do receptor MAS (A779; $5 \mu \mathrm{g} / \mathrm{Kg} / \mathrm{h})$ por 14 dias. Parâmetros de morfologia e função cardíaca foram avaliados, bem como a modulação dos componentes do SRA frente aos diferentes tratamentos. Os elevados níveis de Ang 1-7 nos animais TGR-L3292 foram capazes de atenuar os efeitos tróficos induzidos por T3, diminuindo a massa cardíaca e aumentando a expressão gênica de $\beta$-MHC. O aumento de Ang 1-7 também atenuou o hiperdinamismo cardíaco e promoveu melhora da função cardíaca dos animais hipertireoideos. O tratamento com o A779, por sua vez, inibiu total ou parcialmente as ações cardioprotetoras da Ang 1-7. Em relação à modulação do SRA, os elevados níveis de T3 promoveram ativação do SRA local, com aumento da Ang II, do receptor AT1 e da atividade da ECA2 no coração. O efeito anti-hipertrófico da Ang 1-7 também foi verificado in vitro, no qual o tratamento com Ang 1-7 (1000nM) foi capaz de impedir o aumento da área de superfície celular 
em cultura primária de cardiomiócitos neonatos tratados com T3 (10nM) por 24 horas. Sendo assim, estes dados demonstram, pela primeira vez na literatura, ações cardioprotetoras da Ang 1-7 frente às ações cardíacas e hipertróficas do T3. Estudos futuros serão necessários para identificar os mecanismos moleculares responsáveis pela ação da Ang 1-7 sobre o coração hipertireoideo.

Palavras-chave: Hipertrofia cardíaca. Função cardíaca. Hormônio Tireoidiano. Sistema-Renina-Angiotensina. Angiotensina 1-7. 


\section{Abstract}

SENGER, N. Evaluation of cardiac effects of angiotensin 1-7 in an animal model of hyperthyroidism. 2015. 92 p. Masters thesis (Morphological Sciences) - Instituto de Ciências Biomédicas, Universidade de São Paulo, São Paulo, 2015.

High levels of thyroid hormones (TH) are responsible by promoting changes in the cardiovascular system, which culminate in the development of hypertrophy and cardiac dysfunction. We have previously demonstrated that $\mathrm{TH}$ promote cardiac hypertrophy and other cardiovascular manifestations through Renin-AngiotensinSystem (RAS) activation, especially due to Angiotensin II (Ang II). On the other hand, Angiotensin 1-7 (Ang 1-7), a peptide synthesized by RAS, promotes opposite cardioprotective actions of Ang II and corresponds to an important regulatory arm in RAS. The aim of this study is to verify if Ang 1-7 may influence the cardiovascular effects induced by TH. Transgenic rats that constitutively overexpress Ang 1-7 (TGRL3292) were used in this study. The animals received daily intraperitoneal injections of T3 $(7 \mu \mathrm{g} / 100 \mathrm{~g}$ of body weight/ day) for 14 days. Cardiac morphology, function parameters and RAS components were evaluated in the heart of all animals. High levels of Ang 1-7 were able to attenuate cardiac hypertrophy induced by T3, decreasing cardiac mass and increasing $\beta-\mathrm{MHC}$ gene expression. Ang 1-7 treatment attenuated hemodynamic parameters and improved the cardiac function of hyperthyroid animals, while $A 779$ treatment $(5 \mu \mathrm{g} / \mathrm{Kg} / \mathrm{h})$ inhibited or attenuated the cardioprotective actions of Ang 1-7. Moreover, high levels of T3 promoted local RAS activation, which was represented by increased Ang II levels, AT1 receptor and ACE2 activity in the heart. Anti-hypertrophic effects of Ang 1-7 were also observed in vitro. Ang 1-7 treatment (1000nM) prevented the increase in cell surface area in primary cultures of neonatal cardiomyocytes treated with T3 (10nM) for 24 hours. For the first time, cardioprotective actions of Ang 1-7 were observed in the heart of hyperthyroid animals. Future study will be necessaries to evaluate the molecular mechanisms involved to the Ang 1-7 actions on the hyperthyroid heart.

Keywords: Cardiac hypertrophy. Cardiac function. Thyroid hormone. Reninangiotensin-system. Angiotensin-(1-7). 


\section{LISTA DE FIGURAS}

Figura 1 - Caracterização da hipertrofia cardíaca concêntrica e hipertrofia cardíaca excêntrica

Figura 2 - Esquema representativo dos principais componentes do SRA.

Figura 3 - Vias de sinalização ativadas pela Angiotensina (1-7) em cardiomiócitos.

Figura 4 - Representação dos componentes estruturais do constructo para geração dos animais transgênicos.

Figura 5 - Ganho de massa corporal (em g) nos diferentes grupos experimentais

Figura 6 - Massa cardíaca (em g) normalizada pelo comprimento da tíbia (em $\mathrm{cm})$ nos animais selvagens

Figura 7 - Massa cardíaca (em g) normalizada pelo comprimento da tíbia (em $\mathrm{cm}$ ) nos animais transgênicos.

Figura 8 - Massa do VE e VD normalizadas pelo comprimento da tíbia nos animais selvagens.

Figura 9 - Massa do VE e VD normalizadas pelo comprimento da tíbia nos animais transgênicos.

Figura 10 - Expressão gênica de $\alpha-M H C$ e $\beta$-MHC nos diferentes grupos experimentais.

Figura 11 - Parâmetros funcionais avaliados por ecocardiograma nos diferentes grupos experimentais.

Figura 12 - Razão E/A avaliada por exames ecocardiográficos nos diferentes grupos experimentais. 
Figura 13 - Níveis de Ang I/II, nos diferentes grupos experimentais

Figura 14 - Expressão proteica do receptor Mas, nos diferentes grupos experimentais.

Figura 15 - Expressão proteica dos receptores da Ang II, receptor AT1 e AT2 nos diferentes grupos experimentais.

Figura 16 - Atividade da enzima ECA no VE nos diferentes grupos experimentais.

Figura 17 - Atividade da enzima ECA2 no VE nos diferentes grupos experimentais.

Figura 18 - Imagens das culturas primárias de cardiomiócitos neonatos com diferentes tratamentos experimentais

Figura 19 - Área de superfície celular dos cardiomiócitos neonatos nos diferentes tratamentos experimentais.

Figura 20 - Corte transversal do coração, em uma altura equidistante da base e do ápice, coletado logo após eutanásia.

Figura 21 - Massa cardíaca normalizada pelo comprimento da tíbia nos diferentes grupos experimentais

Figura 22 - Massa do VE e VD normalizadas pelo comprimento da tíbia nos diferentes grupos experimentais

Figura 23 - Corte histológico do VE corado com Hematoxilina e Eosina nos diferentes grupos experimentais, no aumento de $40 \mathrm{X}$

Figura 24 - Diâmetro transversal dos cardiomiócitos (em micrômetros) nos diferentes grupos experimentais

Figura 25 - Frequência cardíaca (em bpm) nos diferentes grupos experimentais. 
Figura 26 - Pressão de cauda (em $\mathrm{mmHg}$ ) nos diferentes grupos experimentais. 


\section{LISTA DE TABELAS}

Tabela 1 - Divisão dos animais (selvagens e transgênicos) nos diferentes grupos experimentais.

Tabela 2 - Sequência dos primers utilizados nos ensaios de PCR em tempo real.

Tabela 3 - Lista de anticorpos primários utilizados para a técnica de Western Blotting

Tabela 4 - Tratamentos das culturas primárias de cardiomiócitos neonatos.

Tabela 5 - Parâmetros morfológicos avaliados por ecocardiografia nos diferentes grupos experimentais.

Tabela 6 - Parâmetros funcionais avaliados por ecocardiografia nos diferentes grupos experimentais 


\section{LISTA DE ABREVIATURAS}

A779 - D-Ala-Angiotensin I/II 1-7

Alfa-MHC - Myosin Heavy Chain, Miosina de Cadeia Pesada Alfa

ANF - Atrial Natriuretic Factor, Fator Natriurético Atrial

Ang - Angiotensinogênio

Ang 1-7 - Angiotensina 1-7

Ang I - Angiotensina I

Ang II - Angiotensina II

Ang 1-9 - Angiotensina 1-9

ANOVA - Análise de variância

AP- Aminopeptidase

AT1 - Receptor da Ang II do tipo 1

AT2 - Receptor da Ang II do tipo 2

Beta-MHC - Myosin Heavy Chain, Miosina de Cadeia Pesada Beta

BNP - Brain Natriuretic Peptídeo, Peptídeo Natriurético Cerebral

BSA - Bovine serum albumine - albumina de soro bovino

$\mathrm{Ca}^{2+}$ - Cálcio

DC - Débito Cardíaco

DTT - Ditiotreitol

DI-VE - Diâmetro Interno do VE

DX600 - Peptídeo inibidor específico da ECA2

ECA - Enzima Conversora de Angiotensina

ECA 2 - Enzima Conversora de Angiotensina II 
ECL - Enhanced Chemiluminescence

EDTA - Ethylenediamine tetraacetic acid - ácido etilenodiamino tetra-acético

FC - Frequência Cardíaca

FE - Fração de ejeção

FS - Fração de encurtamento

GAPDH - Gliceraldeído 3-Fosfato Desidrogenase

Hepes - 4-(2-hidroxietil) -1-piperazinoetanossulfónico

HT - Hormônios Tireoidianos

IC - Insuficiência Cardíaca

$\mathbf{K C l}-$ Cloreto de potássio

Mas - Receptor da Angiotensina 1-7

$\mathrm{MgCl}^{2+}$ - Cloreto de Magnésio

MHz - Megahertz

n - Número de animais/ repetições

$\mathrm{NaCl}$ - Cloreto de sódio

NaOH - Hidróxido de sódio

NEP - Endopeptidase neutra

NO - Óxido Nítrico

PCP - Propil-carboxipeptidase

PEP - Propil-endopeptidase

PMSF - Fluoreto de fenilmetilsulfonilo

PP-VE - Parede Posterior do VE

rhACE2 - Enzima recombinante humana, ECA2 
SD - Ratos da linhagem Sprague Dawley

SDS - Dodecilsulfato de sódio

SERCA 2 - $\mathrm{Ca}^{2+}$ ATPase de Retículo sarcoplasmático

SI - Septo Interventricular

SRA - Sistema Renina-Angiotensina

T3 - Triiodotironina

T4 - Tiroxina

TBST - Tampão Salina Tris Tween-20

TGF-beta - Transforming Growth Factor, Fator de crescimento

TGR-L3292 - Ratos transgênicos que superexpressam Ang 1-7 circulante

Tris - Tris (hidroximetil) aminometano

Tris- $\mathbf{H C l}$ - Tris (hidroximetil) aminometano cloridrato

TRs - Receptores nucleares dos Hormônios Tireoidianos

VD - Ventrículo direito

VE - Ventrículo esquerdo

$\mathrm{ZnCl}_{2}-$ Cloreto de zinco 


\section{Sumário}

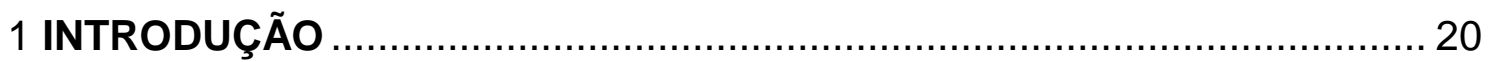

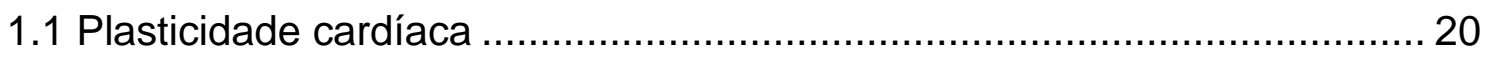

1.2 Hipertrofia cardíaca induzida pelos hormônios tireoidianos (HT) ............... 22

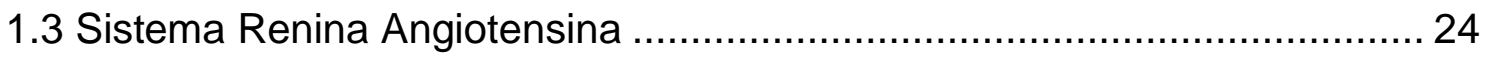

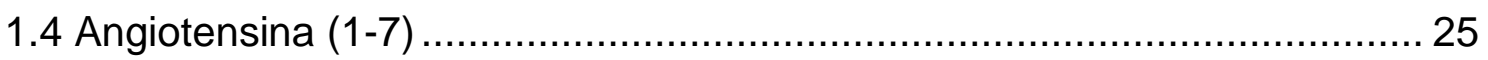

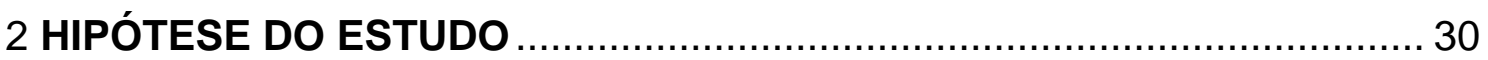

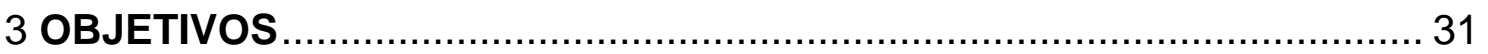

4 METODOLOGIA

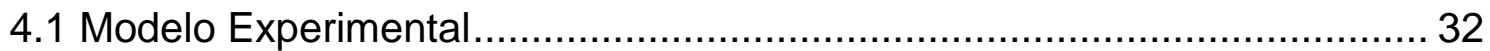

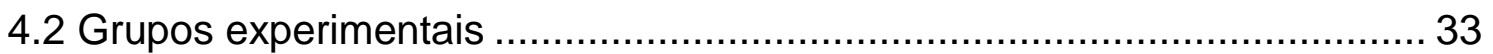

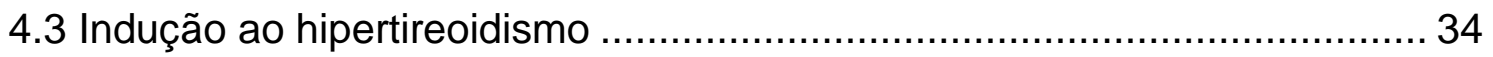

4.4 Implantação de minibombas osmóticas (Alzet 2004) ………..................... 35

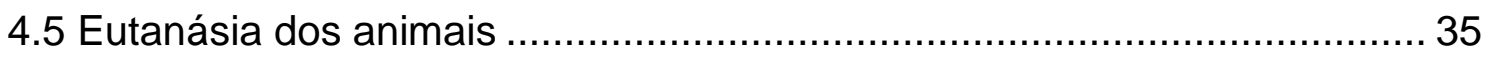

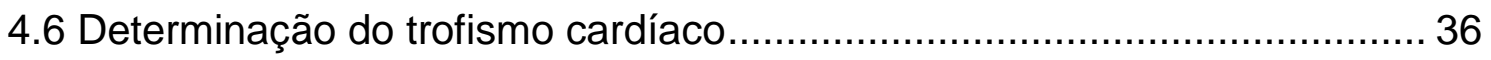

4.7 Avaliação da expressão gênica - RT-PCR ............................................. 36

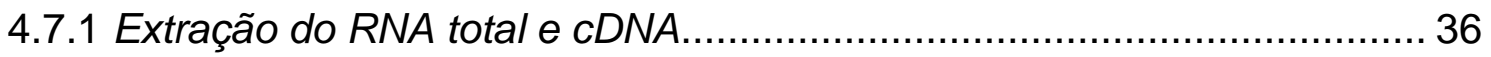

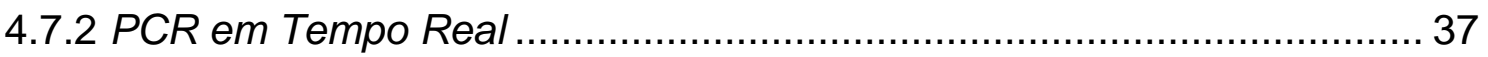

4.8 Análise da função cardíaca por Ecocardiograma .................................... 37

4.9 Avaliação da expressão proteica - Western Blotting ………………….... 38

4.10 Ensaio da Atividade da Enzima Conversora de Angiotensina (ECA) ....... 39

4.11 Ensaio da Atividade da Enzima Conversora de Angiotensina II (ECA2) .. 40

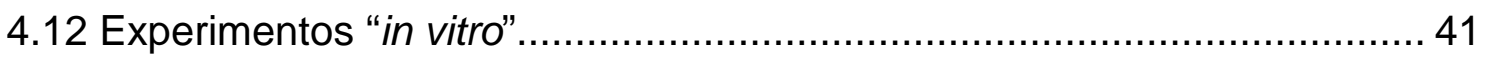

4.12.1 Cultura primária de cardiomiócitos .................................................... 41

4.12.2 Medida da área de superfície celular ................................................ 42

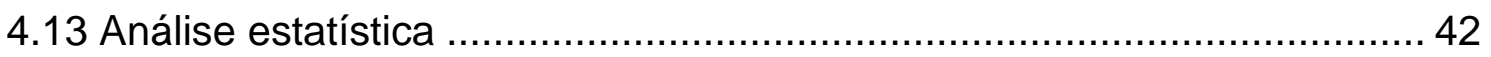




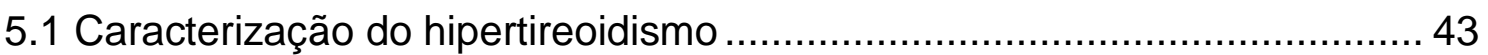

5.2 Caracterização do Trofismo cardíaco ........................................................ 44

5.3 Análise da morfologia e função cardíaca por Ecocardiografia..................... 49

5.4 Modulação do Sistema Renina Angiotensina - SRA.................................. 53

5.4.1 Expressão proteica dos componentes do SRA ………………............. 53

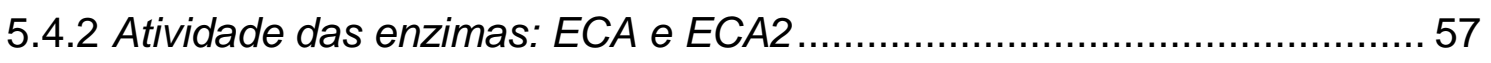

5.5 Análise do papel da Ang 1-7 nos efeitos tróficos induzidos pelo T3, in vitro59

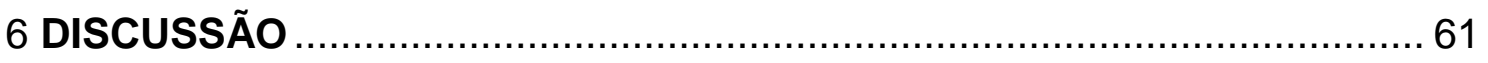

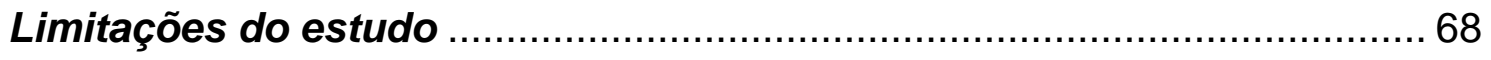

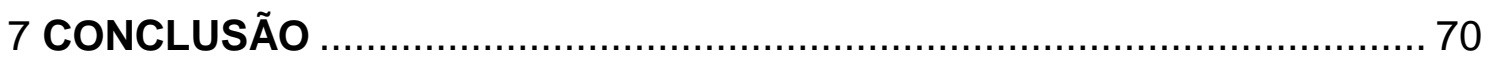

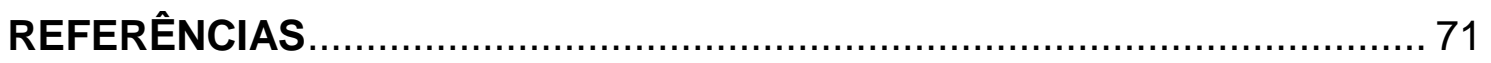

ANEXOS

A - Resultados obtidos em ratos tratados com infusão contínua de Ang1-7. 844

B - Tabela com os parâmetros funcionais avaliados por ecocardiograma. . 9090 


\section{INTRODUÇÃO}

\subsection{Plasticidade cardíaca}

O coração apresenta uma importante capacidade de se adaptar a aumentos da demanda hemodinâmica por meio do aumento da massa cardíaca, diminuindo o estresse da parede ventricular e preservando a função cardíaca (MAILLET; BERLO; MOLKENTIN, 2013). Neste sentido, devido ao fato do cardiomiócito ser a principal célula presente no coração em termos de volume ( $85 \%$ do volume cardíaco) e ser responsável pela função contrátil, o aumento da massa cardíaca está diretamente relacionado a processos tróficos dessa célula (BERNARDO et al., 2010). Após o nascimento, os cardiomiócitos passam a apresentar baixa ou nenhuma capacidade de se multiplicar (KAJSTURA et al., 2012); no entanto, ao longo da vida, diferentes estímulos podem promover o aumento da massa muscular cardíaca, a qual pode ocorrer de forma adaptativa/compensada ou descompensada (fisiológica e patológica, respectivamente) (MAILLET; BERLO; MOLKENTIN, 2013).

De maneira geral, como exemplo de hipertrofia compensada, temos aquela que acompanha o crescimento do coração ao longo do período uterino e pós-natal (MAILLET; BERLO; MOLKENTIN, 2013); ou ainda aquela que ocorre em decorrência da prática constante de exercícios físicos (PLUIM et al., 2000). Nesses casos, o aumento da massa muscular cardíaca (ou hipertrofia cardíaca) ocorre com um crescimento proporcional do coração, ou seja, ocorre espessamento da parede do ventrículo esquerdo com proporcional ganho de função cardíaca.

Por outro lado, o aumento da massa muscular cardíaca também pode estar associado a um prejuízo funcional, uma vez que pode promover remodelamento cardíaco, caracterizado por desencadeamento do processo de fibrose e deposição de colágeno no tecido cardíaco (PONTES; LEÃES, 2004). Neste caso, a hipertrofia descompensada, ou considerada por alguns autores como "patológica", irá levar à perda da capacidade contrátil da parede do ventrículo esquerdo, o que contribui para um desequilíbrio na pós-carga do coração, podendo causar arritmias cardíacas e taquicardia (KLEIN; OJAMAA, 2001). Além disso, quando os estímulos agressivos ao coração persistem mesmo após o processo hipertrófico instalado, o coração pode dilatar e diminuir sua função cardíaca desenvolvendo Insuficiência Cardíaca (IC) 
(HEINEKE; MOLKENTIN, 2006; HUNTER; CHIEN, 1999), sendo esta considerada uma das doenças mais comuns, caras e com alto índice de mortalidade no mundo atual (MCMURRAY; PFEFFER, 2005). Exemplos de hipertrofia cardíaca descompensada são aquelas relacionadas à sobrecarga de pressão crônica, como a hipertensão arterial sistêmica ou pulmonar (REMME, 2003).

Ainda no que concerne ao crescimento da massa muscular cardíaca, este pode ocorrer de forma concêntrica ou excêntrica. Na hipertrofia concêntrica ocorre um espessamento da parede do ventrículo esquerdo, sem grandes alterações no volume da câmara ventricular. Entretanto, a hipertrofia excêntrica apresenta um aumento na espessura da parede do ventrículo com aumento ainda maior da câmara ventricular (BERNARDO et al., 2010), conforme observado na Figura 1. Neste caso, a hipertrofia cardíaca excêntrica apresenta maiores riscos cardiovasculares do que a hipertrofia concêntrica, uma vez que a dilatação da câmara ventricular acarreta em disfunção sistólica e diastólica, com redução da função contrátil e da fração de ejeção do ventrículo esquerdo, a qual está muito associada com o desenvolvimento de IC (BERENJI et al., 2005).

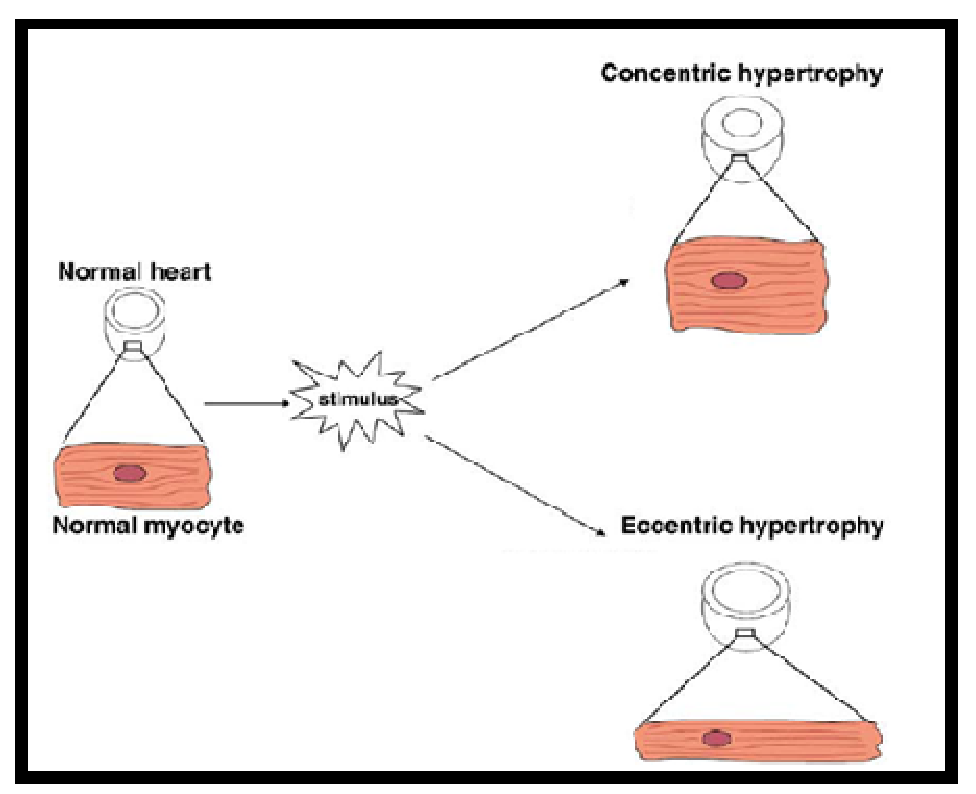

Figura 1 - Caracterização da hipertrofia cardíaca concêntrica e hipertrofia cardíaca excêntrica (adaptado de BERNARDO et al., 2010).

Em nível celular, além do aumento do volume do cardiomiócito, a hipertrofia vem acompanhada pela ativação de genes fetais, os quais voltam a ser expressos em 
resposta aos estímulos hipertróficos aos quais o cardiomiócito passa a estar exposto; e como exemplo temos: o Peptídeo Natriurético Cerebral (BNP), o Peptídeo Atrial Natriurético (ANF) e a Miosina de Cadeia Pesada do tipo $\beta$ ( $\beta-M H C$ ) (IZUMO et al., 1987; OGAWA; BOLD, 2014). A análise da expressão destes genes no coração, juntamente a outros parâmetros, corresponde então a um bom marcador do aumento da massa cardíaca. Estes genes estão ainda alterados em algumas cardiopatias e, por isso a sua dosagem sérica também tem relevância clínica em doenças cardiovasculares em geral (MASTER et al., 1993, 1999; YOKOTA et al., 1995).

1.2 Hipertrofia cardíaca induzida pelos hormônios tireoidianos $(\mathrm{HT})$

A principal célula-alvo das ações dos hormônios tireoidianos é o cardiomiócito, no qual atuam promovendo, entre outras funções, o aumento da síntese proteica. Os hormônios tireoidianos (HT) (triiodotironina ou T3 e tiroxina ou T4) correspondem a moduladores críticos no desenvolvimento e na ativação de diversas vias hipertróficas dos cardiomiócitos (KLEIN; OJAMAA, 2001). Desta forma, quando em altas concentrações, o T3 pode induzir a hipertrofia cardíaca mediante a ação direta do hormônio nas células cardíacas, após ligação a receptores nucleares, denominados TRs, ou através da ativação de vias de sinalização que independem da ligação dos HT aos receptores nucleares, mediante ações não-genômicas (BERGH, 2005; DAVIS; LEONARD; DAVIS, 2008; YEN, 2001).

Hadj-Sahraoui et. al. (2000) demonstraram em camundongos que, após o nascimento, os níveis séricos dos HT aumentam drasticamente para promover o crescimento do coração, e são reduzidos após a terceira semana de vida. Entretanto, no adulto, distúrbios da glândula tiroide podem levar a um fenótipo de hipertireoidismo e, como consequência, induzir a um processo de hipertrofia cardíaca.

A hipertrofia cardíaca desencadeada por elevados níveis de HT é inicialmente adaptada ou compensada (JANSSEN et al., 2014; OJAMAA, 2010), levando ao aumento da função contrátil, o que resulta no aumento do débito cardíaco; além do aumento da capilaridade e da redução do estresse oxidativo, do tônus vascular e da pós-carga (CASTRO et al., 2014; DILLMANN, 2010; FADEL et al., 2000; MAITY et al., 2013; PANTOS; MOUROUZIS; MARKAKIS, 2008). Por outro lado, níveis séricos 
elevados de T3 por períodos de tempo prolongados, em adultos, podem causar cardiopatias, uma vez que promovem alteração da excitabilidade cardíaca, contribuindo para o desenvolvimento de arritmias e dano mitocondrial (JOHNSON; FREEDBERG; MARSHALL, 1973; MAITY et al., 2013), além de sobrecarregar a função cardíaca, acarretando no desenvolvimento de insuficiência cardíaca (SIU et al., 2007).

Pacientes hipertireoideos sem controle dos níveis séricos dos hormônios tireoidianos progridem para um quadro de insuficiência cardíaca, com baixa fração de ejeção e arritmias cardíacas (WILDEMBERG et al., 2007). Também, em modelos animais (ratos Wistar adultos tratados por 14 dias com T3 - 20 vezes a dose fisiológica) um aumento no número de episódios arrítmicos foi evidenciado pelo nosso grupo, sem que houvesse, no entanto, até o fim do tratamento, qualquer sinal de fibrose (TAVARES et al., 2013).

Diversos estudos da literatura, inclusive os de nosso grupo, já demonstraram uma forte ligação entre os níveis circulantes do hormônio tireoidiano e a ativação do Sistema Renina-Angiotensina (SRA) no desenvolvimento da hipertrofia cardíaca. O aumento dos níveis circulantes de T3 foi responsável por um aumento dos níveis cardíacos de renina, Angl/Angll e dos receptores de Angiotensina II, AT1 e AT2 (CARNEIRO-RAMOS et al., 2006; DINIZ et al., 2012; KOBORI et al., 1997; MARCHANT et al., 1993).

Além da modulação dos componentes do SRA, a utilização de inibidores da ECA, do receptor AT1 (HU et al., 2003) ou do AT2 (CARNEIRO-RAMOS et al., 2010) preveniram total ou parcialmente a hipertrofia cardíaca induzida pelo hormônio tireoidiano, atuando sobre vias de sinalização específicas, o que comprova uma importante relação entre SRA e HT para o desenvolvimento da hipertrofia cardíaca. No entanto, o envolvimento de outros componentes do SRA, como a Ang 1-7, neste modelo de hipertrofia induzido por HT ainda não foi estudado e, se tratando de um eixo contralateral ao SRA clássico, é possível que também venha a ser modulado pelos HT, apresentando papel importante nos efeitos cardiovasculares, sob estas condições. 


\subsection{Sistema Renina Angiotensina}

O Sistema Renina-Angiotensina (SRA) corresponde a uma cascata hormonal, composta por diversas enzimas, peptídeos e receptores, os quais apresentam importante ação no controle homeostático da pressão sanguínea dentre outras ações atribuídas a este sistema (CROWLEY; COFFMAN, 2012). O SRA é composto primeiramente pela renina, uma enzima sintetizada e armazenada pelas células justaglomerulares renais (HAGAMAN et al., 1998), a qual é responsável por clivar o angiotensinogênio (Ang), molécula sintetizada pelo fígado (DESCHEPPER, 1994), em Angiotensina I (Ang I). A Ang I é um decapeptídeo que não apresenta ação biológica, sendo considerada, portanto, biologicamente inativa. Entretanto, este decapeptídeo é clivado mediante a ação da Enzima Conversora de Angiotensina I (ECA), em um octapeptídeo biologicamente ativo, conhecido como Angiotensina II (Ang II) (CORVOL et al., 1995).

Por muito tempo, este sistema foi considerado apenas um sistema endócrino oriundo da ativação da renina renal. Todavia, hoje já se sabe que as células de diferentes órgãos, como é o caso do coração, também são capazes de sintetizar, no seu interior, os RNAs mensageiros que codificam alguns dos componentes do SRA, caracterizando o SRA local. Sendo assim, paralelamente ao SRA endócrino existe o SRA local ou tecidual, com cinéticas enzimáticas diferentes e com capacidade de sintetizar a Ang II independentemente do SRA endócrino, a qual irá agir localmente promovendo ações fisiológicas e patológicas no sistema cardiovascular (RE, 2004). Atualmente, também já se tem conhecimento do SRA subcelular, ou também denominado intrácrino, como é o caso do SRA presente em organelas como a mitocôndria, retículo endoplasmático e núcleo e, que funcionam independentemente do SRA endócrino ou local e podem estar envolvidos no controle do estresse oxidativo intracelular ou mesmo na transcrição gênica (ABADIR et. al., 2011, 2012; TADEVOSYAN et al., 2010).

As principais ações biológicas da Ang II dependem de sua ligação a um receptor específico acoplado à proteína $\mathrm{G}$. Foram descritas duas classes de receptores para a Ang II, com ações fisiológicas distintas, conhecidos como receptor AT1 e AT2 (CHIU et al., 1989). Embora esses receptores tenham sido identificados ao mesmo tempo, inicialmente as ações fisiológicas da Ang II foram atribuídas apenas ao receptor AT1 (WRIGHT; HARDING, 1995). 
Os receptores AT1 estão presentes em maior quantidade nos vasos e, quando ativados pela Ang II, causam vasoconstrição devido à ativação da fosfolipase $\mathrm{C}$ e da proteína quinase C (APLIN et al., 2007; BALAKUMAR; JAGADEESH, 2014; JAGADEESH, 1998), além de contribuir para o desenvolvimento de aterosclerose, uma vez que a Ang II está relacionada com a formação de espécies reativas de oxigênio, assim como aumento da expressão de genes com ações pró inflamatórias (BALAKUMAR; JAGADEESH, 2014; DAUGHERTY; MANNING; CASSIS, 2000; IRANI, 2000; WEISS; KOOLS; TAYLOR, 2001).

No coração, a Ang II via receptor AT1 é responsável pela ativação de vias de crescimento celular e de produção de matriz extracelular, mediante ativação da via AKT/GSK3-B/mTOR (KUZMAN et al., 2005; MATSUI; NAGOSHI; ROSENWEIG, 2003; NGUYEN; MULLER, 2010) e da ativação de diacilglicerol, proteína quinase $C$ e ERK1/2 (BALAKUMAR; JAGADEESH, 2014; MEHTA; GRIENDLING, 2006), assim como responsável pelo aumento de SERCA e cálcio $\left(\mathrm{Ca}^{2+}\right)$, o que contribui para o aumento da força de contração (BALAKUMAR; JAGADEESH, 2014).

O receptor AT2, por sua vez, é expresso em altas quantidades durante a vida fetal e reduzido drasticamente após o nascimento (CAREY; WANG; SIRAGY, 2000). Sendo assim, este receptor apresenta grande participação no desenvolvimento embriológico (NOUET; NAHMIAS, 2000). A ligação da Ang II ao receptor AT2 promove efeitos vasodilatadores, por ativação da via P13K/AKT e efeitos antihipertróficos (DANYEL et al., 2013). Portanto, a ligação da Ang II ao receptor AT2 promove um efeito cardioprotetor que se opõe às ações deflagradas pela ativação do receptor $A T 1$, sendo que essa ação já foi demonstrada em diferentes modelos experimentais (BOOZ; BAKER, 1996; KESTEREN et al., 1997), inclusive no modelo de hipertrofia induzida por elevados níveis de HT (CARNEIRO-RAMOS et al., 2007; TAVARES et al., 2013).

\subsection{Angiotensina (1-7)}

Além dos peptídeos apresentados anteriormente, os quais compõem o SRA clássico, a descoberta de uma nova enzima (Enzima Conversora de Angiotensina II ECA 2) e de seus produtos, como exemplo da Angiotensina 1-7 (Ang 1-7), permitiu uma visão mais ampla sobre o papel do SRA e suas ações fisiopatológicas em 
doenças cardiovasculares e renais (FARAG et al., 2015; SANTOS et al., 1988, 2014).

Conforme observado na Figura 2, a Ang 1-7 pode ser sintetizada a partir da Ang I ou Ang II (SANTOS; CAMPAGNOLE-SANTOS; ANDRADE, 2000). As enzimas responsáveis pela síntese de Ang 1-7 a partir da Ang I são a propil-endopeptidase (PEP) e a endopeptidase neutra (NEP). Por outro lado, a principal enzima responsável pela formação da Ang 1-7 a partir da Ang II é a ECA 2 (SANTOS et al., 1988), sendo que sua afinidade catalítica pela Ang II é cerca de 400x maior que a afinidade pela Ang I (VICKERS et al., 2002). Entretanto, este peptídeo também pode ser sintetizado a partir da Ang II pela ação da propil-carboxipeptidase (PCP) e da PEP, embora estas apresentem papel secundário (SANTOS; CAMPAGNOLESANTOS; ANDRADE, 2000).

A Ang I também pode ser hidrolisada por ação da ECA 2 em Angiotensina 1-9 (Ang 1-9), que por sua vez é convertida em Ang 1-7 pela ação da ECA ou da NEP (RICE et al., 2004). Por outro lado, a Ang 1-7 é degradada por ação da ECA em um peptídeo metabolicamente inativo, Angiotensina 1-5 (Ang 1-5) (CHAPPELL et al., 1998; DEDDISH et al., 1991; NEVES et al., 1995). Sendo assim, a enzima ECA apresenta importante relação com a inativação da Ang 1-7 na circulação e nos tecidos (CHAPPELL et al., 2000; YAMADA et al., 1998).

Em 2003, Santos e cols. identificaram um receptor específico para a Ang 1-7, denominado receptor Mas, o qual pertence à família dos receptores acoplados à proteína G (PROBST et al., 1992). Este receptor foi originalmente descrito por Young e cols. (1986) como um proto-oncogene humano, devido à sua capacidade para induzir à tumorigenicidade em camundongos e, por isso recebeu o nome de MAS1 - proto-oncogene Mas. A presença do receptor Mas em cardiomiócitos foi descrita primeiramente por Tallant, Ferrario e Gallacher (2005), os quais demonstraram a presença desse receptor em cardiomiócitos neonatais, além de mostrar um efeito direto da Ang 1-7 nessas células. Posteriormente, também foi descrita a presença do receptor Mas em cardiomiócitos de adultos (SANTOS et al., 2006). 


\section{Angiotensinogênio}

(Asp-Arre-Val-Try-lè-His-Pro-Phe-His-Leu-Val-|le-His-Ser)

\section{Renina}

\section{Angiotensina I}

(Asp-Arg-Val-Try-Ile-His-Pro-Phe-His-Leu)!

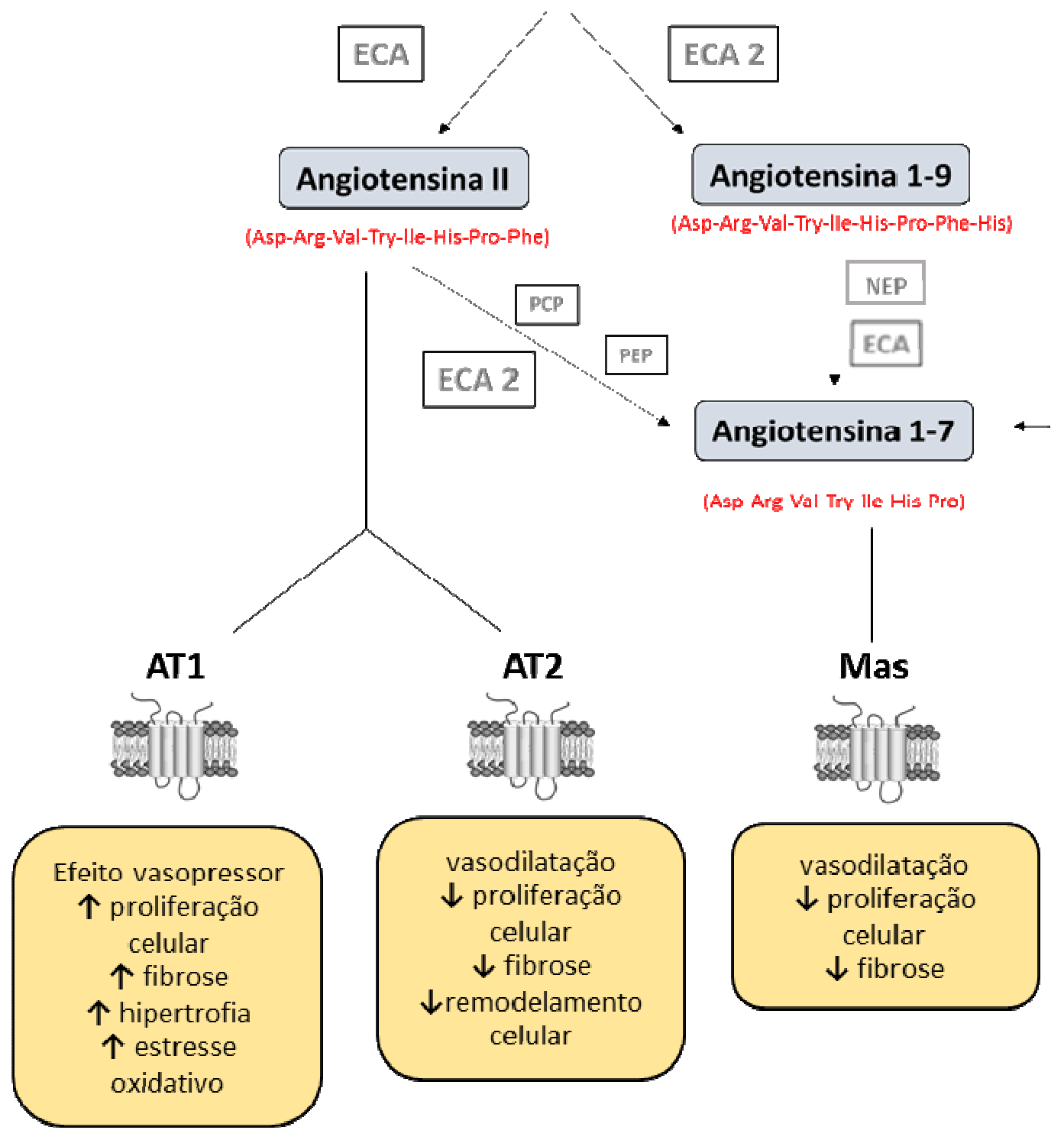

Figura 2 - Esquema representativo dos principais componentes do SRA. ECA: enzima conversora de angiotensina I; ECA2: enzima conversora de angiotensina II; PEP: propil-endopeptidase; NEP: endopeptidase neutra; PCP: propil-carboxipeptidase; AT1: receptor de Ang II tipo I; AT2: receptor de Ang II tipo 2; Mas: receptor de Ang 1-7 (adaptado de SANTOS et al., 2013). 
A Ang 1-7, uma vez se ligando a receptores Mas nos cardiomiócitos, promove a ativação de diversas vias de sinalização desencadeando respostas com ações "benéficas" ao sistema cardiovascular, como diminuição da resposta inflamatória, mediante a modulação negativa da migração de leucócitos e da expressão de citocinas pró-inflamatórias e aumento do efeito vasodilatador da bradicinina (ALMEIDA et al., 2000; BARROSO et al., 2012; JIN et al., 2012; MARQUES et al., 2012; PAULA et al., 1995). Além disso, no coração, a Ang 1-7 via receptor Mas também é capaz de promover vasodilatação coronariana (GRIENDLING et al., 1994), apresentar efeitos anti-arritmogênicos, uma vez que a Ang 1-7 está envolvida com a ativação de canais de sódio (DE MELLO, 2004; FERREIRA; SANTOS; ALMEIDA, 2001) e age sobre a expressão de proteínas relacionadas ao remodelamento cardíaco, diminuindo a deposição de colágeno (GROBE et al., 2006).

Dentre as ações da Ang 1-7, também foi observada uma importante relação do peptídeo com a produção de Óxido Nítrico (NO) em células epiteliais, uma vez que a Ang 1-7 é capaz de modular a via de sinalização PI3-K/ AKT/ NOS3, promovendo efeitos vasodilatadores (DIAS-PEIXOTO et al., 2008; SAMPAIO et al., 2007).

Além das ações mencionadas anteriormente, diversos estudos demonstraram ainda que a Ang 1-7 também é responsável por ações anti-hipertróficas em cardiomiócitos, uma vez que impede a ativação das MAPKs (TALLANT; FERRARIO; GALLACHER, 2005) e ativa a via anti-hipertrófica NO/GMPc (ENÉAS et al., 2009), conforme ilustrado na Figura 3. Ainda, a Ang 1-7 impede o aumento da proteína TGF- $\beta$, a qual, segundo alguns autores, é indispensável para induzir o efeito hipertrófico promovido pela Ang II (BUJAK; FRANGOCIANNIS, 2007). 


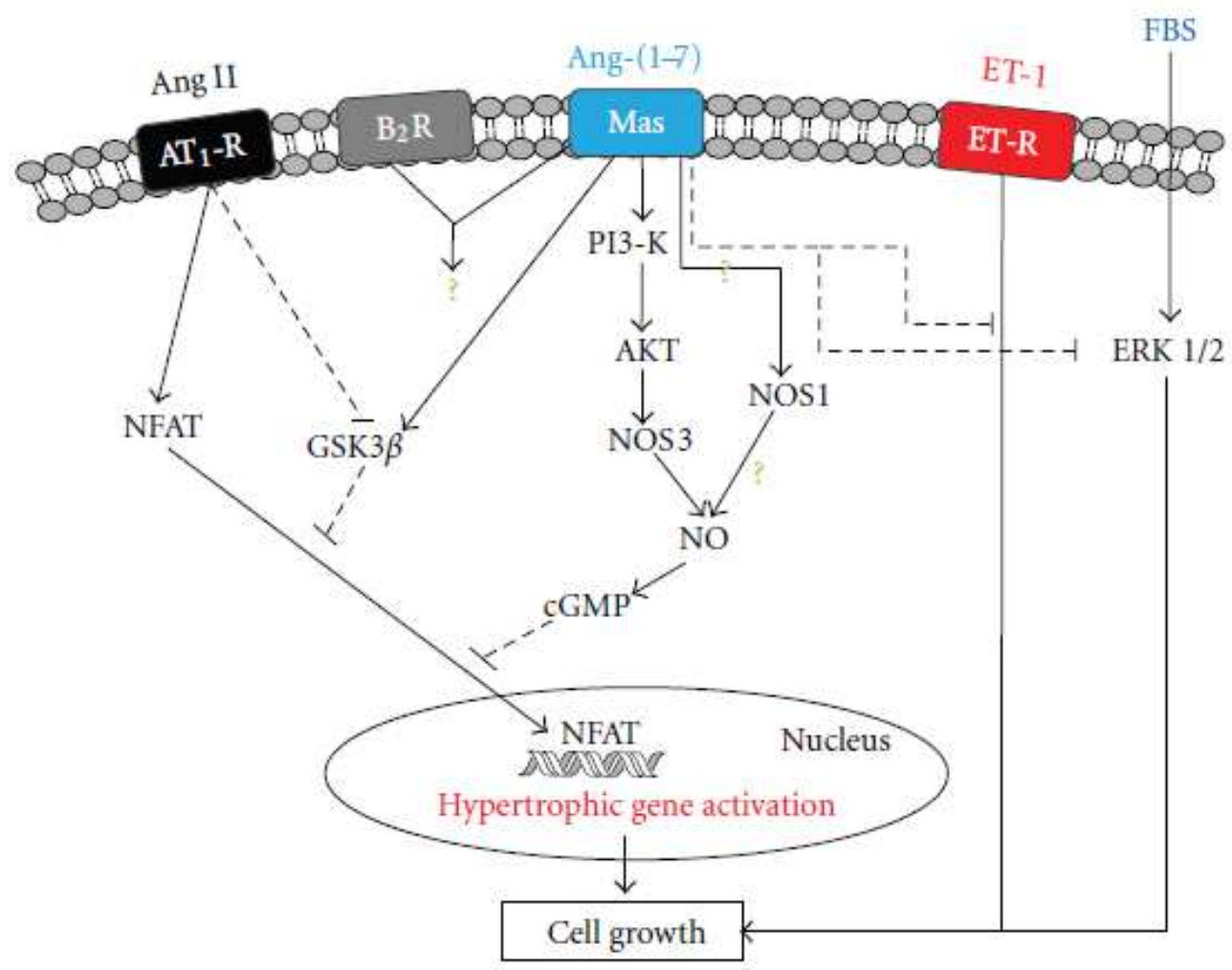

Figura 3 - Vias de sinalizações ativadas pela Angiotensina (1-7) em cardiomiócitos (GOMES et al., 2012).

Sendo assim, a Ang 1-7 apresenta importante papel na regulação do trofismo e da função cardíaca, contrabalanceando os efeitos promovidos pela Ang II via receptores do tipo AT1.

Com isto, algumas revisões recentes já sugerem o SRA sendo dividido em dois eixos antagônicos: o eixo ECA-Ang II- AT1, o qual apresenta um papel crítico ("de diabo") e o eixo ECA2-Ang 1-7-Mas, promovendo um papel antagônico àquele ("de anjo") do sistema (BALAKUMAR; JAGADEESH, 2014); embora saibamos que os dois eixos funcionam em relativa harmonia e são necessários para garantir a homeostasia do sistema. A cada dia novos peptídeos são identificados e, por conseguinte, a complexidade do sistema aumenta ainda mais. 


\section{HIPÓTESE DO ESTUDO}

Nosso grupo de pesquisa, assim como outros autores, já tem previamente demonstrado que elevados níveis de hormônios tiroidianos (HT) promovem uma série de alterações cardiovasculares, as quais culminam com a instalação de um processo hipertrófico, aumentando o risco de desenvolver cardiomiopatias crônicas (BARRETO-CHAVES et al., 2010, 2011; CAPPOLA et al., 2006), as quais representam a principal causa de morbidade e mortalidade no mundo atual (WORLD HEALTH ORGANIZATION - WHO, 2014).

Além das ações cardiovasculares propriamente ditas, o efeito direto dos HT sobre o cardiomiócito isolado indica a ação direta que esses hormônios possuem na estimulação de genes específicos e proteínas relacionadas ao trofismo cardíaco, as quais vêm sendo documentadas (TAKANO; DINIZ; BARRETO-CHAVES, 2013).

Um dos mecanismos para os HT levarem à hipertrofia é via Sistema ReninaAngiotensina, uma vez que a inibição in vivo ou in vitro de componentes deste sistema (ECA, AT1 ou AT2), inibem total ou parcialmente os efeitos tróficos dos HT (DINIZ; CARNEIRO-RAMOS; BARRETO-CHAVES, 2010; HU et al., 2003), indicando haver um importante cross-talk entre esses dois sistemas endócrinos.

Por outro lado, a descoberta da Ang 1-7, um heptapeptídeo biologicamente ativo cujas ações são frequentemente opostas àquelas atribuídas às da Ang II via receptor AT1, surgiu como um importante braço contra-regulatório dentro do SRA (TRASK; FERRARIO, 2007), tornando-se um potencial alvo terapêutico para o desenvolvimento de novos fármacos cardiovasculares (MARQUES et al., 2011, 2012). Este peptídeo apresenta efeitos anti-arrítmicos (FERREIRA; SANTOS; ALMEIDA, 2001) e inibe o crescimento do cardiomiócito, através da ativação do receptor MAS (TALLANT; FERRARIO; GALLACHER, 2005).

Sendo assim, a hipótese do presente estudo é a de que o aumento de Ang 1-7 circulante e seus efeitos cardioprotetores consigam atenuar ou prevenir os efeitos cardiovasculares associados ao hipertireoidismo. 


\section{OBJETIVOS}

Baseado no cross-talk existente entre o SRA e os HT, o presente estudo tem como objetivo:

- Avaliar o potencial da Ang 1-7 em atenuar ou prevenir os efeitos cardíacos (morfológicos e funcionais) observados em situações de hipertireoidismo. 


\section{METODOLOGIA}

\subsection{Modelo Experimental}

Para abordar os objetivos propostos neste estudo foram utilizados ratos geneticamente modificados que superexpressam o peptídeo Ang 1-7 (TGR-L3292), os quais foram gentilmente cedidos pelo Prof. Dr. Robson Augusto Santos, do Departamento de Fisiologia e Biofísica da Universidade Federal de Minas Gerais (UFMG). A escolha deste modelo experimental se baseou no fato de experimentos anteriores nos quais se administrou o peptídeo Ang 1-7 por meio de infusão contínua em ratos Wistar não terem apresentado sucesso, provavelmente devido à pequena meia-vida do peptídeo (resultados apresentados no ANEXO A).

Os animais transgênicos (TGR-L3292), da linhagem Sprague Dawley (SD), superexpressam o peptídeo Angiotensina 1-7 no testículo, o que culmina com um aumento na ordem de 2,5 vezes desse peptídeo no sangue venoso e arterial, caracterizando, portanto, um aumento de Ang 1-7 circulante (SANTOS et al., 2004). Esses animais foram gerados a partir da técnica de fusão proteica mediante a ação proteolítica da enzima furina, a qual permite aumentar a liberação de peptídeos em tecidos específicos, ou linhagem de células específicas, sem a necessidade dos componentes clássicos do SRA (METHOT et al., 1997, 2001). Neste sentido, foi desenvolvido por Santos et al (2004) um construto, o qual encontra-se esquematizado na Figura 4. Desta forma, por meio da ação proteolítica da furina no sítio de clivagem, o peptídeo Ang 1-7 é liberado no testículo, resultando em um aumento da ordem de 4,5 vezes de Ang 1-7 nessas gônadas, quando avaliado por radioimunoensaio. Esse aumento nos níveis de Ang 1-7 nos testículos não ocorre, por outro lado, em outros tecidos, como átrio e ventrículo esquerdo, na glândula adrenal, no fígado ou nos rins. Da mesma maneira, esses animais transgênicos não apresentam alterações nos níveis de Ang II nesses tecidos, quando avaliados por radioimunoensaio. 


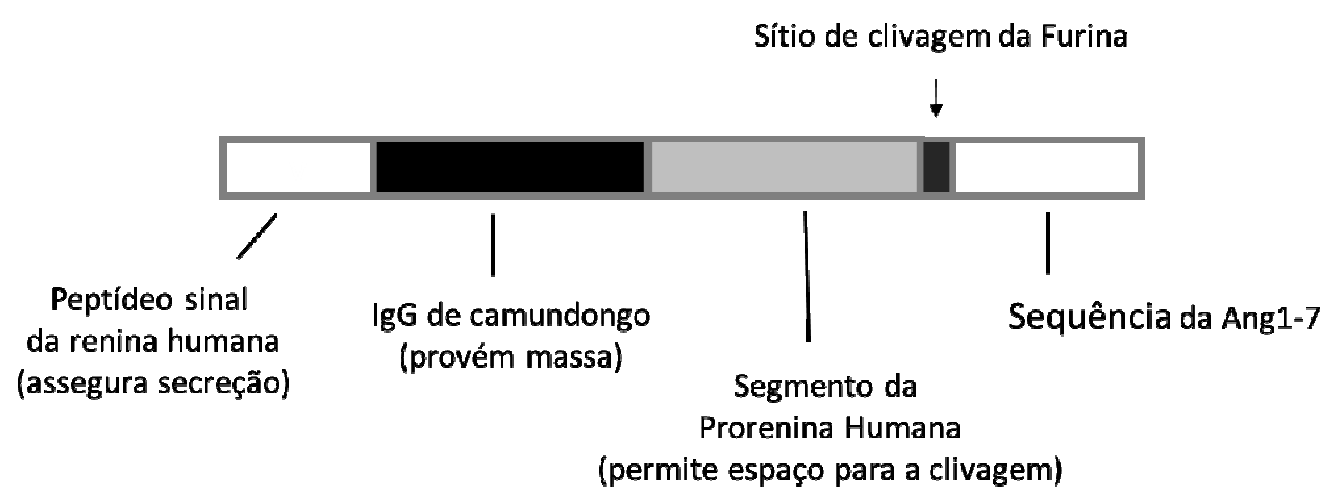

Figura 4 - Representação dos componentes estruturais do construto para a geração dos animais transgênicos, os quais superexpressam o peptídeo Angiotensina 1-7 (Santos et al., 2004).

\subsection{Grupos experimentais}

Ratos TGR-L3292 e ratos selvagens, da linhagem Sprague Dawley (SD), com idade entre 10 e 12 semanas, provenientes do Biotério de Animais Transgênicos do Laboratório de Hipertensão do Departamento de Fisiologia e Biofísica do Instituto de Ciências Biológicas da Universidade Federal de Minas Gerais, foram divididos em 5 grupos experimentais (Tabela 1). Durante todo o protocolo experimental, os animais foram mantidos no biotério e acondicionados em gaiolas plásticas $(49 \times 34 \times 16 \mathrm{~cm})$, com no máximo 5 animais por caixa, temperatura controlada $\left(21^{\circ} \mathrm{C}\right.$ a $\left.23^{\circ} \mathrm{C}\right)$, ciclo de claro-escuro de 12 horas (06:00h-18:00h) e com livre acesso à água e alimentação. $\mathrm{O}$ tratamento dos animais por 14 dias baseou-se em trabalhos anteriores do nosso grupo, nos quais o modelo de hipertireoidismo foi previamente caracterizado (COTOMACCl et al., 2012; TAVARES et al., 2013).

Todos os procedimentos realizados com os animais obedeceram às normas estabelecidas pela Comissão de Ética no Uso de Animais do ICB/USP, seguindo o protocolo de experimentação animal No. 030/12/CEUA. 
Tabela 1 - Divisão dos animais nos diferentes grupos experimentais.

\begin{tabular}{|c|c|}
\hline $\begin{array}{c}\text { GRUPOS } \\
\text { EXPERIMENTAIS }\end{array}$ & TRATAMENTO \\
\hline $\begin{array}{l}\text { Grupo Controle } \\
\qquad \begin{array}{l}(\mathrm{C}) \\
n=5\end{array}\end{array}$ & $\begin{array}{l}\text { Ratos selvagens receberam injeções intraperitoneais de } \\
\text { solução salina, diariamente, durante } 14 \text { dias. }\end{array}$ \\
\hline $\begin{array}{l}\text { Grupo T3 } \\
\text { (T3) } \\
\text { n=6 }\end{array}$ & $\begin{array}{l}\text { Ratos selvagens foram induzidos ao hipertireoidismo com } \\
\text { injeções intraperitoneais de T3 }(7 \mu \mathrm{g} / 100 \mathrm{~g}) \text {, durante } 14 \text { dias. }\end{array}$ \\
\hline $\begin{array}{l}\text { Grupo Ang 1-7 } \\
\begin{array}{c}(A) \\
n=5\end{array}\end{array}$ & $\begin{array}{l}\text { Ratos TGR-L3292 receberam injeções intraperitoneais de } \\
\text { solução salina diariamente, durante } 14 \text { dias. }\end{array}$ \\
\hline $\begin{array}{c}\text { Grupo Ang 1-7 + T3 } \\
\text { (AT3) } \\
n=6\end{array}$ & $\begin{array}{l}\text { Ratos TGR-L3292 foram induzidos ao hipertireoidismo com } \\
\text { injeções intraperitoneais de T3 }(7 \mu \mathrm{g} / 100 \mathrm{~g}) \text {, durante } 14 \text { dias. }\end{array}$ \\
\hline $\begin{array}{c}\text { Grupo Ang 1-7 + T3 } \\
+ \text { A779 } \\
(\text { AT3A) } \\
n=6\end{array}$ & $\begin{array}{c}\text { Ratos TGR-L3292 receberam infusão contínua de A779 } \\
\text { (antagonista seletivo do receptor Mas) por minibombas } \\
\text { osmóticas e injeções intraperitoneais de T3 }(7 \mu \mathrm{g} / 100 \mathrm{~g}) \text {, } \\
\text { durante } 14 \text { dias. }\end{array}$ \\
\hline
\end{tabular}

\subsection{Indução ao hipertireoidismo}

Os animais foram induzidos ao hipertireoidismo mediante injeções intraperitoneais (i.p), uma vez ao dia, de T3 (Sigma-Aldrich). O T3 foi diluído primeiramente em hidróxido de sódio $(\mathrm{NaOH})(0,35 \mathrm{M})$, formando uma solução mãe, a qual foi devidamente armazenada em freezer $-20{ }^{\circ} \mathrm{C}$. No momento da aplicação do T3 nos animais, a solução mãe de T3 foi descongelada e diluída novamente em solução salina com concentração final de $7 \mu \mathrm{g} / 100 \mathrm{~g}$ de peso corpóreo/dia, o que corresponde a 20 vezes a dose fisiológica (BIANCO; SILVA, 1987).

Os animais que não foram tratados com T3 (animais do grupo controle e grupo Ang 1-7) receberam diariamente injeções intraperitoneais de solução salina contendo a mesma quantidade de $\mathrm{NaOH}(0,34 \mathrm{M})$, solução veículo. 
4.4 Implantação de minibombas osmóticas (Alzet 2004)

Com o intuito de verificarmos a participação do receptor Mas nas ações cardioprotetoras da Ang 1-7, utilizamos um antagonista seletivo para este receptor, D-Ala-Angiotensin I/II 1-7 (A779) (BACHEM H-2888), o qual foi administrado via minibombas osmóticas de liberação contínua (Alzet, modelo 2004: 0,25 $\mu \mathrm{l} / \mathrm{h}, 28$ dias). Para isso, as mesmas foram pesadas quando vazias e, em seguida, preenchidas com A779, diluído em solução salina, sendo a dose de A779 correspondente a $5 \mathrm{\mu g} / \mathrm{Kg} / \mathrm{h}$ (SANTOS et al., 1994). Posteriormente, as bombas com seu volume já completo foram pesadas novamente para assegurar que 90\% (no mínimo) de seu volume tivesse sido preenchido. Após esta etapa, as minibombas foram armazenadas em solução salina a $37^{\circ} \mathrm{C}$ durante $28 \mathrm{hs}$ antes da implantação nos animais, para assegurar a liberação imediata de A779 quando implantadas nos animais, conforme solicitado nas instruções do fabricante.

Para a implantação das minibombas osmóticas na região dorsal, os animais foram anestesiados com uma solução de Xilazina e Ketamina, por via intraperitoneal, em uma concentração de $0,1 \mathrm{ml}$ de Xilazina e $0,5 \mathrm{ml}$ de Ketamina para cada 100 gramas de peso do animal (MASSONE, 1988). O dia referente à implantação das minibombas osmóticas foi considerado o dia zero e, a partir dele, contados 4 dias de pré-tratamento com o antagonista do receptor Mas (A779). Após este período, iniciaram-se as injeções com T3 durante 14 dias, período no qual também houve liberação contínua do A779 mediante as minibombas osmóticas.

\subsection{Eutanásia dos animais}

Os animais foram decapitados sem utilização de anestésico, com o intuito de evitarmos a sua interferência nas dosagens bioquímicas, conforme já descrito na literatura (SANTOS; KRIEGER; GREENE, 1985). Os animais foram submetidos à toracotomia e o coração exposto foi rapidamente retirado e colocado em um béquer contendo solução salina $0,9 \%$. Posteriormente, o coração foi pesado e separado o ventrículo esquerdo (VE) (juntamente com o septo interventricular) e o ventrículo direito (VD), os quais também foram pesados separadamente. O VE e VD foram armazenados em microtubos de centrifugação previamente identificados, os quais foram inicialmente congelados em nitrogênio líquido e posteriormente armazenados em freezer $-80^{\circ} \mathrm{C}$. 
4.6 Determinação do trofismo cardíaco

A determinação e caracterização do trofismo cardíaco foi realizada utilizando os dados de massa cardíaca obtidos no dia da eutanásia dos animais, normalizados pelo comprimento da tíbia, o qual foi obtido com auxílio de um paquímetro. As massas relativas ao VE e ao VD, normalizadas pelo comprimento da tíbia, foram também avaliadas separadamente.

\subsection{Avaliação da expressão gênica - RT-PCR}

Para a confirmação do trofismo cardíaco nos diferentes grupos experimentais, avaliamos a expressão gênica dos seguintes marcadores de hipertrofia cardíaca: $\alpha$ MHC e $\beta-M H C$, os quais foram normalizados pela expressão gênica de GAPDH. A escolha do normalizador se deu baseada em estudos prévios os quais mostraram que o GAPDH não sofre alterações em sua expressão gênica em corações de animais tratados com hormônio tireoidiano (CARNEIRO-RAMOS et al., 2010).

\subsubsection{Extração do RNA total e cDNA}

A extração de RNA total foi realizada a partir de 50-100 mg de tecido cardíaco (VE), homogeneizadas em $1 \mathrm{~mL}$ de Trizol (Invitrogen), com auxílio de um Polytron (KINEMATICA POLYTRON HOMOGENIZER MIXER -PCU11). Após esta etapa, realizou-se uma série de centrifugações com clorofórmio, álcool isopropílico e etanol 75\% para possibilitar a precipitação do RNA, o qual posteriormente foi diluído em água MilliQ autoclavada. O RNA total foi dosado no espectrofotômetro de alta sensibilidade, utilizando um programa específico para análise de ácidos nucléicos (Gen5 Data Analysis Software, BioTek), em comprimento de onda 260 e $280 \mathrm{~nm}$. Após esta etapa, a integridade do RNA extraído foi verificada em gel de Agarose corado com Brometo de Etídio, sendo observadas duas subunidades de RNA ribossomal (18 s e 20 s) sob luz ultravioleta. Confirmada a integridade do RNA, seguiu-se com a reação de transcrição reversa para a síntese da fita simples do DNA complementar (cDNA), mediante utilização de $1 \mu \mathrm{g}$ de RNA total e da enzima M-MLV (Reverse Transcriptase, Invitrogen) no termociclador (MJ Research PTC200). 


\subsubsection{PCR em Tempo Real}

Para cada gene avaliado foram realizadas curvas de quantidades progressivas de cDNA, a fim de identificar a concentração ideal de cDNA, além de evitar saturação das amostras durante a reação. Todas as análises foram realizadas em duplicatas e em cada reação foi utilizado um controle negativo, o qual não continha o cDNA. Nas reações utilizou-se SYBR Green PCR Master Mix (coquetel de reagentes - Invitrogen), primer (10 $\mu \mathrm{M})$, cDNA e água para completar um volume final de $12 \mu \mathrm{l}$. As amostras foram submetidas a 40 ciclos com temperatura de anelamento de $60^{\circ} \mathrm{C}$. Os primers utilizados estão listados na Tabela 2.

Tabela 2 - Sequência dos primers utilizados nos ensaios de PCR em tempo real.

\begin{tabular}{cc}
\hline Gene & Sequência dos primers \\
\hline Alfa-MHC & $\begin{array}{c}\text { sense: 5' ACAGAGTGCTTCGTGCCTGAT 3' } \\
\text { anti-sense: 5'CGAATTTCGGAGGGTTCTGC 3' }\end{array}$ \\
\hline Beta-MHC & $\begin{array}{c}\text { sense: 5' AGCGAGGCTCCACCCCACAT 3' } \\
\text { anti-sense: 5' CAAGGTGCCCTTGCCTGGGG 3' }\end{array}$ \\
\hline GAPDH & $\begin{array}{c}\text { sense: 5' TGGTGGACCTCATGGCCTAC 3' } \\
\text { anti-sense: 5' CAGCAACTGAGGGCCTCTCT 3' }\end{array}$ \\
\hline
\end{tabular}

\subsection{Análise da função cardíaca por Ecocardiograma}

Para avaliação da função cardíaca frente às diferentes manobras experimentais foi realizado o exame de ecocardiografia transtorácica, com avaliação da morfologia cardíaca e da função ventricular sistólica e diastólica. Os parâmetros ecocardiográficos avaliados se basearam nas recomendações da Sociedade Americana de Ecocardiografia (SAHN et al., 1978). Para a realização do exame, os animais foram anestesiados com isoflurano $(3,5 \%)$ e posicionados em decúbito dorsal em mesa equipada com eletrodos eletrocardiográficos para mensuração contínua da frequência cardíaca (FC). As análises foram realizadas utilizando o equipamento de alta resolução VEVO $2100 \mathrm{com}$ transdutores de 16-21 MHz (Visual Sonics, Toronto, Canada) e os parâmetros morfológicos e funcionais avaliados com imagens geradas em modo $\mathrm{M}$ e avaliação bidimensional do eixo curto do coração. 
4.9 Avaliação da expressão proteica - Western Blotting

A técnica de Western Blotting foi utilizada para avaliar a expressão proteica de diferentes componentes do SRA, tais como os receptores de Angiotensina II, AT1 e AT2, o receptor da Angiotensina 1-7, MAS, assim como os níveis de Ang I/II, no tecido cardíaco dos diferentes grupos experimentais. Todas as análises foram normalizadas pela expressão proteica do GAPDH, uma vez que esta proteína não se apresenta alterada no modelo de hipertrofia cardíaca induzida por HT (TAKANO et al., 2013). Desta forma, amostras de VE armazenadas em freezer $-80^{\circ} \mathrm{C}$ foram homogeneizadas no Polytron em tampão apropriado $(90 \mathrm{mM} \mathrm{KCl}, 10 \mathrm{mM}$ Hepes, 3 mM MgCl2, 5 mM EDTA, 1\% glicerol, 1 mM DTT, 0,04\% SDS; pH 7,4), juntamente com um mix de inibidores de proteases $(20 \mathrm{mM}$ aprotinina, $20 \mathrm{mM}$ pepstatina, 20 mM leupepstatina, $40 \mu \mathrm{M}$ PMSF e $100 \mathrm{mM}$ ortovanadato).

$\mathrm{O}$ lisado proteico foi centrifugado a $10.000 \mathrm{rpm}$ durante 20 minutos a $4^{\circ} \mathrm{C}$ e o sobrenadante foi coletado e armazenado em freezer $-80{ }^{\circ} \mathrm{C}$. A quantificação da concentração proteica das amostras foi obtida pelo Método de Bradford (Bradford, 1976) e calculada segundo a equação da reta obtida a partir da curva de concentração padrão com Albumina Sérica Bovina - BSA, sendo todas as amostras dosadas em duplicatas.

Para cada ensaio foram utilizados $30 \mu \mathrm{g}$ de proteína, as quais foram separadas por eletroforese (140 volts por 1 hora e 30 minutos) mediante seu peso molecular em gel de $10 \%$ de SDS-Poliacrilamina (Sódio Dodecil Sulfato-Poliacrilamina) e, então transferidas (20 volts por 1 hora) para uma membrana de nitrocelulose (BioRad). Após o término da transferência, a membrana foi marcada com solução Ponceau para avaliar tanto a efetividade da transferência, como a existência da mesma quantidade de proteína nos diferentes poços. A membrana foi lavada com Tampão Salina Tris Tween-20 (TBST) (50 mM Tris, 150 mM NaCl, 2\% Tween-20; pH $7,5)$ por 10 minutos a temperatura ambiente para garantir a retirada por completo da solução Ponceau. As membranas foram incubadas a $4{ }^{\circ} \mathrm{C}$, overnight, com anticorpo primário específico para cada proteína de interesse. No dia seguinte, após lavagem com TBST 3 vezes por 10 minutos, as membranas foram incubadas com o anticorpo secundário ligado à peroxidase por 1 hora a temperatura ambiente e, lavadas novamente com TBST. A solução de ECL (Enhanced Chemiluminescence - Thermo Scientific $\left({ }^{\circ}\right)$ foi adicionada e a membrana foi revelada mediante utilização do 
aparelho UVITEC Cambrigde. A banda correspondente à proteína de interesse foi quantificada utilizando o Programa UVITEC (UVI-1D). A lista de anticorpos primários utilizados para análise da expressão proteica por Western Blotting encontra-se na Tabela 3.

Tabela 3 - Lista de anticorpos primários utilizados para a técnica de Western Blotting.

\begin{tabular}{cccc} 
Proteína & Marca & Peso Molecular & Titulação \\
\hline AT1 & Sigma-Aldrich & $43 \mathrm{KDa}$ & $1: 1000$ \\
\hline AT2 & VBP & $45 \mathrm{KDa}$ & $1: 1000$ \\
\hline Mas & ++ & $33 \mathrm{KDa}$ & $1: 500$ \\
\hline Ang I/II & Santa Cruz & $60 \mathrm{KDa}$ & $1: 1000$ \\
\hline- O anticorpo para o receptor MAS foi produzido e gentilmente cedido pelo Prof.
\end{tabular}

Robson A. dos Santos, UFMG.

4.10 Ensaio da Atividade da Enzima Conversora de Angiotensina (ECA)

A atividade da ECA nos corações dos animais dos diferentes grupos experimentais foi determinada por ensaio fluorimétrico, conforme descrito previamente (SANTOS; KRIEGER; GREENE, 1985). As amostras do ventrículo esquerdo foram homogeneizadas (Politron) em tampão de borato de sódio $0,4 \mathrm{M}(\mathrm{pH}$ 8,3) contendo $\mathrm{NaCl} 0,9 \mathrm{M}$ e centrifugadas a $1500 \mathrm{rpm}$ durante 20 minutos a $4{ }^{\circ} \mathrm{C}$, para a coleta do sobrenadante. Posteriormente, $10 \mu \mathrm{l}$ do homogeinato de VE foram incubados com $490 \mu \mathrm{l}$ do substrato da ECA (substrato Hip-His-Leu) (Sigma St. Louis, $\mathrm{MO}$, USA) durante 30 minutos a $37^{\circ} \mathrm{C}$. A reação foi interrompida com a adição de $1,2 \mathrm{ml}$ de $\mathrm{NaOH} 0,34 \mathrm{M} \mathrm{e}$, em seguida foram adicionados $100 \mu \mathrm{l}$ de ortoftaldialdeído 
(20 $\mathrm{mg} / \mathrm{mL}$ em metanol). Após 10 minutos em temperatura ambiente, foram acrescidos $200 \mu \mathrm{l}$ de $\mathrm{HCl} 3 \mathrm{~N}$.

O produto da reação, His-Leu, foi medido por fluorimetria (excitação 365 nm; emissão 495 nm) (SPECTROFLUOROPHOTOMETER; Shimadzu; RF-1501). As leituras foram normalizadas pela concentração proteica das respectivas amostras, dosadas pelo Método Bradford e, expressas em nmoles de His-Leu/min/mg de proteína. Para corrigir uma possível fluorescência intrínseca do ensaio, foi preparado um branco e, todas as amostras foram realizadas em duplicatas, assim como 0 branco.

\subsection{Ensaio da Atividade da Enzima Conversora de Angiotensina II (ECA2)}

Para a determinação da atividade da ECA 2 foi realizado um ensaio cinético, com utilização de um substrato fluorogênico (Fluorogenic Peptide Substrate VI R\&D Systems) (FRAGA-SILVA et al, 2013). Para isso, as amostras de VE foram homogeneizadas (Politron) com tampão de extração (10X) contendo Tris-HCl 750 $\mathrm{mM}$ e $\mathrm{ZnCl} 25 \mu \mathrm{M}, \mathrm{pH}$ 7,5, e o homogenato centrifugado a $3000 \mathrm{rpm}$ durante 10 minutos a $4{ }^{\circ} \mathrm{C}$. A concentração de proteína no homogenato foi quantificada pelo método de Bradford (BRADFORD, 1976). Uma solução de reação foi preparada, contendo $70 \mu \mathrm{g}$ de proteína da amostra, $1 \mu \mathrm{l}$ de captopril (com concentração final de $10 \mu \mathrm{M}$ ), $10 \mu \mathrm{l}$ do substrato (concentração final de $50 \mu \mathrm{M}$ ), $2 \mu \mathrm{l}$ de $\mathrm{NaCl} 5 \mathrm{M}$ e $1 \mu \mathrm{l}$ do tampão de ECA2 (10X), sendo o volume completado para $100 \mu \mathrm{l}$ com tampão de extração 1X. Para preparação do controle negativo da fluorescência foi adicionado à reação um inibidor da ECA2 (Dx600) e, para preparação do controle positivo foi adicionada a enzima recombinante humana, rhACE2. Imediatamente após a adição do substrato, iniciou-se o ensaio cinético e a leitura de fluorescência foi realizada em espectrofluorímetro de placa (Biotek Synergy TH), a cada 1 minuto, durante 1 hora a $37{ }^{\circ} \mathrm{C}$. O resultado foi obtido através da média dos últimos 5 minutos de leitura, sendo todos os resultados normalizados pelo branco. A atividade da ECA2 foi expressa em unidades de fluorescência/minuto/ mg de proteína. 


\subsection{Experimentos "in vitro"}

\subsubsection{Cultura primária de cardiomiócitos}

Para avaliar o possível efeito anti-hipertrófico da Ang1-7 no modelo in vitro, foram realizadas culturas primárias de cardiomiócitos, obtidas a partir de ratos neonatos Wistar com 1 a 3 dias de vida, de acordo com o protocolo previamente descrito (BARRETO-CHAVES; HEIMANN; KRIEGER, 2000).

O tecido cardíaco (ventrículos) foi submetido a sucessívas digestões enzimáticas a $37^{\circ} \mathrm{C}$ com tampão à base de colagenase (Worthington, Lakewood, N.J., USA) e pancreatina (GIBCO, Grand Island, N.Y., USA). Posteriormente, os homogenatos celulares foram centrifugados em um gradiente de Percoll (GE Healthcare, Uppsala, Suécia), permitindo a separação dos cardiomiócitos dos demais tipos celulares presentes no coração, como fibroblastos, células endoteliais e células sanguíneas. A viabilidade celular foi estimada pelo uso do corante Trypan Blue Stain 0,4\% (Amresco, Solon, Ohio, USA). Em seguida, os cardiomiócitos foram contados em hemocitômetro e cultivados em placas de 6 poços, numa densidade de aproximadamente 3,7 $\times 10^{4}$ células $/ \mathrm{cm}^{2}$, em meio DMEM (GIBCO) contendo $5 \%$ de soro de bezerro neonato (NCS, GIBCO) e $10 \%$ de soro de cavalo (HS, GIBCO). As placas foram mantidas em estufa de $\mathrm{CO}_{2}(5 \%)$ a $37^{\circ} \mathrm{C}$, sob condições estéreis, as quais receberam diferentes tratamentos, conforme a tabela 4.

A concentração de Ang1-7 baseou-se em trabalhos anteriores da literatura avaliando o seu potencial anti-hipertrófico em outros modelos experimentais, os quais apresentaram curvas de concentração da Ang1-7 em culturas primárias de cardiomiócitos. (SAMPAIO et al, 2007; TALLANT; FERRARIO; GALLACHER, 2005). $O$ tempo de tratamento e a concentração de T3 basearam-se em trabalhos prévios do nosso laboratório (DINIZ; CARNEIRO-RAMOS; BARRETO-CHAVES, 2009; TAKANO; DINIZ; BARRETO-CHAVES, 2013). 
Tabela 4 - Diferentes tratamentos das culturas primárias de cardiomiócitos neonatos.

\begin{tabular}{cc}
\hline $\begin{array}{c}\text { GRUPOS } \\
\text { EXPERIMENTAIS }\end{array}$ & TRATAMENTO DAS CÉLULAS \\
\hline $\begin{array}{c}\text { Grupo Controle } \\
\text { (C) }\end{array}$ & Células mantidas em DMEM durante 24 horas. \\
\hline $\begin{array}{c}\text { Grupo tratado com T3 } \\
\text { (T3) }\end{array}$ & $\begin{array}{r}\text { As células foram mantidas em DMEM, depletadas e } \\
\text { tratadas com T3 (10 nM) durante 24 horas. }\end{array}$ \\
\hline $\begin{array}{c}\text { Grupo tratado com } \\
\text { Ang 1-7 }\end{array}$ & $\begin{array}{c}\text { As células foram mantidas em DMEM, depletadas e } \\
\text { tratadas com Ang 1-7 (1000 nM) durante 24 horas. }\end{array}$ \\
\hline $\begin{array}{c}\text { Grupo tratado com T3 } \\
\text { e Ang 1-7 } \\
\text { (A-T3) }\end{array}$ & $\begin{array}{r}\text { As células foram mantidas em DMEM, depletadas e } \\
\text { tratadas com T3 (10 nM) e Ang 1-7 (1000 nM) } \\
\text { durante 24 horas. }\end{array}$ \\
\hline
\end{tabular}

\subsubsection{Medida da área de superfície celular}

A hipertrofia das células foi avaliada mediante a quantificação da área de superfície dos cardiomiócitos. Para isso, após 24 horas com os respectivos tratamentos foram obtidas imagens de aproximadamente 60 células, as quais foram capturadas usando microscópio invertido (Axio Observer D1, Zeiss, Jena, Alemanha) acoplado a câmara digital, com magnificência de 200x. A área dos cardiomiócitos foi medida usando o programa Axio Vision 4.

\subsection{Análise estatística}

Os resultados obtidos foram analisados e comparados por Teste t de "Student" ou por Análise de Variância (ANOVA) de um caminho (One Way), seguida do pósteste de Tukey, mediante a utilização do programa GraphPad Prism 6 (GraphPad Software). Os valores com $\mathrm{p}<0,05$ foram considerados estatisticamente significativos e apresentados como média \pm desvio-padrão. $O$ valor de " $n$ " foi correspondente ao número de animais utilizados em cada experimento ou ao número de culturas celulares realizadas. 


\section{RESULTADOS}

\subsection{Caracterização do hipertireoidismo}

Para avaliação do estado hipertireoideo dos animais, avaliamos o ganho de massa corporal durante os 14 dias de tratamento, o qual corresponde à diferença entre a massa corpórea no último dia de tratamento (dia da eutanásia) e aquela do início do protocolo (dia 0) É importante pontuar que todos os animais iniciaram os seus respectivos protocolos experimentais com massa corpórea similar, não havendo diferença significativa quanto a este parâmetro entre os grupos (C: 368,75 $\pm 22,86$; T3: $377,5 \pm 8,66$; A: $352,5 \pm 15,52$; AT3: $348,75 \pm 11,08$; AT3A: $328,7 \pm$ $13,14 \mathrm{~g})$.

Conforme observado na Figura 5, os animais que foram tratados com T3 durante 14 dias, apresentaram perda da massa corporal em relação aos animais controles (T3: $-42 \pm 18,9$ vs. C: $27 \pm 7,5 \mathrm{~g}$ ), o mesmo ocorrendo nos animais geneticamente modificados (AT3: $-15 \pm 3,6$ vs. A: $31,0 \pm 13,8$ g). A redução no ganho de massa corporal nos animais tratados com T3 contribui para a caracterização do hipertireoidismo, uma vez que o hipertireoidismo está associado a um aumento da atividade metabólica e, portanto, comumente associado à perda da massa corpórea.

Embora seja notório o efeito do T3 sobre a perda de massa corporal no grupo dos animais que superexpressam Ang 1-7 (Grupo AT3), em relação ao seu respectivo controle (Grupo A), observa-se que este efeito foi atenuado em relação ao efeito do T3 nos animais selvagens (Grupo T3), indicando, portanto, um possível papel da Ang 1-7 prevenindo os efeitos do T3 na perda de massa corpórea, mesmo que parcialmente. Por outro lado, os animais que superexpressam Ang 1-7 (Grupo A) obtiveram um ganho de massa corporal similar àquele observado nos animais selvagens (Grupo C) (Figura 5).

Em relação ao tratamento com A779 (Grupo AT3A), não foi possível verificar uma modulação no ganho de massa corporal em relação aos animais do Grupo AT3 (AT3: $-15 \pm 3,6$ vs. AT3A: $-15,0 \pm 3,5 \mathrm{~g}$ ), o que indica que este possível efeito da Ang 1-7 em atenuar a perda de massa corporal promovida pelo T3, não está diretamente 
envolvido com o receptor Mas. Todavia, outros estudos devem ser realizados para melhor compreensão desse efeito.

Ganho de massa corporal

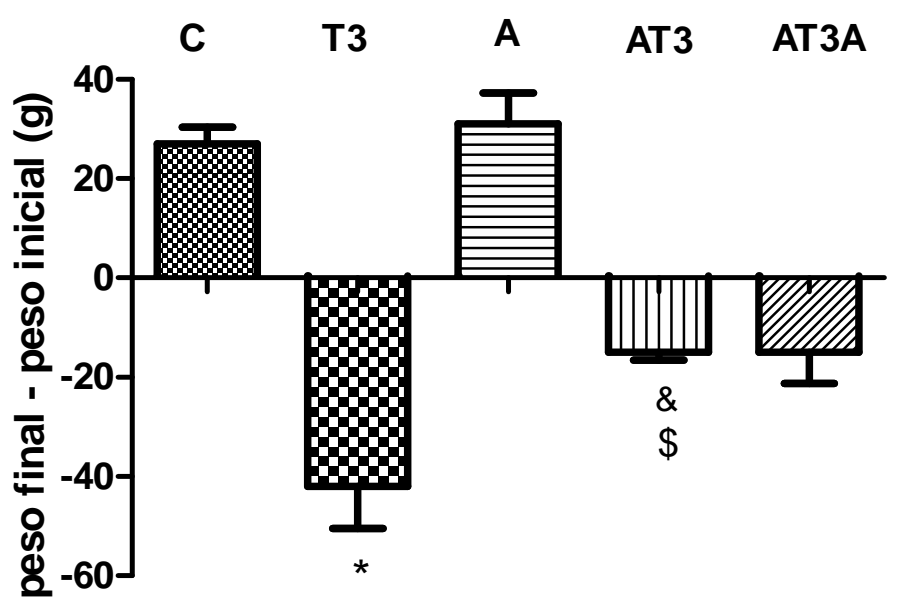

\footnotetext{
${ }^{*}$ vs. Controle $(p<0,0001)$

\& vs. $A(p<0,0001)$

$\$$ vs. T3 $(p<0,05)$
}

Figura 5 - Ganho de massa corporal (em g) nos diferentes grupos experimentais (diferença entre a massa corpórea no fim e no início do tratamento) [C: Grupo controle, animais selvagens ( $n=5)$; T3: Grupo hipertireoideo, animais selvagens ( $n=6)$; A: Grupo controle de animais TGR-L3292 ( $n=5)$; AT3: Grupo hipertiroideo de animais TGR-L3292 ( $n=5)$; AT3A: Grupo hipertiroideo de animais TGR-L3292 tratados com A779 $(n=6)]$. O teste estatístico utilizado foi ANOVA One Way, seguida de pós-teste Tukey.

\subsection{Caracterização do Trofismo cardíaco}

Assim como esperado, a indução do hipertireoidismo nos animais selvagens (Grupo T3) foi responsável pela instalação de um processo hipertrófico no coração, levando a um aumento de $37,8 \%$ do índice que leva em conta a razão da massa cardíaca pelo comprimento da tíbia, em relação àquele observado nos animais do grupo controle (T3: 0,47 $\pm 0,04$ vs. C: 0,34 $\pm 0,02 \mathrm{~g} / \mathrm{cm}$ ) (Figura 6). 


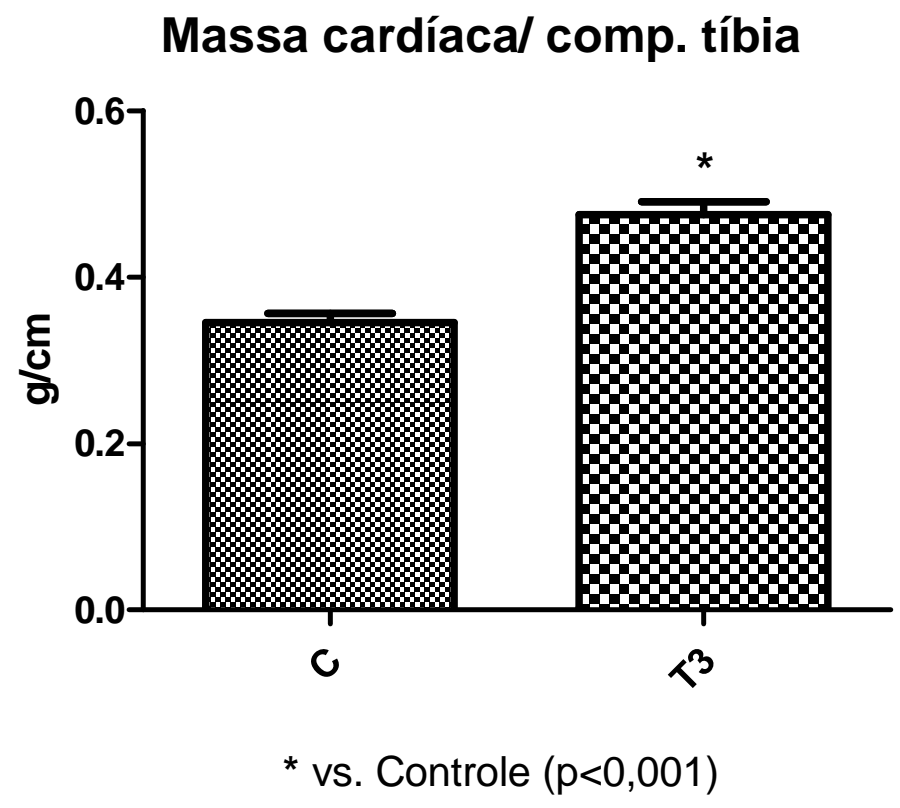

Figura 6 - Massa cardíaca (em g) normalizada pelo comprimento da tíbia (em $\mathrm{cm}$ ) nos animais selvagens [C: Grupo controle ( $n=5)$; T3: Grupo hipertireoideo $(n=6)$ ]. O teste estatístico utilizado foi Teste t de "Student".

A indução do hipertireoidismo nos animais transgênicos (Grupo AT3) não foi capaz de promover significativa hipertrofia cardíaca (AT3: $0,36 \pm 0,01$ vs. A: $0,31 \pm$ 0,01 $\mathrm{g} / \mathrm{cm}$ ), o que comprova uma ação anti-hipertrófica da Ang 1-7 frente aos estímulos cardíacos do T3 (Figura 7). Por outro lado, a utilização de um antagonista seletivo para o receptor da Ang 1-7 (Grupo AT3A) foi capaz de promover um aumento de $31,7 \%$ no índice relativo à hipertrofia cardíaca, em relação àquele dos animais do Grupo A (AT3A: $0,41 \pm 0,05$ vs. A: $0,31 \pm 0,01 \mathrm{~g} / \mathrm{cm}$ ), confirmando que a ação anti-hipertrófica da Ang 1-7 observada nos animais do Grupo AT3 ocorreu via receptor Mas, uma vez que inibindo este receptor, o processo hipertrófico foi instalado (Figura 7). 


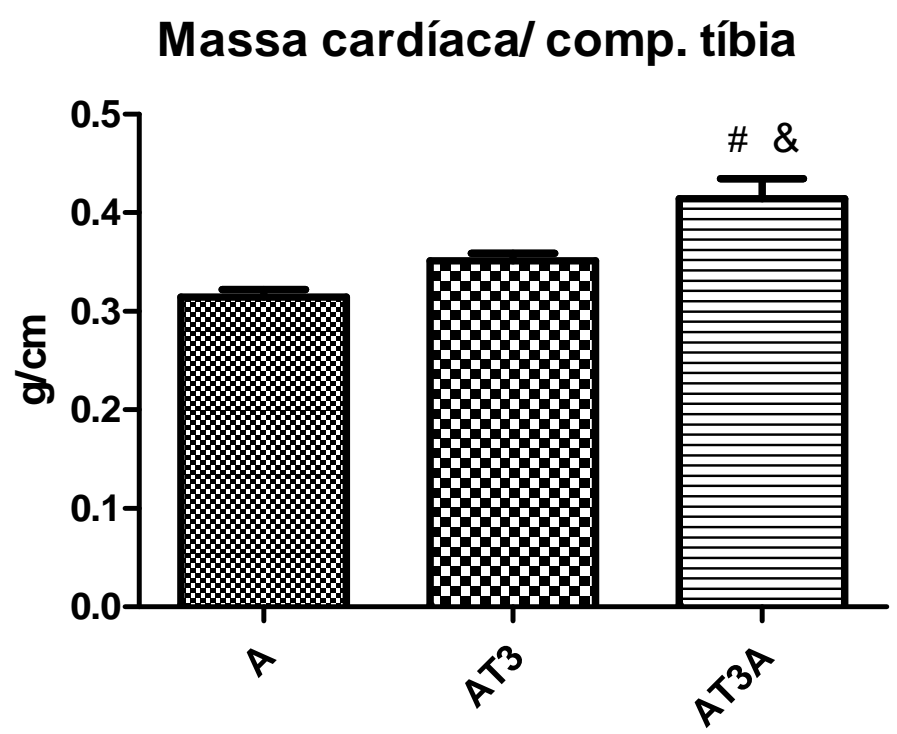

\& vs. $A(p<0,001)$

\# vs. Grupo AT3 $(p<0,05)$

Figura 7 - Massa cardíaca (em g) normalizada pelo comprimento da tíbia (em $\mathrm{cm}$ ) nos animais transgênicos [A: Grupo controle $(n=5)$; AT3: Grupo hipertireoideo $(n=6)$; AT3A: Grupo hipertireoideo e tratado com A779]. O teste estatístico utilizado foi ANOVA One Way, seguida de pós-teste de Tukey.

Quando avaliadas as massas do VE e VD, separadamente, os animais selvagens induzidos ao hipertireoidismo (Grupo T3) apresentaram um aumento de $21,46 \%$ da massa do VE (T3: $0,29 \pm 0,006$ vs. C: $0,23 \pm 0,006 \mathrm{~g} / \mathrm{cm}$ ) (Figura 8 A) e um aumento de $20,7 \%$ na massa do VD (T3: $0,09 \pm 0,004$ vs. C: $0,07 \pm 0,003 \mathrm{~g}$ ) (Figura $8 \mathrm{~B}$ ), quando comparadas àquelas dos seus respectivos controles. Todavia, conforme apresentado na Figura 9, a superexpressão do peptídeo Ang 1-7 foi capaz de prevenir o aumento da massa cardíaca tanto no VE (AT3: $0,25 \pm 0,008$ vs. A: 0,22 $\pm 0,03 \mathrm{~g} / \mathrm{cm}$ ), como no VD (AT3: $0,07 \pm 0,003$ vs. A: $0,06 \pm 0,03 \mathrm{~g} / \mathrm{cm}$ ), comprovando novamente as ações anti-hipertróficas da Ang 1-7 em modelo de hipertireoidismo. Tais ações foram novamente inibidas com o tratamento crônico com A779, confirmando ocorrerem via receptor MAS (Figura 9). 
A

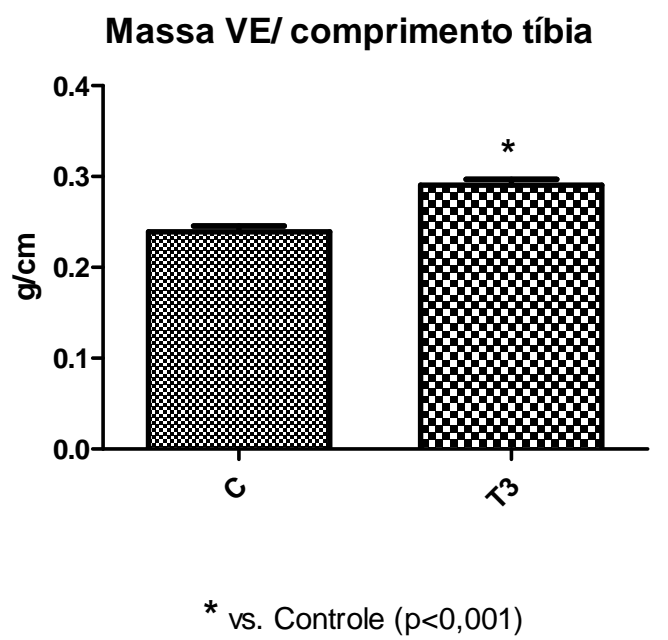

B

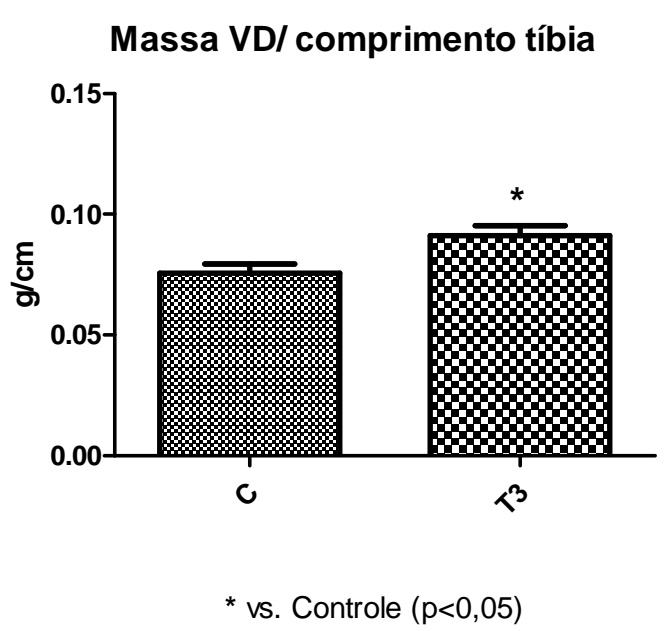

Figura 8 - Massa do VE e VD (em g) normalizadas pelo comprimento da tíbia (em $\mathrm{cm}$ ) nos animais selvagens. A) Massa do VE [C: Grupo controle ( $n=5)$; T3: Grupo hipertireoideo $(n=6)]$. B) Massa do VD [C: Grupo controle ( $n=5)$; T3: Grupo hipertireoideo $(n=6)$ ]. O teste estatístico utilizado foi o Teste t de "Student".

A

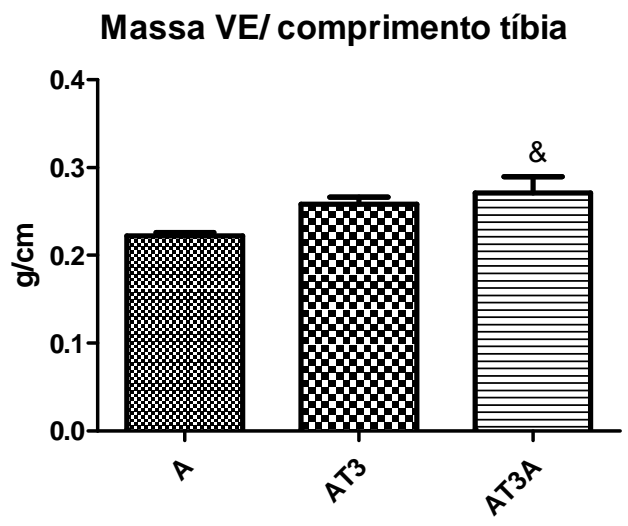

\& vs. Grupo A $(p<0,05)$
B

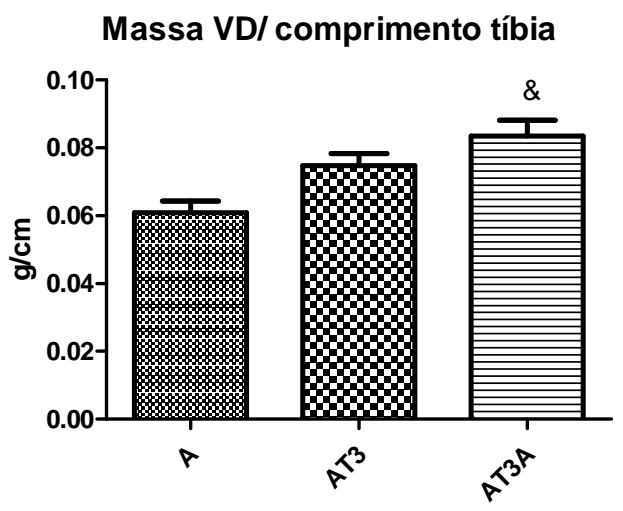

\& vs. Grupo $A(p<0,01)$

Figura 9 - Massa do VE e VD (em g) normalizadas pelo comprimento da tíbia (em $\mathrm{cm}$ ) nos animais transgênicos. A) Massa do VE [A: Grupo controle $(n=5)$; AT3: Grupo hipertireoideo $(n=6)$; AT3A: Grupo hipertireoideo tratado com A770]. B) Massa do VD [A: Grupo controle ( $n=5)$; AT3: Grupo hipertireoideo $(n=6)$; AT3A: Grupo hipertireoideo tratado com A770 $(n=6)]$. O teste estatístico utilizado foi ANOVA One Way, seguida de Pós-teste de Tukey. 
Além da análise da massa cardíaca, também avaliamos a expressão gênica de marcadores hipertróficos no VE. Neste sentido, conforme observado na Figura 10, os animais selvagens induzidos ao hipertireoidismo (Grupo T3) apresentaram um aumento da expressão gênica de $\alpha-M H C$ (T3: 1,81 $\pm 0,5$ vs. C: 1,0 $\pm 0,3$ u.a.) e uma diminuição na expressão de $\beta-\mathrm{MHC}$ (T3:0,07 \pm 0,06 vs. C:1,03 \pm 0,05 u.a.), em relação aos animais controles (Grupo C). Essa alteração no padrão de expressão gênica das alfa e beta miosinas no tecido cardíaco é característico no coração submetido ao tratamento com HT e confirma, mais uma vez, a condição hipertiroidea desses animais. (Figura 10).

Em relação à $\alpha-\mathrm{MHC}$, a expressão aumentada de Ang 1-7 nos animais hipertiroideos (grupo AT3) não modificou o padrão induzido pelo T3, uma vez que o hormônio promoveu, assim como no grupo selvagem, significativo aumento da expressão desse gene (Figura $10 \mathrm{~A}$ ). Já em relação à $\beta-\mathrm{MHC}$, o tratamento com T3 nos animais que superexpressam Ang 1-7, embora tivessem apresentado tendência à diminuição deste gene, esta não chegou a ser significativa. $O$ tratamento com 0 A779, por outro lado, promoveu uma queda ainda maior na expressão deste gene (Figura $10 \mathrm{~B}$ ). Estes dados indicam que estes genes, considerados na literatura como marcadores de hipertrofia, talvez possam ser diretamente regulados pela Ang 1-7 e/ou A779, independentemente do processo hipertrófico.

A

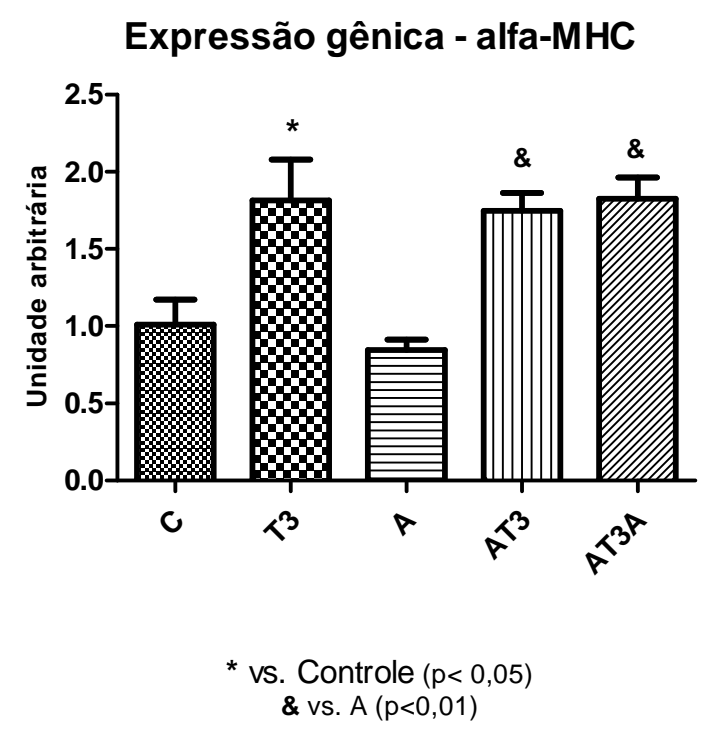


B

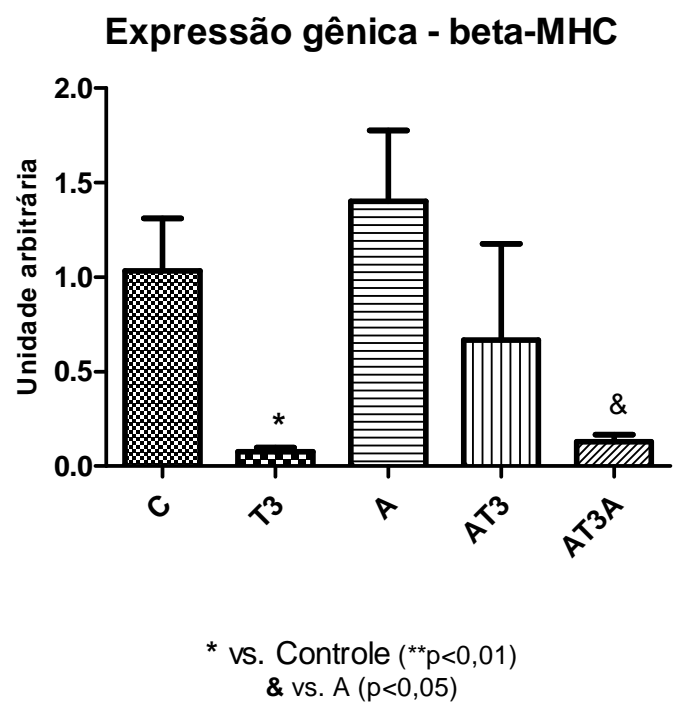

Figura 10 - Expressão gênica de $\alpha-M H C$ e $\beta-M H C$ nos diferentes grupos experimentais. A) Expressão gênica de $\alpha-M H C$ [C: Grupo controle $(n=5)$; T3: Grupo hipertireoideo $(n=6)$; A: Grupo transgênico controle $(n=5)$; AT3: Grupo transgênico hipertireoideo $(n=6)$; AT3A: Grupo hipertireoideo tratado com A770 (n=6)]. B) Expressão gênica de $\beta-M H C$ [C: Grupo controle $(n=5)$; T3: Grupo hipertireoideo $(n=6)$; A: Grupo transgênico controle $(n=5)$; AT3: Grupo transgênico hipertireoideo $(n=6)$; AT3A: Grupo hipertireoideo tratado com A770 $(n=6)]$. O teste estatístico utilizado foi ANOVA One Way, seguida de Pós-teste de Tukey.

\subsection{Análise da morfologia e função cardíaca por Ecocardiografia}

Embora a avaliação de parâmetros morfológicos utilizando exames ecocardiográficos possa ser questionável, estes foram obtidos nos vários grupos experimentais (Tabela 5). Neste sentido, os animais selvagens induzidos ao hipertireoidismo (Grupo T3) apresentaram significativo aumento do Septo Interventricular (SI), da Parede Posterior do VE (PP-VE) e da Parede do VD (sístole), acompanhado pela diminuição do Diâmetro Interno do VE (DI-VE) (sístole), conforme Tabela 5.

Por outro lado, os animais que superexpressam Ang 1-7 e foram induzidos ao hipertireoidismo (Grupo AT3), de forma diferente do ocorrido nos selvagens, não apresentaram alterações no SI (sístole) e na parede do VD (sístole). O tratamento dos animais com inibidor seletivo do receptor Mas (Grupo AT3A) promoveu redução significativa do DI-VE (sístole e diástole). 
Tabela 5 - Parâmetros morfológicos avaliados por ecocardiograma nos diferentes grupos experimentais.

\begin{tabular}{|c|c|c|c|c|c|c|c|c|}
\hline & \multicolumn{2}{|c|}{ SI (mm) } & \multicolumn{2}{|c|}{ PP-VE (mm) } & \multicolumn{2}{|c|}{ Parede do VD (mm) } & \multicolumn{2}{|c|}{ DI-VE (mm) } \\
\hline & Sístole & Diástole & Sístole & Diástole & Sístole & Diástole & Sístole & Diástole \\
\hline Controle & $2,17 \pm 0,08$ & $1,41 \pm 0,06$ & $2,86 \pm 0,16$ & $1,86 \pm 0,09$ & $1,19 \pm 0,07$ & $0,78 \pm 0,05$ & $4,69 \pm 0,09$ & $7,91 \pm 0,08$ \\
\hline T3 & $2,98 \pm 0,08$ * & $1,7 \pm 0,04$ * & $3,56 \pm 0,12^{*}$ & $2,15 \pm 0,04^{*}$ & $1,56 \pm 0,1^{*}$ & $0,86 \pm 0,03$ & $3,27 \pm 0,16$ * & $7,3 \pm 0,2$ \\
\hline A & $2,18 \pm 0,13$ & $1,31 \pm 0,01$ & $2,63 \pm 0,04$ & $1,76 \pm 0,05$ & $1,02 \pm 0,11$ & $0,65 \pm 0,05$ & $5,43 \pm 0,16$ & $8,35 \pm 0,29$ \\
\hline AT3 & $2,6 \pm 0,1^{\$}$ & $1,58 \pm 0,08^{\&}$ & $3,35 \pm 0,14^{\&}$ & $2,1 \pm 0,08^{\&}$ & $1,12 \pm 0,06^{\$}$ & $0,68 \pm 0,01^{\$}$ & $4,57 \pm 0,26^{\& \$}$ & $8,03 \pm 0,25$ \\
\hline AT3A & $2,66 \pm 0,08{ }^{*} \&$ & $1,58 \pm 0,07^{\&}$ & $2,98 \pm 0,13^{\&}$ & $1,94 \pm 0,04^{\&}$ & $1,14 \pm 0,10$ & $0,67 \pm 0,06^{\$}$ & $3,34 \pm 0,22{ }^{*} \# \&$ & $6,89 \pm 0,19$ * $\& \#$ \\
\hline
\end{tabular}

[C: Grupo controle $(n=5)$; T3: Grupo hipertireoideo $(n=6)$; A: Grupo transgênico controle $(n=5)$; AT3: Grupo transgênico hipertireoideo ( $n=6)$; AT3A: Grupo hipertireoideo tratado com A770 ( $n=6)$ ). SI: Septo Interventricular; PP-VE: Parede Posterior do VE; DI-VE: Diâmetro Interno do VE. O teste estatístico utilizado foi ANOVA One Way, seguida de Pós-teste de Tukey, sendo * vs Controle; \& vs A; \$ vs T3 e \# vs AT3. 
Em relação à função cardíaca, foram avaliados parâmetros como frequência cardíaca (FC), débito cardíaco (DC) e frações de ejeção (FE) e de encurtamento (FS) (Figura 11). Os dados referentes ao volume sistólico no VE (sístole e diástole), bem como o tempo de ejeção aórtico, encontram-se junto ao Anexo B, no final da Dissertação.

É importante pontuar que não houve diferença em qualquer dos parâmetros cardíacos avaliados, entre os animais controles selvagens e transgênicos. Em relação ao tratamento com T3, este promoveu significativo aumento nos parâmetros de FC, FE e FS tanto nos animais selvagens (T3), como naqueles que superexpressam Ang1-7 (AT3). No entanto, embora seja nítido o efeito do T3 nos animais transgênicos, todos os parâmetros listados acima foram significativamente atenuados em comparação aos efeitos promovidos pelo T3 nos animais selvagens. Estes resultados indicam que os níveis elevados de Ang1-7 minimizaram os efeitos cardíacos do hormônio. Uma vez tendo observado o efeito dos elevados níveis de Ang1-7 nestes parâmetros de função cardíaca, seguiu-se analisando a contribuição do receptor MAS. O tratamento com A779, um inibidor seletivo do receptor MAS, preveniu o efeito dos elevados níveis de Ang1-7 nos parâmetros relativos a FE e FS (grupo AT3A), sendo estes similares aos resultados referentes ao grupo T3.

Outro parâmetro avaliado foi a função diastólica, dada pela Razão E/A, a qual é indicativa do influxo de sangue pela válvula mitral. Os animais selvagens tratados com T3 apresentaram uma redução significativa desse parâmetro quando comparados com os animais controles (Grupo C), indicando um aumento na pressão do átrio esquerdo e/ou uma maior rigidez do ventrículo esquerdo. No entanto, este efeito do T3 deixou de ser observado nos animais que superexpressam a Ang1-7, uma vez que não houve diferença significativa entre o grupo AT3 e o grupo A. (Figura 12). Embora o grupo $A 779$ tenha apresentado redução da razão E/A em relação ao grupo AT3, esta não foi estatisticamente significante. 
A

Frequência Cardíaca

(FC)

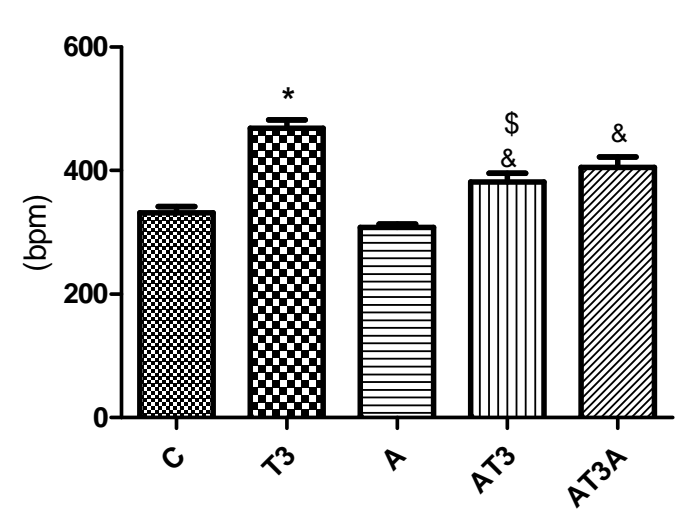

* vs. Controle $(p<0,001)$

\& vs. $A(p<0,05)$

$\$$ vs. T3 $(p<0,05)$

C

Fração de ejeção

(FE)

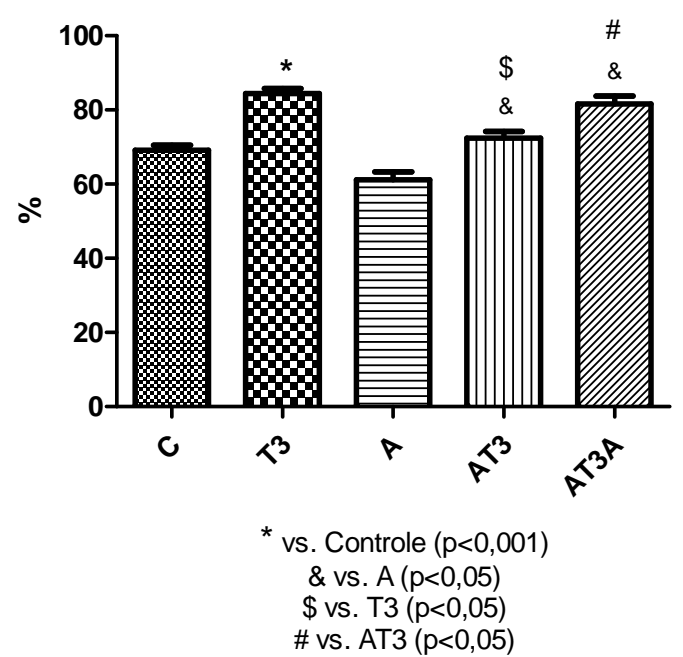

B

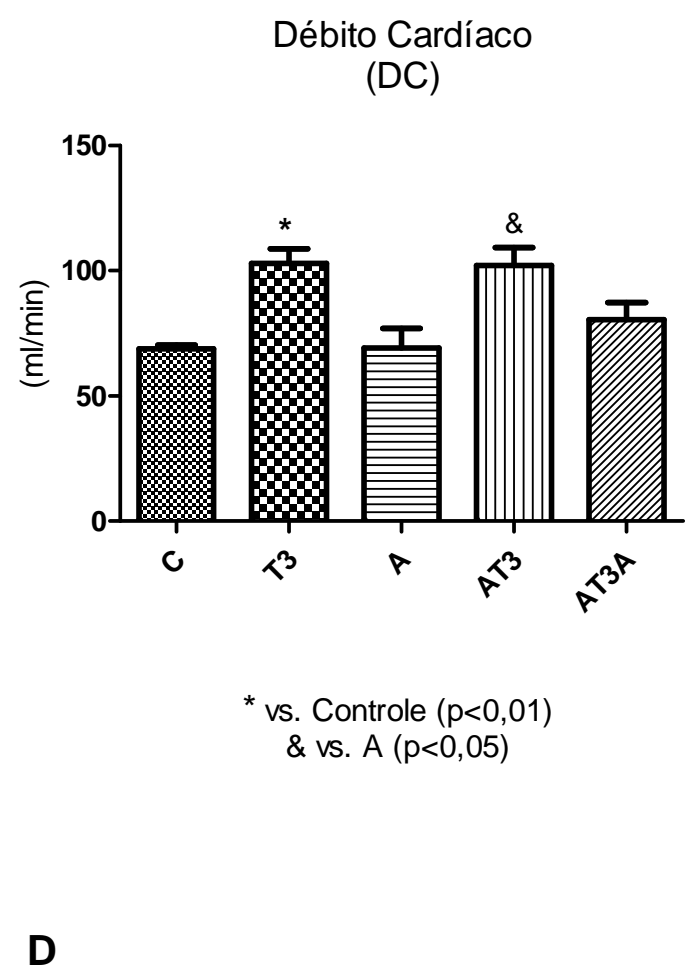

Fração de encurtamento

(FS)

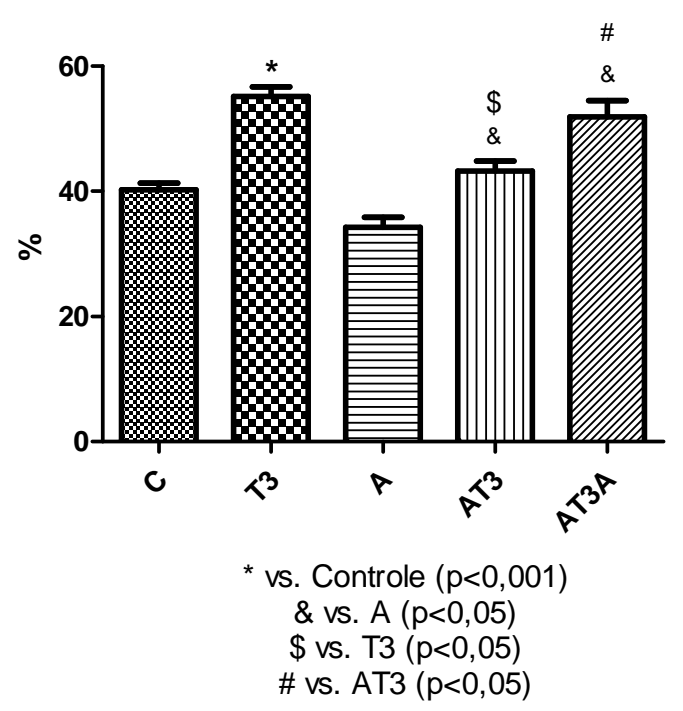

Figura 11 - Parâmetros funcionais avaliados por ecocardiograma nos diferentes grupos experimentais. A) Frequência Cardíaca (em bpm). B) Débito Cardíaco (em $\mathrm{ml} / \mathrm{min})$. C) Fração de ejeção (em \%). D) Fração de encurtamento (em \%). [C: Grupo controle ( $n=5)$; T3: Grupo hipertireoideo ( $n=6)$; A: Grupo transgênico controle $(n=5)$; AT3: Grupo transgênico hipertireoideo $(n=6)$; AT3A: Grupo hipertireoideo tratado com A770 $(n=6)]$. O teste estatístico utilizado foi ANOVA One Way, seguida de Pós-teste de Tukey. 
Razão E/A

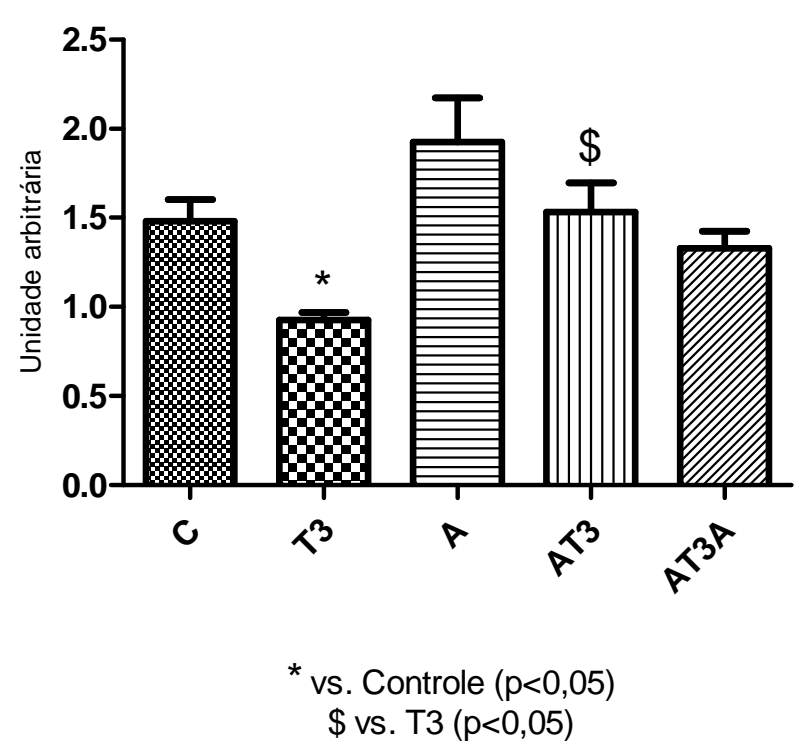

Figura 12 - Razão E/A avaliada por exames ecocardiográficos nos diferentes grupos experimentais. [C: Grupo controle ( $n=5)$; T3: Grupo hipertireoideo $(n=6)$; A: Grupo transgênico controle $(n=5)$; AT3: Grupo transgênico hipertireoideo ( $n=6)$; AT3A: Grupo hipertireoideo tratado com A770 $(n=6)]$. O teste estatístico utilizado foi ANOVA One Way, seguida de Pós-teste de Tukey.

\subsection{Modulação do Sistema Renina Angiotensina - SRA}

\subsubsection{Expressão proteica dos componentes do SRA}

A possível contribuição da modulação dos componentes do SRA nos efeitos observados nos diferentes grupos experimentais foi analisada. Neste sentido, a indução ao hipertireoidismo (Grupo T3) foi responsável por aumentar em $45 \%$ os níveis de Ang $\mathrm{I} / \mathrm{II}$ no $\mathrm{VE}$, quando comparados àqueles observados nos animais controles (Figura 13). Da mesma forma, os animais transgênicos, independentemente do tratamento experimental, também apresentaram um aumento de cerca de $48 \%$ nos níveis de Ang I/II, em relação aos animais controles (Grupo C) (Figura 13). 


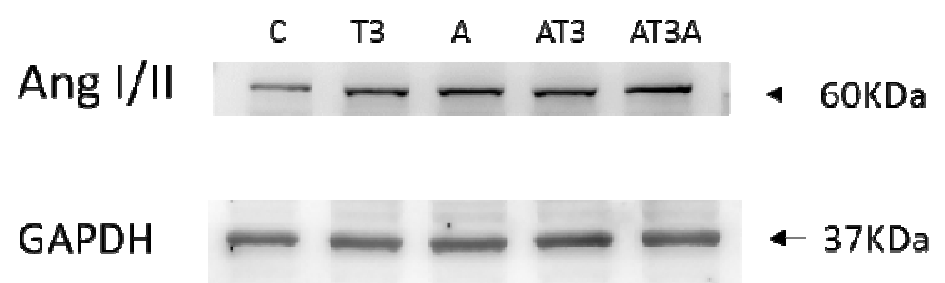

Expressão protéica Ang I/II

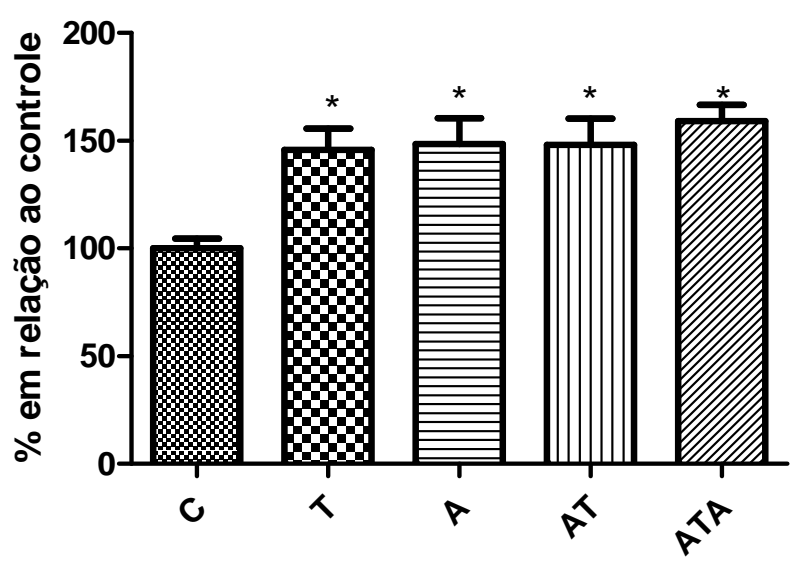

* vs. Controle $(p<0,01)$

Figura 13 - Níveis de expressão de Ang I/II, nos diferentes grupos experimentais. [C: Grupo controle $(n=5)$; T3: Grupo hipertireoideo ( $n=5)$; A: Grupo transgênico controle $(n=5)$; AT3: Grupo transgênico hipertireoideo ( $n=5)$; AT3A: Grupo hipertireoideo tratado com A770 $(n=5)]$. O teste estatístico utilizado foi ANOVA One Way, seguida de Pós-teste de Tukey.

Quando avaliada a expressão proteica dos principais receptores constituintes do SRA, a indução ao hipertireoidismo nos animais selvagens (Grupo T3) não foi capaz de promover uma modulação significativa na expressão proteica do receptor Mas (Figura 14), assim como do receptor AT2 de Angll (Figura 15 B), quando comparados com os animais controles (Grupo C). Todavia, conforme observado na Figura 14 e Figura 15 B, apesar de não significativo, os animais hipertireoideos apresentaram uma tendência em aumentar a expressão proteica dos receptores estudados. O mesmo ocorreu com os animais transgênicos induzidos ao hipertireoidismo, uma vez que, apesar de não significativo, os animais do grupo AT3 também apresentaram uma tendência em aumentar a expressão proteica dos receptores Mas e AT2, quando comparados com os animais do grupo A (Figura $14 \mathrm{e}$ 
Figura 15 B). Por outro lado, o tratamento com T3 foi responsável por aumentar em cerca de $49 \%$ a expressão proteica do receptor AT1, tanto nos animais selvagens (Grupo T3), como nos animais transgênicos (Grupo AT3), quando comparados com os respectivos controles, conforme observado na Figura $15 \mathrm{~A}$.

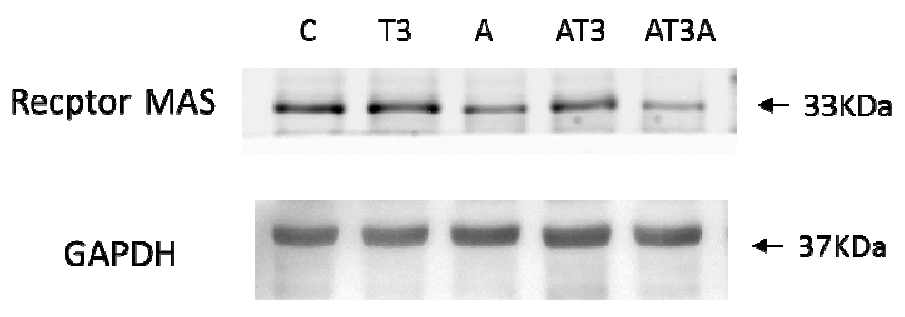

Expressão proteica Receptor Mas

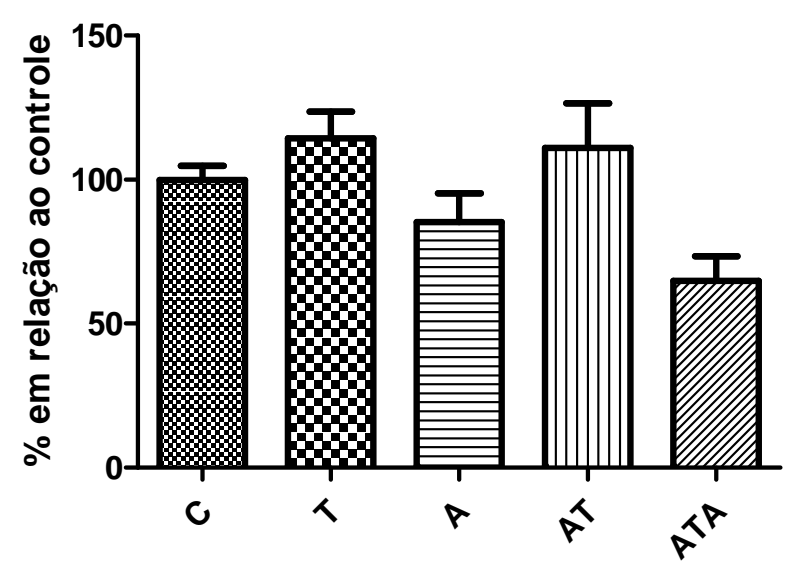

Figura 14 - Expressão proteica do receptor Mas, nos diferentes grupos experimentais. [C: Grupo controle $(n=5)$; T3: Grupo hipertireoideo $(n=5)$; A: Grupo transgênico controle $(n=5)$; AT3: Grupo transgênico hipertireoideo $(n=4)$; AT3A: Grupo hipertireoideo tratado com A770 $(n=5)]$. O teste estatístico utilizado foi ANOVA One Way, seguida de Pós-teste de Tukey. 
A

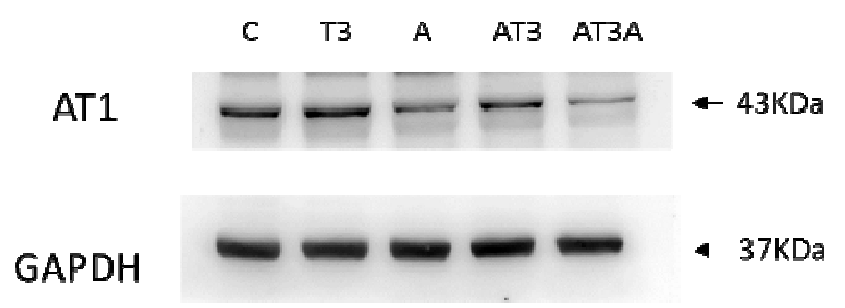

Expressão proteica AT1

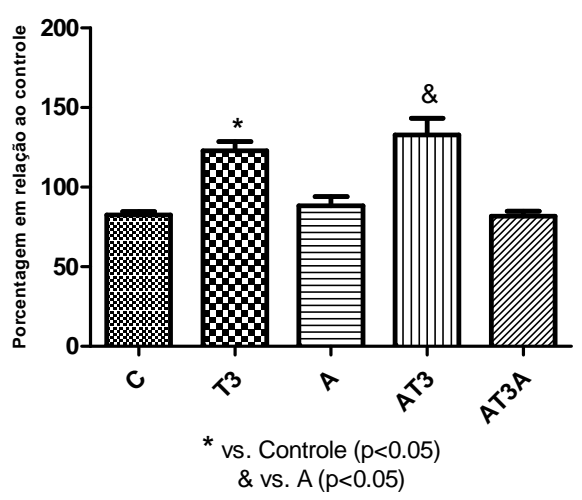

B

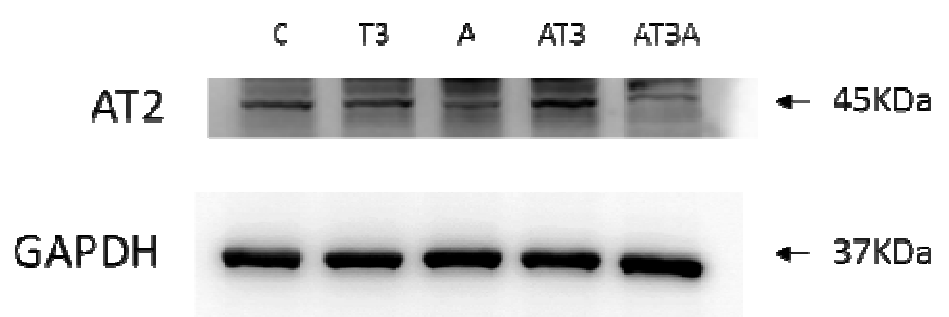

Expressão proteica AT2

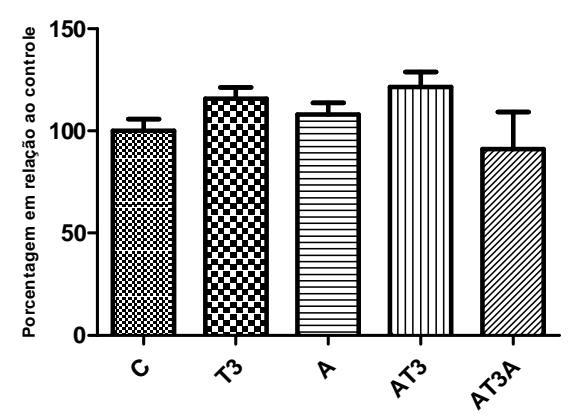

Figura 15 - Expressão proteica dos receptores de Ang II, receptor AT1 e AT2 nos diferentes grupos experimentais. A) Expressão do receptor AT1. B) Expressão do receptor AT2. [C: Grupo controle $(n=5)$; T3: Grupo hipertireoideo $(n=4)$; A: Grupo transgênico controle $(n=4)$; AT3: Grupo transgênico hipertireoideo ( $n=4)$; AT3A: Grupo hipertireoideo tratado com A770 $(n=4)]$. O teste estatístico utilizado foi ANOVA One Way, seguida de Pós-teste de Tukey. 


\subsubsection{Atividade das enzimas: ECA e ECA2}

A atividade de duas importantes enzimas constituintes do SRA, ECA e a ECA2, foi avaliada nos corações (VE) dos diferentes grupos experimentais, sendo a enzima ECA a responsável pela formação da Ang II e a enzima ECA2 a responsável pela formação de Ang 1-7.

Em relação à atividade da ECA, os animais induzidos ao hipertireoidismo (Grupo T3) não apresentaram uma diferença significativa em relação aos animais controles (Grupo C) (C: 10,08 \pm 1,16 vs T3: 7,88 \pm 0,88 nmoles His-Leu/min/mg de proteína) (Figura 16). Todavia, embora não significativa, foi possível verificar uma tendência de redução da atividade da ECA nos animais tratados com T3. Por outro lado, os animais transgênicos induzidos ao hipertireoidismo (Grupo AT3) não apresentaram essa mesma tendência de redução quando comparados com os animais do Grupo $A$ (A: 7,86 \pm 0,58 vs AT3: 7,1 $\pm 2,17$ nmoles His-Leu/min/mg de proteína).

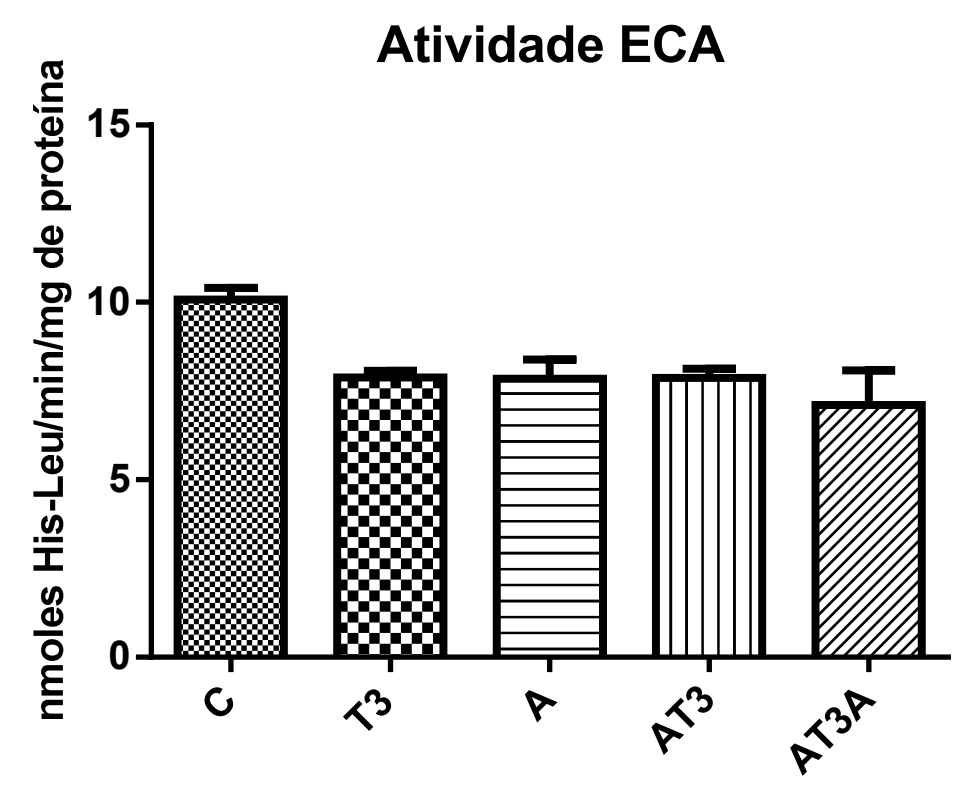

Figura 16 - Atividade da enzima ECA no ventrículo esquerdo (VE) nos diferentes grupos experimentais, expressa em nmoles de His-Leu/min/mg de proteína [C: Grupo controle ( $n=5)$; T3: Grupo hipertireoideo $(n=5) ; A$ : Grupo transgênico controle $(n=5) ;$ AT3: Grupo transgênico hipertireoideo ( $n=5)$; AT3A: Grupo hipertireoideo tratado com A770 $(n=5))$. O teste estatístico utilizado foi ANOVA One Way, seguida de Pós-teste de Tukey. 
A indução ao hipertireoidismo nos animais selvagens (Grupo T3) foi responsável por um aumento significativo na atividade da enzima ECA2, dada em unidades arbitrárias de fluorescência (u.a.)/min/mg de proteína (C: $45,4 \pm 12,7$ vs T3: 79,8 \pm 11,4) (Figura 17). Tal aumento pode sugerir um mecanismo de cardioproteção nos animais hipertireoideo. Todavia, os animais transgênicos induzidos ao hipertireoidismo (Grupo AT3 e Grupo AT3A) não apresentaram alterações na atividade dessa enzima, quando comparados com os animais do grupo A (A: 48,3 \pm 10,48; AT3: 52,6 \pm 16,6; AT3A: 48,4 $\pm 16,9$ ) (Figura 17).

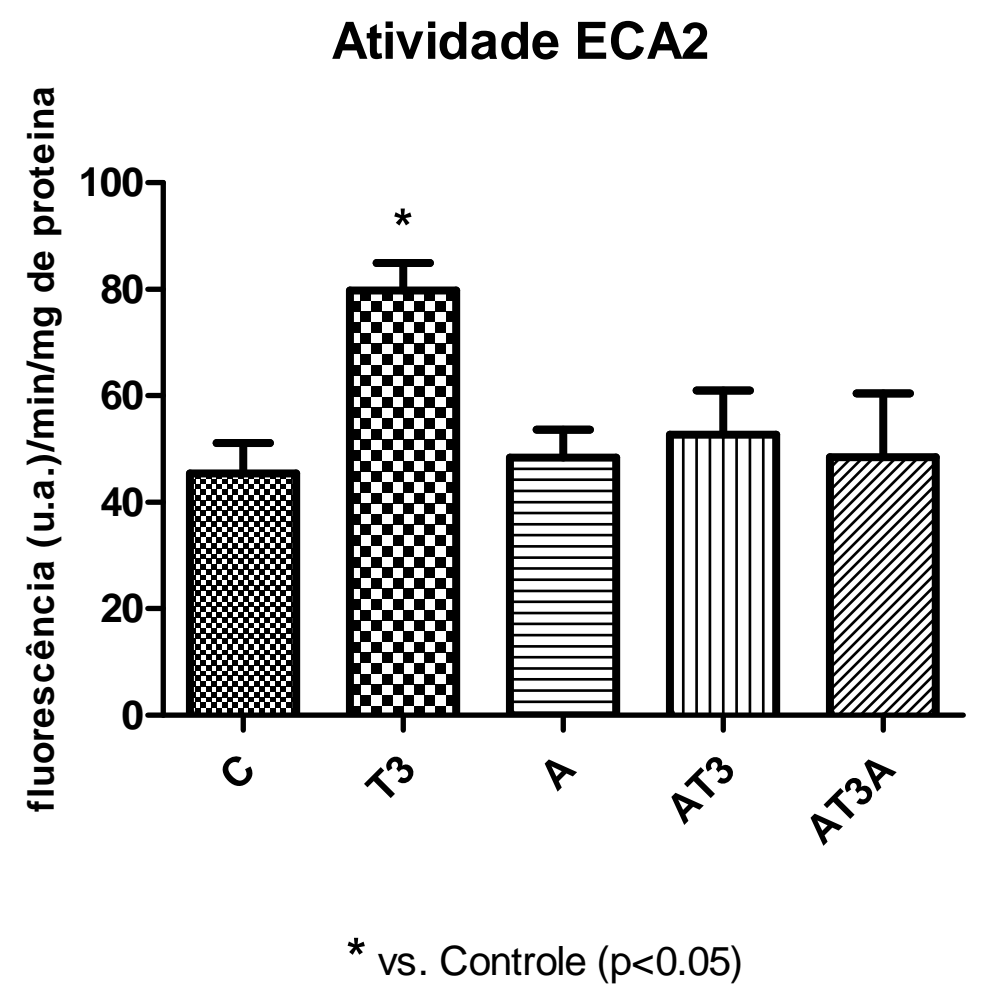

Figura 17 - Atividade da enzima ECA2 no ventrículo esquerdo (VE) nos diferentes grupos experimentais, expressa em fluorescência (u.a.)/mim/mg de proteína [C: Grupo controle ( $n=5$ ); T3: Grupo hipertireoideo $(n=5) ; A$ : Grupo transgênico controle $(n=5)$; AT3: Grupo transgênico hipertireoideo $(n=5)$; AT3A: Grupo hipertireoideo tratado com A770 $(n=5)]$. O teste estatístico utilizado foi ANOVA One Way, seguida de Pós-teste de Tukey. 
5.5 Análise do papel da Ang 1-7 nos efeitos tróficos induzidos pelo T3, in vitro.

Nós temos demonstrado que as ações tróficas do T3 ocorrem independentemente das alterações hemodinâmicas promovidas por este hormônio (TAKANO; DINIZ; BARRETO-CHAVES, 2013). O tratamento com T3, em cultura primária de cardiomiócitos neonatos, foi responsável por agir diretamente nos cardiomiócitos, promovendo aumento de cerca de $28 \%$ da área celular, em relação ao controle (Figura 19). Diante disso, decidimos verificar se a ação anti-hipertrófica da Ang 1-7, observada no nosso modelo animal, também estaria ocorrendo por ações diretas do peptídeo nos cardiomiócitos e não apenas por redução do hiperdinamismo cardíaco induzido pelo T3.

Conforme observado na Figura 19, de maneira muito interessante, as células tratadas com T3 e concomitantemente com Ang 1-7 (1000 nM) não apresentaram aumento na área celular em relação ao controle, mostrando que a administração de Ang 1-7 foi capaz de prevenir totalmente o efeito induzido pelo T3 in vitro. Estes resultados sugerem que, paralelamente às ações hemodinâmicas já apresentadas, a Ang1-7 também atue diretamente no cardiomiócito prevenindo o aumento da área celular proteica induzida pelo T3 (Figura 19), o que poderia contribuir para o efeito anti-hipertrófico observado nos experimentos in vivo.

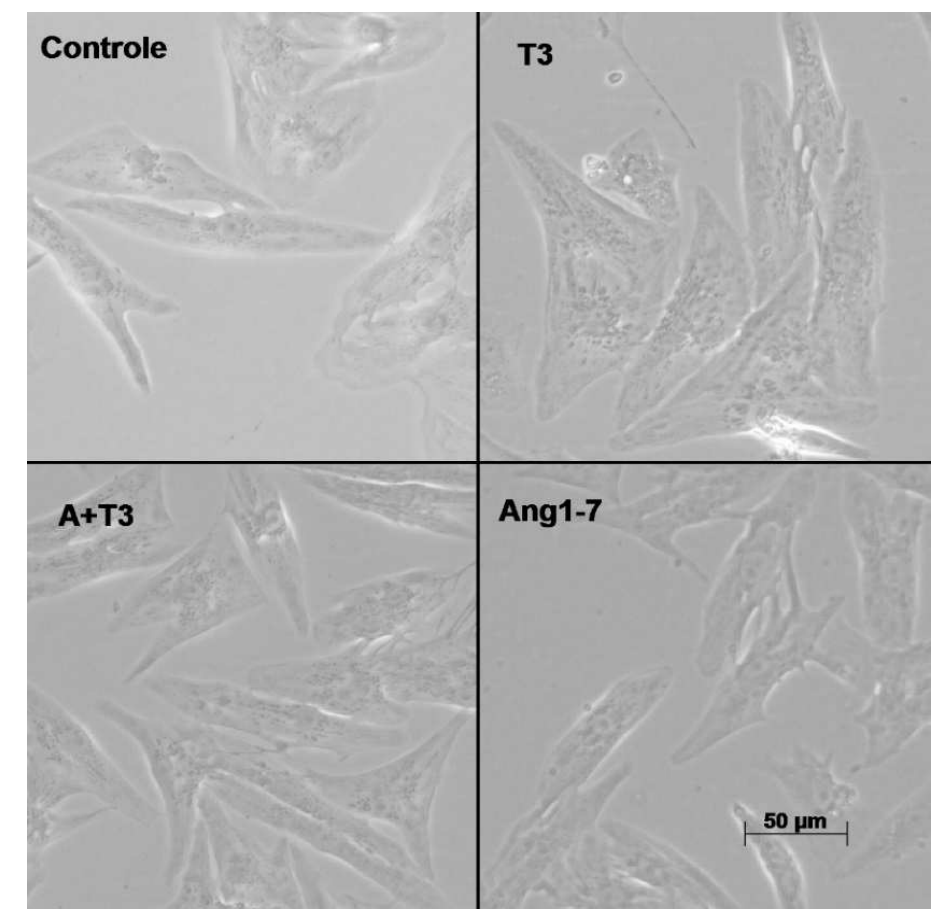

Figura 18 - Imagens das culturas primárias de cardiomiócitos neonatos. As imagens foram obtidas após 24 horas com os respectivos tratamentos, aumento de 20X. 


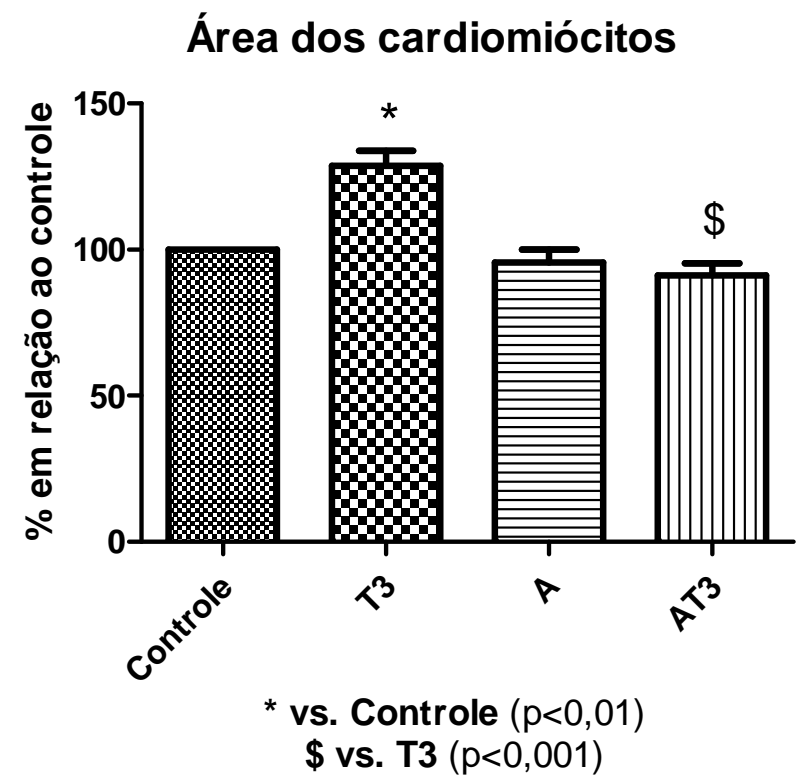

Figura 19 - Área de superfície celular dos cardiomiócitos neonatos nos diferentes tratamentos experimentais [C: Grupo controle ( $n=5)$; T3: Grupo hipertireoideo $(n=5)$; A: Grupo tratado com Ang 1-7 $(n=5)$; AT3: Grupo hipertireoideo tratado com Ang 1-7 $(n=5)]$. O teste utilizado foi ANOVA One Way, seguida de Pós-teste Tukey. 


\section{DISCUSSÃO}

O SRA clássico apresenta uma importante participação na regulação da função cardíaca e da pressão sanguínea, fazendo com que este sistema seja o principal alvo na terapia convencional de diversas patologias do sistema cardiovascular (PAULIS; UNGER, 2010). Diante disso, a fim de aprimorar a modulação farmacológica sobre o SRA iniciou-se a busca por novos alvos deste sistema, o que culminou com a descoberta de outros eixos do SRA, com ações bastante distintas (BADER et al., 2012; PASSOS-SILVA; BRANDAN; SANTOS, 2015; PESSÔA et al., 2013).

Sendo assim, desde a descoberta do eixo ECA2/Ang 1-7/Mas, diversos trabalhos vêm amplamente estudando suas ações cardiovasculares em diferentes modelos animais. Tal importância se deve ao fato deste eixo agir diretamente no controle homeostático da pressão arterial, uma vez que animais knouckouts, que não expressam ECA2, apresentam redução dos níveis séricos de Ang 1-7 e aumento da pressão arterial (PA) (TIKELLIS; BERNARDI; BURNS, 2011). O bloqueio do eixo ECA2/Ang 1-7/Mas também é responsável por promover injúria cardíaca, aumento de fibrose, inflamação, apoptose, dentre outros danos para o sistema cardiovascular (MENG et al., 2014; SONG et al., 2013), indicando o papel protetor desse eixo para o coração. Portanto, a Ang 1-7 tornou-se um importante e potente alvo terapêutico para diversas doenças cardiovasculares (SANTOS; FERREIRA; SIMOES, 2008; TWIST; KROON; LEEUW, 2014), o que resultou em estudos desenvolvidos em humanos, com a pretensão do uso da Ang 1-7 na prática clínica (SHENOY et al., 2014; TWIST et al., 2013). Neste sentido, pacientes tratados cronicamente com inibidores da ECA ou com inibidores do receptor AT1 apresentam níveis séricos elevados de Ang 1-7 (DAVIE; MCMURRAY, 1999; IYER et al., 1998). Todavia, quando utilizado concomitantemente um inibidor da Ang 1-7 (anticorpo monoclonal específico para Ang 1-7) (IYER et al., 1998) ou um antagonista do receptor da Ang 1-7 (A-779) (DE MOURA; SANTOS; FONTES, 2005), a redução da pressão arterial não é observada, indicando uma importante contribuição desse peptídeo para os efeitos benéficos do tratamento farmacológico com inibidores da ECA ou do AT1.

Embora a eficácia do tratamento com Ang 1-7 já tenha sido comprovada em diferentes modelos experimentais, principalmente aqueles que se relacionam 
diretamente à hipertensão pulmonar, as ações deste heptapeptídeo em modelos como o de hipertireoidismo, nos quais ocorre hipertrofia cardíaca na ausência de hipertensão, ainda não foram abordados. No presente estudo, nós avaliamos as possíveis ações cardioprotetoras da Ang 1-7 frente aos efeitos cardiovasculares desencadeados pelo hipertireoidismo, em ratos. O modelo de indução de hipertireoidismo por 14 dias, utilizado neste estudo, já está bem caracterizado no nosso laboratório. Os animais submetidos a este protocolo experimental apresentam alterações clássicas do hipertireoidismo, além do aumento nos níveis séricos de T3 e redução dos níveis séricos de T4 (TAVARES et al., 2013).

Diversos artigos da literatura já demonstraram uma importante relação entre os elevados níveis séricos de T3 e danos cardiovasculares, visto que este hormônio apresenta ações fisiológicas fundamentais para a regulação estrutural do coração, assim como para a regulação da contratilidade cardíaca e da função eletrofisiológica (DILLMANN, 2010; FAZIO et al., 2004; GRAIS; SOWES, 2014; PARMAR, 2005). Em relação às alterações morfológicas promovidas pelos HT no coração, esses hormônios são responsáveis por ativar diferentes vias hipertróficas, tais como a via da ERK1/2 e PI3K/Akt/mTOR, as quais culminam no aumento da síntese proteica e no aumento da massa cardíaca (GUPTA, 2007; KLEIN; OJAMAA, 2001; PANTOS et al., 2008).

Embora o aumento da massa cardíaca induzido por altas doses de T3 (durante 7 e 14 dias) já tenha sido previamente caracterizada por nós em ratos da linhagem Wistar (CARRILLO-SEPÚLVEDA et al., 2010). Os efeitos da indução do hipertireoidismo com T3 na linhagem Sprague Dawley ainda não havia sido caracterizado. Neste sentido, assim como esperado, os elevados níveis de T3 nos ratos Sprague Dawley selvagens promoveram hipertrofia cardíaca. Além do aumento da massa cardíaca, a instalação de um processo hipertrófico também é representada por uma alteração na expressão de genes fetais, nos quais genes que eram expressos apenas no período de desenvolvimento dos cardiomiócitos voltam a ser expressos na fase adulta (BARRY; DAVIDSON; TOWNSEND, 2008). Na hipertrofia patológica, desenvolvida por estímulos mecânicos, como exemplo de sobrecarga crônica de pressão, observa-se aumento da expressão gênica de $\beta$-MHC e uma redução na expressão de $\alpha-M H C$ em humanos e roedores (BERNARDO et al., 2010; DILLMANN, 2010; IZUMO et al., 1987). Tal modulação está associada 
com uma redução na velocidade de contração e, portanto, relacionada com um prejuízo na função sistólica (MORKIN, 2000). Todavia, a hipertrofia cardíaca induzida por HT é representada por uma redução na expressão gênica de $\beta-\mathrm{MHC}$ e um aumento de $\alpha-\mathrm{MHC}$, que acarreta em um aumento da força de contração e uma melhora na eficiência energética (DILLMANN, 2010; KAHALY; DILLMANN, 2005; OJAMAA; PETRIE; BALKMAN, 1994).

Desta forma, no presente estudo, os animais selvagens induzidos ao hipertireoidismo apresentaram redução de $\beta-\mathrm{MHC}$ e aumento de $\alpha-\mathrm{MHC}$, o que é comumente associado à instalação de uma hipertrofia concêntrica fisiológica (GUPTA, 2007). A presença de uma hipertrofia concêntrica também foi evidenciada nos parâmetros morfológicos avaliados por ecocardiograma, uma vez que os animais selvagens induzidos ao hipertireoidismo apresentaram aumento da espessura do septo interventricular, da parede posterior do VE e da parede do VD, acompanhados de redução do diâmetro interno e do volume do VE.

Contudo, os animais transgênicos induzidos ao hipertireoidismo não apresentaram a instalação de um processo hipertrófico no coração, demonstrando que os elevados níveis de Ang 1-7 que esses animais apresentam previnem o ganho de massa cardíaca, em ambas as câmaras cardíacas, induzida pelo T3. Os parâmetros morfológicos cardíacos avaliados por ecocardiograma nos animais transgênicos também comprovaram a prevenção da hipertrofia cardíaca pela Ang 17, uma vez que os animais transgênicos induzidos ao hipertireoidismo não apresentaram aumento do septo interventricular e da parede do VD na sístole, assim como não apresentaram redução do diâmetro interno do VE na sístole. Por outro lado, o tratamento com A779 foi responsável por inibir as ações anti-hipertróficas da Ang 1-7, uma vez que os animais tratados com o antagonista do receptor Mas apresentaram a instalação de um processo hipertrófico, representado por um aumento na massa cardíaca.

As ações anti-hipertróficas da Ang 1-7 já estão muito bem estabelecidas na literatura, prevenindo ou atenuando a hipertrofia cardíaca em diferentes modelos experimentais; a exemplo de modelos com indução da hipertrofia por aumento da Ang II (FLORES-MUNOZ et al., 2012; HE et al., 2004), por endotelina-1 (TALLANT; FERRARIO; GALLACHER, 2005), por isoproterenol (LUSUF et al., 2008), dentre outros. Contudo, apenas no modelo de indução de hipertrofia cardíaca por DOCA- 
SAL, o tratamento com Ang 1-7, apesar de prevenir o remodelamento cardíaco, não foi capaz de prevenir a hipertrofia cardíaca (GROBE et al., 2006).

Nos animais transgênicos, TGR-L3292, também já foram observadas as ações anti-hipertróficas da Ang 1-7 em modelo de hipertrofia cardíaca induzido por isoproterenol, no qual os animais transgênicos apresentaram atenuação na hipertrofia acompanhada por uma melhora na função cardíaca. Os animais TGRL3292 tratados com isoproterenol apresentaram redução no tempo de arritmia e melhora da função pós-isquêmica em corações perfundidos isoladamente (NADU et al., 2008; SANTOS, 2004). Da mesma maneira, no modelo de hipertrofia cardíaca induzida por Ang II, foi verificada no ventrículo esquerdo dos animais TGR-L3292 uma redução na expressão de genes fetais relacionados à hipertrofia cardíaca, demonstrando mais uma vez os efeitos anti-hipertróficos da Ang 1-7 (GOMES et al., 2010).

Além dos parâmetros morfológicos, parâmetros funcionais também foram avaliados. O T3 foi responsável por aumentar a hemodinâmica cardíaca, com aumento da frequência cardíaca, do débito cardíaco, da fração de ejeção e da fração de encurtamento. $O$ hiperdinamismo é frequentemente observado na clínica, em pacientes hipertireoideos (KLEIN; DANZI, 2007), estando muito associado com o desenvolvimento de taquicardia, arritmia atrial e fibrilação atrial (DANZI; KLEIN, 2014). O aumento da frequência cardíaca promovida pelo tratamento com $H T$ já foi observado em outros trabalhos da literatura (SZKUDLAREK et al., 2014), assim como em trabalhos anteriores do nosso grupo (DINIZ et al., 2012). Dentre as diversas ações atribuídas aos HT, o T3 promove ações indiretas com modulação do sistema nervoso autônomo, as quais resultam no aumento da força e da velocidade de contração sistólica (DANZI; KLEIN, 2012), acompanhadas do aumento da pressão arterial sistólica (PAS) e da FC (SZKUDLAREK et al., 2014). Sendo assim, a hiperfuncionalidade da glândula tireoide está bem associada com um aumento do risco de desenvolver hipertensão (CHOPRA; CHERIAN; JACOB, 2011).

Por outro lado, o eixo ECA2/Ang 1-7/Mas apresenta ações que contribuem para a redução da carga simpática, a exemplo da redução de norepinefrina promovida pela Ang 1-7, reduzindo a taquicardia e possíveis danos cardiovasculares (BYKU; MACARTHUR; WESTFALL, 2010). Em trabalho de Lima et al (2013), o tratamento com Ang 1-7 foi capaz de impedir o aumento da frequência cardíaca induzida por 
isoproterenol. Tal modulação também foi verificada in vitro, uma vez que cardiomiócitos tratados com Ang 1-7 apresentaram redução da frequência de batimentos frente ao tratamento com isoproterenol (LIMA et al., 2013). Da mesma maneira, nossos experimentos mostraram que a supreexpressão de Ang 1-7 nos animais transgênicos foi capaz de atenuar o aumento da frequência cardíaca promovido pelo T3.

Contudo, apesar de apresentar redução na frequência cardíaca, os animais transgênicos induzidos ao hipertireoidismo não apresentaram redução no débito cardíaco. Tal fato pode ser explicado por um possível aumento no volume sistólico promovido pela Ang 1-7, uma vez que este peptídeo promove diminuição da resistência periférica total, o que contribui para o aumento do retorno venoso, resultando no aumento do volume sistólico (BOTELHO-SANTOS et al., 2007, 2012; SAMPAIO; NASCIMENTO; SANTOS, 2003).

As ações diretas da Ang 1-7 nos cardiomiócitos também contribuem para o aumento do volume sistólico, visto que este peptídeo promove aumento da expressão de SERCA 2 e aumento na captação de cálcio $\left(\mathrm{Ca}^{2+}\right)$ nas células, o que contribui para o aumento da força de contração e, consequentemente, para o aumento do volume sistólico (GOMES; SANTOS; GUATIMOSIM, 2012). O tratamento com A779 também evidenciou a importância da Ang 1-7 para a manutenção do débito cardíaco, uma vez que os animais tratados com o antagonista do receptor Mas apresentaram débito cardíaco menor que os animais apenas induzidos ao hipertireoidismo.

Neste sentido, diversos autores já indicaram uma importante participação da Ang 1-7 para a manutenção da função sistólica (LOOT et al., 2002; ZISMAN et al., 2003). Santos et al (2006) demonstrou que camundongos knockout para o receptor Mas apresentaram um prejuízo na função sistólica, com menor fração de encurtamento e maior diâmetro interno do VE na sístole. Em modelo de hipertrofia cardíaca induzido por DOCA-sal, a Ang 1-7 foi capaz de evitar o aumento das frações de ejeção e de encurtamento (SANTIAGO et al., 2010). Do mesmo modo, nossos experimentos mostraram que, apesar dos animais hipertireoideos não terem apresentado uma disfunção sistólica instalada, a Ang 1-7 foi capaz de reduzir o aumento das frações de ejeção e de encurtamento promovido pelo T3. Portanto, no nosso modelo experimental, a Ang 1-7 apresentou uma importante cardioproteção, visto que 
alterações nesses parâmetros funcionais, em longo prazo, podem levar até mesmo ao quadro de Insuficiência Cardíaca (BROWN et al., 2002; DILLMANN, 2010; SIU et al., 2007). Tais ações cardioprotetoras, apresentadas pela Ang 1-7, ocorreram via receptor Mas, uma vez que o tratamento com A779 foi capaz de inibir a modulação promovida pela Ang 1-7 nas frações de encurtamento e de ejeção.

A função diastólica foi avaliada no presente estudo pelo padrão de enchimento do VE, Razão E/A, o qual leva em consideração a velocidade de enchimento diastólico precoce (E) e a velocidade do fluxo sistólico atrial (A). Nossos experimentos mostraram uma redução dessa razão nos animais selvagens induzidos ao hipertireoidismo, o que indica um prejuízo na função diastólica, podendo ocorrer por aumento da pressão do átrio esquerdo e/ou por uma maior rigidez do VE. Da mesma maneira, Szkudlarek et al (2014) também observaram uma disfunção diastólica em ratos induzidos ao hipertireoidismo por 10 dias. Contudo, o aumento de Ang 1-7 nos animais transgênicos induzidos ao hipertireoidismo foi capaz de prevenir totalmente a modulação deste parâmetro, o que indica, novamente, importantes ações cardioprotetoras da Ang 1-7, frente aos efeitos cardíacos do T3.

Em relação à modulação do SRA, diversos trabalhos do nosso grupo de pesquisa vêm demonstrando uma importante relação entre o SRA e os HT. Em nossos estudos temos observado que os efeitos cardiovasculares dos HT, tanto em situação de hipotireoidismo (CARNEIRO-RAMOS et al., 2007), como de hipertiroidismo (DINIZ et al., 2012; TAVARES et al., 2013), ocorrem, em parte, mediados pelo SRA. Neste sentido, nossos experimentos mostraram um aumento de Ang I/II no ventrículo esquerdo dos animais induzidos ao hipertireoidismo. Do mesmo modo, Marchant, Brown e Sernia (1993) observaram uma ativação dos componentes deste sistema frente ao tratamento com T3, representado por um aumento do angiotensinogênio no plasma, bem como por um aumento da atividade da renina plasmática, os quais podem justificar o aumento de Ang I/II observados neste trabalho.

Santos et al (2004) demostraram redução significativa dos níveis de Ang II, avaliados por radioimunoensaio, no ventrículo esquerdo dos animais transgênicos (TGR-L3292) quando comparados com os animais selvagens. Por outro lado, nossos experimentos mostraram um aumento da Ang $\mathrm{I} / \mathrm{ll}$ nos corações dos animais 
que superexpressam Ang 1-7. Acreditamos que essa possa corresponder a uma limitação do presente estudo, uma vez que outras técnicas de dosagens dos peptídeos deveriam ser realizadas para a confirmação nos níveis de Ang II no coração dos animais transgênicos, visto que a técnica utilizada para a quantificação, Western Blotting, por se utilizar de anticorpos, pode apresentar alto grau de ligações inespecíficas com outros peptídeos constituintes do SRA.

Além da modulação dos níveis de Ang II, trabalhos anteriores do nosso grupo de pesquisa também demonstraram, in vivo, aumento na expressão proteica dos receptores da Ang II, receptor AT1 (DINIZ et al., 2012) e receptor AT2 (TAVARES, et al., 2013), bem como do receptor da Ang 1-7, receptor Mas (resultados não publicados) frente ao tratamento com T3. Embora tenhamos observado, neste estudo, um aumento do receptor AT1 no coração dos animais hipertireoideos, os receptores Mas e AT2 não apresentaram alterações significativas com o tratamento com T3, mostrando uma forte tendência ao aumento. Em relação aos animais transgênicos, de forma semelhante aos nossos resultados, Santiago et al (2010) não observaram alterações na concentração dos receptores AT1 e Mas dos animais transgênicos em relação aos animais selvagens, ao passo que outros estudos da literatura demonstraram que infusão de Ang 1-7 promove redução dos níveis de AT1 em células de músculo liso (CLARK; TALLANT; DIZ, 2001) e nos rins (CLARK et al., 2003).

Ainda, com o intuito de verificarmos uma possível modulação dos demais componentes do SRA, avaliamos a atividade das enzimas ECA e ECA2. Em relação à atividade da enzima ECA, o tratamento com T3 promoveu significativa redução na atividade desta enzima no coração. Trabalhos anteriores do nosso laboratório também demonstraram uma importante relação entre o aumento dos níveis circulantes de HT e uma redução da atividade da enzima ECA no coração, sem alterações na atividade sérica da ECA (CARNEIRO-RAMOS et al., 2006; LINO; SHIBATA; BARRETO-CHAVES, 2014). Visto que a enzima ECA é a principal responsável pela formação de Ang II (BALCELLS et al., 1997), a redução de sua atividade nos animais tratados com T3 pode ocorrer como um mecanismo de cardioproteção frente aos estímulos hipertróficos tanto do T3 como da Ang II no coração. Em relação à atividade da enzima ACE2, os animais induzidos ao 
hipertireoidismo apresentaram um aumento significativo na atividade dessa enzima, o que também indica um mecanismo cardioprotetor nos animais hipertireoideos.

Dessa forma, os resultados apresentados neste trabalho mostraram, pela primeira vez na literatura, as ações anti-hipertróficas da Ang 1-7 frente aos efeitos do T3, bem como a melhora na função cardíaca promovida por este peptídeo em modelo de hipertireoidismo. O tratamento com A779 confirmou nossa hipótese de que as ações cardioprotetoras observadas nos animais transgênicos ocorrem devido ao aumento do heptapeptídeo Ang 1-7 e, consequentemente, das suas ações via receptor Mas, uma vez que diversos parâmetros morfológicos e funcionais avaliados foram prevenidos com a inibição deste receptor. O presente trabalho também verificou uma modulação dos principais componentes do SRA no modelo de hipertireoidismo.

\section{Limitações do estudo}

Embora o presente estudo tenha alcançado os objetivos propostos inicialmente, três pontos merecem ser pontuados e deverão ser abordados antes da submissão do(s) artigo(s) científico(s):

1 - Dosagens séricas de T3 e T4. Estas deverão ser realizadas para a confirmação do estado hipertireoideo dos animais. Estes dados não constam da Dissertação pois o Kit importado para tal finalidade (MILLIPLEX RTHY-30K Kit - Millipore) não chegou da importação em tempo hábil, estando prevista a sua chegada em fins de Julho. Por outro lado, vale salientar que outros trabalhos do nosso grupo de pesquisa já caracterizaram e validaram o mesmo modelo experimental de hipertireoidismo induzido por injeções diárias de T3 $(7 \mu \mathrm{g} / 100 \mathrm{~g}$ de peso corpóreo/dia), durante 14 dias. Além disso, os animais induzidos ao hipertireoidismo, neste estudo, apresentaram alterações frequentemente observadas em condições de hipertiroidismo, tais como redução na massa corpórea, hiperdinamismo cardíaco e hipertrofia cardíaca, o que nos garante que a indução ao hipertireoidismo, nestes animais, ocorreu da maneira esperada e com sucesso.

2 - Dosagens dos níveis plasmáticos e cardíacos de Ang 1-7 e Ang II. Os peptídeos contidos no plasma dos animais já foram extraídos e estão aguardando as dosagens, as quais serão realizadas por espectrometria de massa, em colaboração com o Prof. Dr. Robson Santos (UFMG). 
3 - Determinação da Pressão Sistólica nos grupos experimentais. Nós temos demonstrado previamente no nosso modelo que os elevados níveis de HT, paralelamente aos efeitos tróficos, também promovem com o tempo aumento da pressão de cauda (indicativa da pressão sistólica) e da frequência cardíaca (CARNEIRO-RAMOS et al., 2006). O efeito trófico do T3 ocorre de maneira independente das alterações hemodinâmicas, uma vez que a hipertrofia se instala antes mesmo de se observar o aumento da PAS, além de poder ser observado tal efeito trófico também em culturas primárias de cardiomiócitos (DINIZ; CARNEIRORAMOS; BARRETO-CHAVES, 2009). Aparentemente, as ações anti-hipertróficas da Ang 1-7 em culturas de cardiomiócitos, observadas no presente estudo, sugerem que este peptídeo também aja de modo direto na célula, independentemente de suas ações prevenindo o hiperdinamismo induzido pelo T3. Todavia, não sabemos o comportamento desse peptídeo nos parâmetros hemodinâmicos frente aos elevados níveis de T3 e, portanto, ainda temos o interesse em verificar se a Ang 1-7 seria capaz de atenuar o aumento da pressão arterial sistêmica observada nos animais hipertireoideos. De qualquer modo, em relação aos animais transgênicos utilizados neste estudo, Santos et. al. (2004) já demonstrou que, apesar dos elevados níveis séricos de Ang 1-7, os animais TGR-L3292 não apresentam alterações significativas, no caso, diminuição da pressão arterial, em comparação com os animais selvagens.

Em síntese, os resultados apresentados neste estudo sugerem que, em detrimento do ajuste dos níveis séricos de HT, o aumento de Ang 1-7 circulante pode ser uma importante estratégia para o tratamento de cardiopatias frequentemente observadas em pacientes hipertireoideos, os quais, na maioria das vezes, são tratados concomitantemente com inibidores da ECA e/ou AT1. Entretanto, estudos adicionais são necessários para o melhor entendimento dos mecanismos moleculares envolvidos na cardioproteção mediada pela Ang 1-7, tal como o entendimento das vias de sinalização moduladas por este heptapeptídeo em modelo de hipertireoidismo. 


\section{CONCLUSÃO}

Com base nos resultados apresentados neste estudo concluímos que os elevados níveis de Ang 1-7 circulantes, presentes nos animais transgênicos (TGRL3292), foram capazes de prevenir parcial ou totalmente a hipertrofia cardíaca induzida por T3. Além disso, a Ang 1-7 também foi capaz de modular os parâmetros de função sistólica e função diastólica avaliados por ecocardiograma, atenuando o hiperdinamismo e promovendo uma melhora na função cardíaca. $O$ tratamento com o antagonista seletivo do receptor Mas, A779, foi responsável por prevenir ou atenuar diversas ações cardioprotetoras da Ang 1-7, indicando estar o receptor MAS envolvido nessas ações.

As ações anti-hipertróficas da Ang 1-7, frente às ações cardíacas do T3, também foram observadas em modelo in vitro, utilizando cultura primária de cardiomiócitos neonatos, no qual pudemos observar uma ação anti-hipertrófica desse peptídeo direta na célula cardíaca e que, portanto, independe de alterações hemodinâmicas. 


\section{REFERÊNCIAS *}

ABADIR, P. M.; FOSTER, D. B.; CROW, M.; COOKE, C. A.; RUCCKER, J. J.; JAIN, A.; SMITH, B. J.; BURKS, T. N.; COHN, R. D; FEDARKO, N. S.; CAREY, R. M.; O'ROURKE, B.; WALSTON, J. D. Indenfication and characterization of a functional mitochondria angiotensin system. Proceedings of the National Academy of Sciences USA, v.108, n.36, p.1484814854, 2011.

ABADIR, P. M.; WALSTON, J. D.; CAREY, R. M. Subcellular characteristics of functional intracelular renin-angiotensin system. Peptides, v.32, n.2, p.437-445, 2012.

ALMEIDA, A. P.; FRÁBREGAS, B. C.; MADUREIRA, M. M.; SANTOS, R. J.; CAMPAGNOLE-SANTOS, M. J.; SANTOS, R. A. Angiotensin-(1-7) potentiates the coronary vasodilatatory effect of bradykinin in te isolated rat heart. Brazilian Journal of Medical and Biological Resarch, v.33, n.6, p.707-713, 2000.

APLIN, M.; CHRISTENSEN, G. L.; SCHNNERIDER, M.; HEYDOM, A.; GAMMELTOFT, S.; KJOLBYE, A. L.; SHEIKH, S. P.; HANSEN, J. L. The angiotensin type 1 receptor activates extracellular signal-regulated kinases 1 and 2 by $G$ protein-dependent and independent pathways in cardiac myocytes and Langendorff-perfused hearts. Basic \& Clinical Pharmacology \& Toxicology, v.100, p.289-295, 2007.

BADER, M.; SANTOS, R.A.; UNGER, T.; STECKELINGS, U. M. New therapeutic pathways in the RAS. Journal of the Renin-Angiotensin-Aldosterone System, v.13, p.505-508, 2012.

BALAKUMAR, P.; JAGADEESH, G. A centery old renin-angiotensin system still grows with endelles possibilities: AT1 receptor signaling cascades in cardiovascular physiopathology. Celluar Signallings, v.26, n.10, p.2147-2160, 2014.

BALCELLS, E.; MENG,Q. C.; JOHNSON, W. H.; OPARIL, S.; DELL'ITALIA, L. J. Angiotensin II formation from ACE and chymase in human and animal hearts: Methods and species considerations. American Journal of Physiology, v.273, p.1769-1774, 1997.

BARRETO-CHAVES, M. L.; CARRILLO-SEPÚLVEDA, M. A.; CARNEIRO-RAMOS, M. S.; GOMES, D. A.; DINIZ, G. P. The cross talk between thyroid hormones and the ReninAngiotensin System. Vascular Pharmacology, v.52, n.3-4, p.166-170, 2010.

BARRETO-CHAVES, M. L.; de SOUZA MONTEIRO, P.; FURSTENAU, C. R. Acute actions of thyroid hormone on blood vessel biochemistry and physiology. Current Opinion in Endocrinology Diabetes and Obesity, v.18, n.5, p.300-305, 2011.

BARRETO-CHAVES, M. L.; HEIMANN, A.; KRIEGER, J. E. Stimulatory effect of dexamethasone on angiotensin-converting enzyme in neonatal rat cardiac myocytes. Brazilian Journal of Medical and Biological Research, v.33, n.6, p.661-667, 2000.

*De acordo com:

ASSOCIAÇÃO BRASILEIRA DE NORMAS TÉCNIAS. NBR 6023: informação e documentação: referências: elaboração. Rio de Janeiro, 2002. 
BARROSO, L. C.; SILVEIRA, K. D.; LIMA, C. X.; BORGES, V.; BADER, M.; RAICHID, M.; SANTOS, R. A.; SOUZA, D. G.; SIMÕES, E. SILVA, A. C.; TEXEIRA, M. M. Reniprotective effects of AVE0991, a Nonpeptide Mas receptor agonist in experimental acute renal injury. Internacional Journal Hypertension, v.2012, Jan 29, 2012.

BARRY, S. P.; DAVIDSON A. M.; TOWNSEND, P. A. Molecular regulation of cardiac hypertrophy. The Internacional Journal of Biochemistry \& Cell Biology, v.40, p.20232039, 2008.

BERENJI, K.; DRAZNER, M. H.; ROTHERMEL, B. A.; HILL, J. A. Does load-induced ventricular hypertrophy progress to systolic heart failure? American Journal of Physiology. Heart and Circulatory Physiology, v.289, n.1, p.H8-H16, 2005.

BERGH, J. J. Integrin alpha beta 3 contains a cell surface receptor site for thyroid hormone that is linked to activation of mitogen-activated protein kinase and induction of angiogenesis. Endocrinology, v.146, n.7, p.2864-2871, 2005.

BERNARDO, B. C.; WEEKS, K. L.; PRETORIUS, L.; MCMULLEN, J. R. Molecular distinction between physiological and pathological cardiac hypertrophy: experimental findings and therapeutic strategies. Pharmacology \& Therapeutics. v.128, n.1, p.197-227, 2010.

BIANCO, A. C.; SILVA, J. E. Nuclear 3,5,3'-triiodothyronine (T3) in brown adipose tissue: receptor occupancy and sources of T3 as determined by in vivo techniques. Endocrinology, v. 120, p. 55-62, 1987.

BOOZ, G. W.; BAKER, K. M. Role of type 1 and type 2 angiotensin receptors in angiotensin II- induced cardiomyocyte hypertrophy. Hypertension, v.28, p.635-640, 1996.

BOTELHO-SANTOS, G. A.; BADER, M.; ALENINA, N.; SANTOS, R. A. Altered regional blood flow distribution in Mas-deficient mice. Therapeutic Advances in Cardiovascular Diseases, v.6, p.201-211, 2012.

BOTELHO-SANTOS, G. A.; SAMPAIO, W. O.; REUDELHUBER, T. L.; BADER, M.; CAMPAGNOLE-SANTOS, M. J.; SANTOS, R. A. Expression of an angiotensin-(1-7)producing fusion protein in rats induced marked changes in regional vascular resistence. American Journal of Physiology. Heart and Circulatory Physiology, v.292, n.5, p.H2485-H2490, 2007.

BRADFORD, M. M. A rapid and sensitive method for the quantitation of microgram quantities of protein utilizing the principle of protein-dye binding. Analytical Biochemistry, v.7, n.72, p.248-254, 1976.

BROWN, L.; FENNING, A.; CHAN, V.; LOCH, D.; WILSON, K.; ANDERSON, B.; BURSTOW, $D$. Echocardiographic assessment of cardiac structure and function in rats. Heart, Lung and Circulation, v.11, n.3, p.167-173,2002.

BUJAK, M.; FRANGOCIANNIS, N. G. The role of TGF-beta signaling in myocardial infaction and cardiac remodeling. Cardiovascular Research, v.74, n.2, p.184-195, 2007.

BYKU, M.; MACARTHUR, H.; WESTFALL, T. C. Inhibitory effects of angiotensin-(1-7) on the nerve stimulation-induced release of norepinephrine and neuropeptide $Y$ from the mesenteric arterial bed. American Journal of Physiology. Heart and Circulation Physiology, v.298, p.H457-H465, 2010. 
CAPPOLA, A. R.; FRIED, L. P.; ARNOLD, A. M.; DANESE, M. D.; KULLER, L. H.; BURKE, G. L.; TRACY, R. P.; LADENSON, P.W. Thyroid status, cardiovascular risck and mortality in older adults. JAMA, v.295, p.1033-1041, 2006.

CAREY, R. M.; WANG, Z. Q.; SIRAGY, H. M. Role of the angiotensin type 2 receptor in the regulation of blood pressure and renal function. Hypertension, v.35, p.155-163, 2000.

CARNEIRO-RAMOS, M. S.; DINIZ, G. P.; NADU, A. P.; ALMEIDA, J.; VIEIRA, R. L.; SANTOS, R.A.; BARRETO-CHAVES, M. L. Blockage of angiotensin II type 2 receptor prevents thyroxine-mediated cardiac hypertrophy by blocking Akt activation. Basic Research in Cardiology, v.105, n.3, p.325-235, 2010.

CARNEIRO-RAMOS, M. S.; DINIZ, G. P.; ALMEIDA, J.; VIEIRA, R. L.; PINHEIRO, S. V.; SANTOS, R. A.; BARRETO-CHAVES, M. L. Cardiac angiotensin II type I and type II receptors are increased in rats submitted to experimental hypothyroidism. Journal of Physiology, v.583, p.213-223, 2007.

CARNEIRO-RAMOS, M. S.; SILVA, V. B.; SANTOS, R. A.; BARRETO-CHAVES, M. L. Tissue-especific modulation of angiotensin-converting enzyme (ACE) in hyperthyroidism. Peptides, v.27, p.2942-2949, 2006.

CARRILLO-SEPÚVEDA, M. A.; CERAVOLO, G. S.; FORTES, Z. B.; CARVALHO, M. H.; TOSTES, R. C.; LAURINDO, F. R.; WEBB, R. C.; BARRETO-CHAVES, M. L. Thyroid hormone stimulates NO production via activation of the P13K/AKT pathway in vascular myocytes. Cardiovascular Research, v.85, n.3, p.560-570, 2010.

CASTRO, A. L.; TAVARES, A. V.; CAMPOS, C.; FERNANDES, R. O.; SIQUEIRA, R.; CONZATTI, A.; BICCA, A. M.; FERNANDES, T. R.; SARTÓRIO, C. L.; SCHENKEL, P. C.; BELLO-KLEIN, A.; DA ROSA ARAUJO,A. S. Cardioprotective effects of thyroid hormones in a rat model of myocardial infarction are associated with oxidative stress reduction. Molecular and Cellular Endocrinology, v.391, p.22-29, 2014.

CHAPPEL, M. C.; GOMEZ, M. N; PIRRO, N. T.; FERRARIO, C. M. Release of angiotensin(1-7) from the rat hindlimb: influence of angiotensin-converting enzyme inhibition. Hypertension, v.32, n.2, p.348-352, 2000.

CHAPPELL, M. C.; PIRRO, N. T.; SYKES, A.; FERRARIO, C. M. Metabolism of Angiotensin(1-7) by angiotensin-converting enzyme. Hypertension, v.31, n.2, p.356-361, 1998.

CHIU, A. T.; HERBLIN, W. F.; MCCALL, D. E.; ARDECKY, R. J.; CARINI, D. J.; DUNCIA, J.V.; PEASE, L. J.; WONG, P. C.; WEXLER, R. R.; JOHNSON, A. L. Identification of angiotensin II receptor subtypes. Biochemical and Biophysical Research Communications, v.165, p.196-203, 1989.

CHOPRA, S.; CHERIAN, D.; JACOB, J. J. The thyroid hormone, parathyroid hormone and vitamin D associated hypertension. Indian Journal of Endocrinology and Metabolism, v.15, p. S354-360, 2011.

CLARK, M. A.; TALLANT, E. A.; DIZ, D. I. Downregulation of the AT1A receptor by pharmacologic concentrations of angiotensin-(1-7). Journal of Cardiovascular Pharmacology, v.37, p.437-448, 2001.

CLARK, M. A.; TALLANT, E. A.; TOMMASI, E.; BOSCH, S.; DIZ, D. I. Angiotensin-(1-7) reduces renal angiotensin II receptors through a cyclooxygenase- dependent mechanism. Journal of Cardiovascular Pharmacology, v.41, p.276-283, 2003. 
CORVOL, P.; MICHAUD, A.; SOUBRIER, F.; WILLIAMS, T. A. Recent advances in knowledge of the structure and function of the angiotensin I converting enzyme. Journal of Hypertension Supplement, v.13, p.S3-S10, 1995.

COTOMACCI, G.; SARKIS, J. J.; FRUSTENAU, C. R.; BARRETO-CHAVES, M. L. Thyroid hormones are involved in 5'-nucleotidase modulation in soluble fraction of cardiac tissue. Life Sciences, v.91, p.137-142, 2012.

CROWLEY, S. D.; COFFMAN, T. M. Recent advances involving the rennin-angiotensin system. Experimental Cell Research, v.318, n.9, p.1049-1056, 2012.

DANYEL, L. A.; SCHMERLER, P.; PAULIS, L.; UNGER, T.; STECKELINGS, U. M. Impact of AT2-receptor stimulation on vascular biology, kidney function, and blood pressure. Integrated Blood Pressure Control, v.6, p.153-161, 2013.

DANZI, S.; KLEIN, I. Thyroid disease and the Cardiovascular System. Endocrionology Metabolism Clinics of North America, v.43, p.517-528, 2014.

DANZI, S.; KLEIN, I. Thyroid Hormone and the Cardiovascular System. New England Journal of Medicine, v.344, n.7, p.501-509, 2012.

DAUGHERTY, A.; MANNING, M. W.; CASSIS, L. A. Angiotensin II promotes atherosclerotic lesions and aneurysms in apolipoprotein E-deficient mice. Journal of Clinical Investigation, v.105, p.1605-1612, 2000.

DAVIE, A. P.; McMURRAY, J. J. Effect of angiotensin-(1-7) and bradykinin in patients with heart failure treated with an ACE inhibitor. Hypertension, v.34, p.457-460, 1999.

DAVIS, P. J.; LEONARD, J. L.; DAVIS, F.B. Mechanisms of nongenomic actions of thyroid hormone. Frontiers in Neuroendocrinology, v.29, n.2, p.211-218, 2008.

DE MELLO, W. C. Angiotensin (1-7) re-establishes impulse conduction in cardiac muscle during ischemia-reperfusion. The role of the sodium pumb. Journal of Renin-AngiotensinSystem, v.5, n.4, p.203-208, 2004.

DE MOURA, M. M.; SANTOS, R. A.; FONTES, M. A. Evidence for a functional cardiac interation between losartan and angiotensin-(1-7) receptors revealed by orthostatic tilting in rats. Brazilian Journal of Pharmacology, v.144, n.6, p.755-600, 2005.

DEDDISH, P. A.; MARCIC, B.; JACKMAN, H. L.; WANG, H. Z.; SKIDGEL, R. A.; ERDOS, E. G. N-domain specific substrate and c-domain inhibition of angiotensin-converting enzyme: Angiotensin-(1-7) and Keto-ACE. Hypertension, v.17, p.131-138, 1991.

DESCHEPPER, C. F. Angiotensinogen: hormonal regulation and relative importance in the generation of angiotensin II. Kidney Internacional, v.46, p.1561-1563, 1994.

DIAS-PEIXOTO, M. F.; SANTOS, R. A.; GOMES, E. R.; ALVES, M. N.; ALMEIDA, P. W.; GRECO, L.; ROSA, M.; FAULER, B.; BADER, M.; ALENINA, N.; GUATIMOSIM, S. Molecular mechanisms involved in the angiotensin-(1-7)/mas signaling pathway in cardiomyocytes. Hypertension, v.52, n.3, p.542-548, 2008.

DILLMANN, W. Cardiac hypertrophy and thyroid hormone signaling. Heart Failure Reviews, v.15, p.125-132, 2010. 
DINIZ, G. P.; TAKANO, A. P.; BRUENETO, E.; SILVA, F. G.; NUNES, M. T.; BARRETOCHAVES, M. L. New insight into the mechanism associated with the rapid effect of T3 on AT1R expression. Journal of Molecular Endocrinology, v.49, n.1, p.11-20, 2012.

DINIZ, G. P.; CARNEIRO-RAMOS, M. S.; BARRETO-CHAVES, M. L. Angiotensin type 1 receptor mediates thyroid hormone-induced cardiomyocyte hyperthophy through the AKT/GSK-3beta/mTOR signaling pathway. Arquivos Brasileiros de Cardiologia, v.104, n.6, p.653-667, 2009.

DINIZ, G. P.; CARNEIRO-RAMOS, M. S.; BARRETO-CHAVES, M. L. Thyroid hormone increases TGF-beta 1 in cardiomyocytes cultures independently of angiotensin II type 1 and type 2 receptors. Journal of Endocrinology., v.2010, 2010.

ENÉAS, R. M.; LARA, A. A.; ALMEIDA, P. W.; GUIMARÃES, D.; RESENDE, R. R.; CAMPAGNALE-SANTOS, M. J.; BADER, M.; SANTOS, R. A.; GUATIMOSIN, S. Angiotensin-(1-7) prevents cardiomyocyte pathological remodeling through a nitric/guanosine 3',5'cyclic monophosphate-dependen pathway. Hypertension, v.55, p.153-160, 2009.

FADEL, B. M.; ELLAHHAM, S.; RINGEL, M. D.; LINDSAY, J. Jr.; WARTOFSKY, L.; BURMAN, K. D. Hyperthyroid heart disease. Clinical Cardiology, v.23, p.402-408, 2000.

FARAG, E.; MAHESHWARI, K.; MORGAN, J.; SARK, ESA, W. A.; DOYLE, D. J. An update of the Renin Angiotensin in cardiovascular homeostasis. Anesthesia \& Analgesia, v.120, n.2, p.275-292, 2015.

FAZIO, S.; PALMIERI, E. A; LOMBARDI, G.; BIONDI, B. Effects of thyroid hormone on the cardiovascular system. Recent Progress in Hormonal Reseasrch, v.59, p.31-50, 2004.

FERREIRA, A. J.; SANTOS, R. A. S.; ALMEIDA, A. P. Angiotensin-(1-7): cardioprotective effect in myocardial ischemia/reperfusion. Hypertension, v.38, p.665-668, 2001.

FLORES-MUNOZ, M.; GODINHO B. M.; ALMALIK, A.; NICKLIN, S. A. Adenoviral delivery of angiotensin-(1-7) or angiotensin-(1-9) inhibits cardiomyocyte hypertrophy via the Mas or Angiotensin type 2 receptor. Plos One, v.7, n.9, 2012.

FRAGA-SILVA, R. A.; COSTA-FRAGA, F. P.; MURÇA, T. M.; MORAES, P. L.; MARTINS, L. A.; LAUTNER, R. Q.; CASTRO, C. H.; SOARES, C. M.; BORGES, C. L.; NADU, A. P.; OLIVEIRA, M. L.; SHENOY, V.; KATOVICH, M. J.; SANTOS, R. A.; RAIZADA, M. K.; FERREIRA, A. J. Angiotensin-converting enzyme 2 activation improves endothelial function. Hypertension, v.61, n.6, p.1233-1238, 2013.

GOMES, R. M. E.; SANTOS, R. A. S.; GUATIMOSIM, S. Angiotensin-(1-7)-Mediated Signaling in Cardiomyocytes. Internacional Journal of Hypertension, v.2012, 2012.

GOMES, R. M.; LARA, A. A.; ALMEIDA, P. W.; GUIMARÃES, D.; RESENDE, R. R.; CAMPAGNOLE-SANTOS, M. J.; BADER, M.; SANTOS, R. A.; GUATIMOSIM, S. Angiotensin-(1-7) prevents cardiomyocyte pathological remodeling through a nitric oxide/guanosine 3',5'-cyclic monophosphate-depent pathway. Hypertension, v.55, n.1, p.153-160, 2010.

GUPTA, M. P. Factors controlling cardiac myosin-isoform shift during hypertrophy and heart failure. Journal of Molecular Cell Cardiology, v.43, n.4, p.388-403, 2007.

GRAIS, I. M.; SOWERS, J. R. Thyroid and the Heart. The American Journal of Medicine, v. 127, n.8, p.691-998, 2014. 
GRIENDLING, K. K.; MINIERI, C. A.; OLLERENSHAW, J. D.; ALEXANDER, R. W. Angiotensin II stimulates NADH and NADPH oxidase activity in cultures vascular smooth muscle cells. Circulation Research, v.74, p.1141-1148, 1994.

GROBE, J. L.; MECCA, A. P.; MAO, H.; KATOVICH, M. J. Chronic angiotensin-(1-7) prevents cardiac fibrosis in DOCA-salt modelo hypertension. American Journal of Physiology. Heart and Circulation Physiology, v.290, n.6, p.H2417-H2423, 2006.

HADJ-SAHRAOUI, N.; SEUGNET, I.; GHORBEL, M. T.; DEMENEIX, B. Hypothyroidism prolongs mitotic activity in the post-natal mouse brain. Neuroscience Letters, v.280, p.7982, 2000.

HAGAMAN, J. R.; MOYER, J. S.; BACHMAN, E. S.; SIBONY, M.; MAGYAR, P. L.; WELCH, J. E.; SMITHIES, O.; KREGE, J. H.; O'BRIEN, D. A. Angiotensin-converting enzyme and male fertility. Proceedings of the National Academy of Sciences, v.95, p.2552-2557, 1998.

HE, J. G.; HUANG, Y. Y; MA, H.; HE, X. H.; LIAO, X. X.; WANG, L. C.; ZHOU, J. Z. Effects of angiotensin-(1-7) on remodeling of myocardial collagen network in pressure-over loaded rats. Zhongguo Wei Zhong Bing Ji Jiu Yi Xue, v.16, p.523-526, 2004.

HEINEKE, J.; MOLKENTIN, J. D. Regulation of cardiac hypertrophy by intracellular signaling pathways. Nature Reviews Molecular Cell Biology, v.7, p.589-600, 2006.

HU, L. W.; BENVENTURI, L. A.;LIBERTI, E. A.; CARNEITO-RAMOS, M. S.; BARRETOCHAVES, M. L. Thyroxine-induced cardiac hypertrophy: influence of adrenergic nervous system versus renin-angiotensin system on myocyte remodeling. American Journal of Physiology. Regulatory, Integrative and Comparative Physiology, v.285, p.R1473R1480, 2003.

HUNTER, J. J.; CHIEN, K. R. Signaling pathways for cardiac hypertrophy and failure. New England Journal of Medicine, v.341, p.1276-1283, 1999.

IRANI, K. Oxidant signaling in vascular cell growth, death and survival. A review of the roles of reactive oxygen species in smooth muscle and endothelial cell mitogenic and apoptotic signaling. Circulation Research, v.87, p.179-183, 2000.

IYER, S. N.; CHAPPELL, M. C.; AVERILL, D. B.; DIZ, D. I.; FERRARIO, C. M. Vasopressor actions of angiotensin-(1-7) unmasked combined treatment with Lisinopril and losartan. Hypertension, v. 31, n.2, p.699-705, 1998.

IZUMO, S.; LOMPRE, A. M.; MATSUOKA, R.; KOREN, G.; SCHAWARTZ, K.; NADALGINARD, B.; MAHDAVI, V. Myosin heavy chain messenger RNA and protein isoform transitions during cardiac hypertrophy. Interaction between hemodynamic and thyroid hormone-induce signals. Journal of Clinic Investigation, v.79, p.970-977, 1987.

JAGADEESH, G. Angiontensin II receptors-antagonists, molecular biology, and signal transduction. Indian Journal of Experimental Biology, v.36, n.12, p.1171-1194, 1998.

JANSSEN, R.; ZUIDWIJK, M. J.; KUSTER, D. W.; MULLER, A.; SIMONIDES, W. S. Thyroid hormone-regulated cardiac microRNAs are predicted to suppress pathological hypertrophic signaling. Frontiers Endocrinology, v.5, n.171, 2014.

JIN, H. Y.; SONG, B.; OUDIT, G. Y.; DAVIDGE, S. T.; YU, H. M.; JIANG, Y. Y.; GAO, P. J.; ZHU, D. L.; NING, G.; KASSIRI, Z.; PENNINGER, J. M.; ZHONG, J. C. ACE2 deficiency 
enhances angiotensin II-mediated aortic profiling-1 expression inflammation and peroxynitrite production. PLoS ONE, v.7, n.6, 2012.

JOHNSON, P. N.; FREEDBERG, A. S.; MARSHALL, J. M. Action of thyroid hormone on the transmembrane potentials from sinoatrial node cells and atrial muscle cells in isolates atria of rabbits. Cardiology, v.58, p.273-289, 1973.

KAHALY, G.J.; DILLMANN, W.H. Thyroid hormone action in the heart. Endocrinol Reviews, v.26, n.5, p.704-728, 2005.

KAJSTURA, J.; ROTA, M.; CAPPETTA, D.; OGOREK, B.; ARRANTO, C.; BAI, Y.; FERREIRA-MARTINS, J.; SIGNOLE, S.; SANADA, F.; MATSUDA, A.; KOSTYLA, J.; CABELLORO, M. V.; FIORINI, C.; D’ALESSANDRO, D. A.; MICHLER, R. E.; DELMONTE, F.; HOSODA, T.; PERRELLA, M. A.; LERI, A.; BUCHHOLZ, B. A.; LOSCALZO, J.; ANVERSA, P. Cardiomyogenesis in the aging and failing human heart. Circulation, v.126, v.15, p.1869-1881, 2012.

KESTEREN, C. A.; HEUGTEN, H. A.; LAMERS, J. M.; SAXENA, P. R.; SCHALEKAMP, M. A.; DANSER, A. H. Angiotensin II-mediated growth and antigrowth effects in cultured neonatal rat cardiac myocytes and fibroblasts. Journal of Molecular Cell Cardiology, v.29, p.2147-2157, 1997.

KLEIN, I.; OJAMAA, K. Thyroid hormone-targeting the heart. Endocrinology, v.142, p.1112, 2001.

KLEIN, I; DANZI, S. Thyroid disease and the heart. Ciculation, v.116, p.1725-1735, 2007.

KOBORI, H.; ICHIHARA, A.; SUZUKI, H.; MIYASHITA, Y.; HAYASHI, M.; SARUTA, T. Thyroid hormone stimulates renin synthesis in rat without involving the sympathetic nervous system. American Journal of Physiology, v.272, p.E227-E232, 1997.

KONO, T.; TANIGUCHI, A.; IMURA, H.; OSEKO, F.; KHOSLA, M. C. Biological activities of angiotensin II- (1-6) hexapeptide and Angiotensin II-(1-7)-heptapeptide in man. Life Sciences, v.38, p.1515-1519, 1986.

KUZMAN, J. A.; VOGELSANG, K. A.; THOMAS, T. A.; GERDES, A. M. L-Thyroxine activates Akt signaling in the heart. Journal of Molecular Cell Cardiology, v.39, n.2, p.251258, 2005.

LIMA, A. M.; XAVIER, C. H.; FERREIRA, A. J.; RAIZADA, M. K.; WALLUKAT, G.; VELLOSO, E. P.; SANTOS, R. A.; FONTES, M. A. Activation of angiotensin-converting enzyme 2/angiotensin-(1-7)/Mas axis attenuates the cardiac reactivity to a acute emotional stress. American Journal of Physiology. Heart and Circulation Physiology, v.305, p.H1057-H1067, 2013.

LINO, C. A.; SHIBATA, C. E. R.; BARRETO-CHAVES, M. L. M. Maternal hyperthyroidism alters the pattern of expression of cardiac renin-angiotensin system components in rat offspring. Jorunal of the Renin-Angiotensin-Aldosterone System, v.15, n.1, p.52-60, 2014.

LOOT, A. E.; ROKS, A. J.; HENNING, R. H.; TIO, R. A.; SUURMEIJER, A. J.; BOOMSMA, F.; GILTS, W. H. Angiotensin-(1-7) attenuates the development of heart failure after myocardioal infarction in rats. Circulation, v.105, n.13, p.1548-1550, 2002. 
LUSUF, D.; HENNING, R. H.; GILTS, W. H.; ROKS, A. J. Angiotensin-(1-7): Pharmacological properties and pharmacotherapeutic persperctives. European Journal of Pharmacology, v. 585, p.303-312, 2008.

MAILLET, M.; BERLO, J. H.; MOLKENTIN. Molecular basis oh physiological heart growth: fundamental concepts and new players. Nature, v.14, n.1, p.38-48, 2013.

MAITY, S.; KAR, D.; DE, K.; CHANDER, V.; BANDYOPADHYAY, A. Hypertyroidism causes cardiac dysfunction by mitochondrial impairment and energy depletion.. Journal of Endocrinology, v.217, n.2, p.215-228, 2013.

MARCHANT C.; BROWN, L.; SERNIA, C. Renin-angiotensin system in thyroid dysfunction in rats. Journal of Cardiovascular Pharmacology, v.22, p.449-445, 1993.

MARQUES, F. D.; FERRARIO, A. J.; SINISTERRA, R. D.; JACOBY, B. A.; SOUSA, F. B.; CALIARI, M. V.; SILVA, G. A.; MELO, M. B.; NADU, A. P.; SOUZA, L. E.; IRIGOYEN, M. C.; ALMEIDA, A. P.; SANTOS, R. A. An oral formulation of angiotensin-(1-7) produces cardioprotective effects in infarcted and isoproterenol-treated rats. Hypertension, v.57, n.3, p.477-483, 2011.

MARQUES, F. D.; MELO, M. B.; SOUZA, L. E.; IRIGOYEN, M. C.; SINISTERRA, R. D.; DE SOUZA, F. B.; SAVERGNINI, S. Q.; BRAGA, V. B.; FERRARIO, A. J.; SANTOS, R. A. Beneficial effects of long-term administration of na oral formulation-(1-7) in infarted rats. Internation Journal of Hypertension, v.2012, Feb 9, 2012.

MASSONE, F. Anestesiologia Veterinária: Farmacologia e Técnicas. Rio de Janeiro: Editora Guanabara Koogan, 235p, 1988.

MASTER, R. G.; DAVIES, R. A.; VEINOT, J. P.; HENDRY, P. J.; SMITH, S. J.; BOLD, A. J. Discoordinate modulation of natriuretic peptides during cardiac allograft rejection in humam. Circulation, v.100, p.287-291, 1999.

MASTER, R. G.; DAVIES, R. A.; KEON, W. J.; WALLEY, V. M.; KOSHAL, A.; BOLD, A. J. Neuroendocrine response to cardiac transplantation. Canadian Journal of Cardiology, v.9, p.609-617, 1993.

MATSUI, T.; NAGOSHI, T.; ROSENWEIG, A. Akt PI 3-kinase signaling in cardiomyocytes hypertrophy and survival. Cell Cycle, v.2, n.3, p.220-223, 2003.

MCMURRAY, J. J; PFEFFER, M. A. Heart failure. Lancet, v.365, p.1877-1889, 2005.

MEHTA, P. K.; GRIENDLING, K. K. Angiotensin II cell signaling: physiological and pathological effects in the cardiovascular system. American Journal of Physiology Cell Physiology, v.292, n.1, p.C82-C97, 2006.

MENG, W.; ZHAO, W.; ZHAO, T.; LIU, C.; CHEN, Y.; LIU, H.; SUN, Y. Autocrine and paracrine function of angiotensin 1-7 in tissue repair during hyoertension. American Jorunal of Hypertension, v.27, p.775-782, 2014.

METHOT, D.; VANKATS, J. P.; LOCHARD, N.; TREMBLAY, F.; SILVERSIDES, D. W.; REUDELHUBER, T. L. Development and application of a biological peptide pump for the study of the in vivo actions of angiotensinpeptides. American Journal of Hypertension, v.14, p.38S-43S, 2001. 
METHOT, D.; LAPOINTE, M. C.; TOUYZ, R. M.; YANG, X. P.; CARRETERO, O. A.; DESCHEPPER, C. F.; SCHIFFTRIN, E. L.; THIBAULT, G.; REUDELHUBER, T. L. Tissue targeting of angiotensin peptides. Journal of Biology Chemistry, v.272, p.12994-12999, 1997.

MORKIN, E. Control of cardiac myosin heavy chain gene expression. Microscopy research and technique, v.50, p.522-531, 2000.

NADU, A. P.; FERREIRA, A. J.; REUDELHUBER, T. L.; BADER, M.; SANTOS, R. A. Reduced isoproterenol-induced renin-angiotensin changes and extracellular matrix deposition in hearts of TGR(A1-7)3292 rats. Journal of the American Society of Hypertension, v.2, n.5, p.341-348, 2008.

NEVES, L. A.; ALMEIDA, A. P.; KLOSLA, M. C.; SANTOS, R. A. Metabolism of angiotensin I in isolated rat hearts. Effect of angiotensin converting enzyme inhibitors. Biochemistry Phamacology, v.50, n.9, p.1451-1459, 1995.

NGUYEN, G.; MULLER, D. N. The biology of the (pro) renin receptor. Journal of the American Society of Nephrology, v.21, p.18-23, 2010.

NOEUT, S.; NAHMIAS, C. Signal transduction from the angiotensin II AT2 receptor. Trends in Endocrinology \& Metabolism, v11, p.1-6, 2000.

OGAWA T.; BOLD, A. J. The heart as an endocrine organ. Endocrine conections. p.R31R44, 2014.

OJAMAA, K. Signaling mechanisms in thyroid hormone-induced cardiac hypertrophy. Vascular Pharmacology, v.52, p.113-119, 2010.

OJAMAA, K.; PETRIE, J. F.; BALKMAN, C. Posttranscriptional modification of myosin heavychain gene expression in the hypertrophied rat myocardium. Proceedings of the National Academy of Sciences USA, v.91, p.3468-3472, 1994.

PANTOS, C.; MOUROUZIS, I.; XINARIS, C.; PAPADOPOULO-DAIFOTI, D.; COKKINOS, D. Thyroid hormone and "cardiac metamorphosis": potential therapeutic implications. Pharmacology Therapy, v.118, p.277-294, 2008.

PANTOS, C.; MOUROUZIS, I.; MARKAKIS, K.; TSAGOULIS, N.; PANAGIOTOU, M.; COKKINOS, D. Long-term thyroid hormone administration reshapes left ventricular chamber and improves cardiac function after myocardial infarction in rats. Basic Research Cardiology, v.103, n.4, p.308-318, 2008.

PAULA, R. D.; LIMA, C. V.; KHOSLA, M. C.; SANTOS, R. A. Angiotensin-(1-7) potentiates the hypotensive effects of bradykinin in conscious rats. Hypertension, v.26, n.6, p.1154$1159,1995$.

PAULIS, L.; UNGER, T. Novel therapeutic targets for hypertension. Nature Reviews Cardiology, v.7, p.431-441, 2010.

PASSOS-SILVA, D. G.; BRANDAN, E.; SANTOS, R. A. S. Angiotensins as therapeutic targets beyond heart disease. Cell Press, 2015, In Press.

PARMAR, M. S. Thyrotoxic atrial fibrillation. Journal of Medicine Genetics, v.7, n.1, 2005. 
PESSÔA, B. S.; LUBBE, N.; VERDONK, K.; ROKS, A. J.; HOORN, E. J.; DANSER, A. H. Key developments in renin-angiotensin-aldosterone system inhibition. Nature Reviews Nephrology, v.9, p.26-36, 2013.

PLUIM, B. M.; ZWINDERMAN, A. H.; LAARSE, A.; WALL, E. E. The athlet's heart - a metaanalysis of cardiac structure and function. Circulation, v.101, n.3, p.336-344, 2000.

PONTES, M. R. N.; LEÃES, P. E. Remodelamento ventricular: dos mecanismos moleculares e celulares ao tratamento. Sociedade de Cardiologia do Rio Grande do Sul, v.13, n.3, 2004.

PROBST, W. C.; SNYDER, L. A.; SCHUSTER, D. I.; BROSIUS, J.; SEALFON, S. C. Sequence alignment of the G-protein coupled receptor superfamily. DNA Cell Biology, v.11, p.1-20, 1992.

RE, R. N. Mechanisms of disease: local renin-angiotensin-aldosterone systems and the pathogenesis and treatment of cardiovascular disease. Nature Clinical Practice Cardiovascular Medicine, v.1, n.1, p.42-47, 2004.

REMME, W. J. Pharmacological modulation of cardiovascular remodeling: a guide to heart failure therapy. Cardiovascular Drugs and Therapy, v.17, n.4, p.349-360, 2003.

RICE, G. I.; THOMAS, D. A.; GRANT, P. J.; TURNER, A. J.; HOOPER, N. M. Evaluation of angiotensin-converting enzyme (ECA) its homologue ECA2 and neprilysin in angiotensin peptide metabolism. The Biochemical Journal, v.383, n.8-1, p.45-51, 2004.

SAHN, D. J.; DEMARIA, A.; KISSLO, J.; WEYMAN, A. Recommendations regarding quantitation in M-mode echocardiography results of a survey of echocardiographic mesurements. Circulation, v.58, n.6, p.1072-1983, 1978

SAMPAIO, W. O.; SANTOS, R. A.; FARIA-SILVA, R.; MACHADO, L. T. M.; SCHIFFRIN, E. L.; TOUYZ, R. M. Angiotensin-(1-7) through receptor Mas mediates endothelial nitric oxide synthase activation via Akt-dependent pathways. Hypertension, v.49, n.1, p.185-192, 2007.

SAMPAIO, W. O.; NASCIMENTO, A. A.; SANTOS, R. A. Sytemic and regional hemodynamic effects of angiotensin-(1-7) in rats. American Journal of Physiology. Heart and Circulation Physiology, v.284,p.H1985-H1994, 2003.

SANTOS, R. A. Angiotensin-(1-7). Hypertension, v.63, p.1138-1147, 2014.

SANTOS, R. A.; CAMPAGNOLE-SANTOS, M. J.; BARACHO, N. C.; FONTES, M. A.; SILVA, L. C.; NEVES, L. A.; OLIVEIRA, D. R.; CALIGIORNE, S. M.; RODRIGUES, A. R.; GROPEN JUNIOR, C. Characterization of a new angiotensin antagonista selective for Angiotensin-(1$7)$ : evidence that the actions of angiotensin-(1-7) are mediated by specific angiotensin receptors. Brain Research Bulletin, v.35, n.4, p.293-298, 1994.

SANTOS, R. A.; BROSNIHAN, K. B.; CHAPPELL, M. C.; PESQUERO, J.; CHEMICKY, C. L.; GREENE, L. J.; FERRARIO, C. M. Converting enzyme activity and angiotensin metabolism in the dog brainstem. Hypertension, v.11, p.153-157, 1988.

SANTOS, R. A.; FERREIRA, A. J.; NADU, A. P.; BRAGA, A. N.; ALMEIDA, A. P.; CAMPGNOLE-SANTOS, M. J.; BALTATU, O.; ILIESCU, R.; REUDELHUBER, T. L.; BADER, $M$. Expression of an angiotensin-(1-7)-producing fusion protein produces cardioprotective effects in rats. Physiology Genomics, v.17, p.292-299, 2004. 
SANTOS, R. A; FERREIRA, A. J.; SIMOES, E. S. A. C. Recent advances in the angiotensinconverting enzyme 2-angiotensin(1-7)-Mas axis. Experimental Physiology, v.93, p.519$527,2008$.

SANTOS, R. A. S.; FERREIRA, A. J.; VERANO-BRAGA, T.; BADER, M. Angiotensinconverting enzyme 2, angiotensin-(1-7) and Mas: new players of the renin -angiotensin system. Journal of Endocrinology, v.216, n.2, p.R1-R17, 2013.

SANTOS, R. A. S.; CASTRO, C. H.; GAVA, E.; PINHEIRO, S. V.; ALMEIDA, A. P.; PAULA, R. D.; CRUZ, J. S.; RAMOS, A. S.; ROSA, K. T.; IRIGOYEN, M. C.; BADER, M.; ALENINA, N.; KITTEN, G. T.; FERREIRA, A. J. Imparement of in vitro and in vivo heart function in angiotensin-(1-7) receptor mas knouckout mice. Hytertension, v.47, n.5, p.996-1002, 2006.

SANTOS, R. A. S.; KRIEGER, E. M.; GREENE, L. J. An improved fluorometric assay of rat serum and plasma converting enzyme. Hypertension, v.7, n.2, p.244-252, 1985.

SANTOS, R. A. S.; SILVA, A. C. S.; MARIC, C.; SILVA, D. M.R.; MACHADO, R. P.; DE BUHR, I.; HERINGER-WALTER, S.; PINHEIRO, S. V.; LOPES, M. T.; BADER, M.; MENDES, E. P.; LEMOS, V. S.; CAMPAGNOLE-SANTOS, M. J.; SCHULTHEISS, H. P.; SPETH, R.; WALTHER, T. Angiotensin-(1-7) is an endogenous ligand for the Groteincouple receptor Mas. Proceedings of the National Academy of Sciences, v.100, p.82588263, 2003.

SANTOS, R. A.; CAMPAGNOLE-SANTOS, M. J. ANDRADE, S. P. Angiotensin-(1-7): an update. Regulatory Peptide, v.91, n.1-3, p.45-62, 2000.

SANTIAGO, N. M.; GUIMAROES, P. S.; SIRVENTE, R. A.; OLIVEIRA, L. A.; IRIGOYEN, M. C.; SANTOS, R. A.; CAMPAGNOLE-SANTOS, M. J. Lifetime overproduction of circulating Angiotensin-(1-7) attenuates deoxycorticosterone acetate-salt hypertension-induced cardiac dysfunction and remodeling. Hypertension, v. 55, n.4, p.889-896, 2010.

SHENOY, V.; KNOW, K. C.; RATHINASABAPATHY, A.; LIN, S.; JIN, G.; SONG, C.; SHIL, P.; NAIR, A.; QI, Y.; LI, Q.; FRANCIS, J.; KATOVICH, M. J.; DANIELL, H.; RAIZADA, M. K. Oral delivery of Angiotensin-Converting enzyme 2 and Angiotensin-(1-7) bioencapsulated in plant cells attenuates pulmonary hypertension. Hypertension, 2014.

SIU, C. W.; YEUNG, C. Y.; LAU, C. P.; KUNG, A. W.; TSE, H. F. Incidence, clinical characteristics and outcome of congestive heart failure as the initial presentation in patients with primary hyperthyroidism. Heart (British Cardiac Society), v.3, n.4, p.483-487, 2007.

SONG, B.; ZHANG, Z. Z.; ZHONG, J. C.; YU, X. Y.; OUDIT, G. Y.; JIN, H. Y.; LU, L.; XU, Y. L.; KASSIRI, Z.; SHEN, W. F.; GAO, P. J.; ZHU, D. L. Loss of angiotensin-converting enzyme 2 exacerbates myocardial injury via activation of the CTGF-fractalking signaling pathway. Circulation Journal, v.77, p.2997-3006, 2013.

SZKUDLAREK, A. C.; ALDENUCCI, B.; MIYAGUI, N. I.; SILVA, I. K.; MORAES, R. N.; RAMOS, H. E.; FOGAÇA, R. T. Short-Term Thyroid Hormone Excess Affects the Heart but Does not Affect Adrenal Activity in Rats. Arquivos Brasileiros de Cardiologia, v.102, n.3, p.270-278, 2014.

TADEVOSYAN, A.; MAGUY, A.; VILLENEUVE, L. R.; BABIN, J.; BONNEFOY, A.; ALLEN, B. G.; NATTEL, S. Nuclear-delimited angiotensin receptor-mediated signaling regulates cardiomyocyte gene expression. The Journal of Biological Chemistry, v.285, p.2233822349, 2010. 
TAKANO, A. P.; DINIZ, G. P.; BARRETO-CHAVES, M. L. AMPK signaling pathways is rapidly activated by $\mathrm{T} 3$ and regulates the cardiomyocyte growth. Molecular Cell Endocrinology, v.376, n.1-2, p.43-50, 2013.

TALLANT, E. A.; FERRARIO, C. M.; GALLACHER, P. E. Angiotensin-(1-7) inhibits growth of cardiac myocytes through activation of the mas receptor. American Journal of Physiology. Heart and Circulation Physiology, v.289, n.4, p.H1560-H1566, 2005.

TAVARES, F. M.; SILVA, I. B.; GOMES, D. A.; BARRETO-CHAVES, M. L. Angiotensin II type 2 receptor (AT2R) is associated with increased tolerance of the hyperthyroid heart to ischemia-reperfusion. Cardiovascular Drugs Therapic, v.27, n.5, p.393-402, 2013.

TIKELLIS, C.; BERNARDI, S.; BURNS W. C. Angiotensin-converting enzyme 2 is a key modulator of the renin-angiotensin system in cardiovascular and renal disease. Current Opinon in Nephrology and Hypertension, v.20, p.62-68, 2011.

TRASK, A. J.; FERRARIO, C. M. Angiotensin-(1-7): Pharmacology and New Perspectives in Cardiovascular Treatments. Cardiovascular Drug Review, v.25, n.2, 2007.

TWIST, D. J. L.; HOUBEN, A. J.; HAAN, M. W.; MOSTARD, G. J.; KROON, A. A.; LEEUW, P. W. Angiotensin-(1-7)-induced renal vasodilation in hypertensive humans is attenuated by low sodium intake and angiotensin II co-infusion. Hypertension, v.62, p.789-793, 2013.

TWIST, D. J. L.; KROON, A. A.; LEEUW, P. W. Angiotensin-(1-7) as a strategy in the treatment of hypertension? Current Opnion, v.23, n.5, 2014.

VICKERS, C.; HALES, P.; KAUSHIK, V.; DICK, L; GAVIN, J.; TANG, J.; GODBOUT, K.; PARSONS, T.; BARONAS, E.; HSIEH, F.; ACTON, S.; PATANE, M.; NICHOLS, A.; TUMMINO, P. Hydrolysis of biological peptides by humam angiotensin-converting enzymerelated carboxypeptidase. Journal of Biological Chemistry. v.277, n.17, p.14838-14843, 2002.

WEISS, D.; KOOLS, J. J.; TAYLOR, W. R. Angiotensin II-induced hypertension accelerates the development of atherosclerosis in apo E- deficient mice. Circulation, v.103, p.448-454, 2001.

WILDEMBERG, L. E. A.; SOUZA, L. L.; FONSECA, L. P.; SAOUZA, M. V. Reversible dilated cardiomyopathy related to hyperthyroidism. Arquivos Brasileiros Endocrinologia $\mathbf{e}$ Metabogia, v. 51, n.9, p.1533-1538, 2007.

WORLD HEALTH ORGANIZATION (WHO). Global status report on nocommunicable diseases, 2014.

WRIGHT, J. W.; HARDING, J. W. Brain angiotensin receptor subtypes AT1, AT2 and AT4 and their functions. Regulation Peptides, v.59, p.269-295, 1995.

YAMADA, K.; IYER, S. N.; CHAPPELL, M. C.; GANTEN, D.; FERRARIO, C. M. Converting enzyme determines the plasma clearance of Angiotensin-(1-7). Hypertension, v.98, p.492502, 1998.

YEN, P. M. Physiological and molecular basis of thyroid hormone action. Physiology Reviews, v.81, p.1097-1142, 2001.

YOKOTA, N. Dissociation of cardiac hypertrophy, myosin heavy chain isoform expression, and natriuretic peptide production in DOCA-salt rats. American Journal of Hypertension, v.8, p.301-310, 1995. 
YOUNG, D.; WAITCHES, G.; BIRCHMEIER, C.; FASANO, O.; WIGLER, M. Isolation and Characterization of a new cellular oncogene encoding a protein with multiple potential transmembrane domains. Cell, v.45, n.5, p.711-719, 1986.

ZISMAN, L. S.; KELLER, R. S.; WEAVER, B.; LIN, Q.; SPETH, R.; BRISTOW, M. R.; CANVER, C. C. Increased angiotensin-(1-7)-forming activity in failure human heart ventricules: evidence for upregulation of the angiotensin-converting enzyme homologue ACE2. Circulation, v.108, p.1707-1712, 2003. 


\section{ANEXOS}

A - Resultados obtidos em ratos tratados com infusão contínua de Ang1-7.

Inicialmente, para responder os objetivos propostos neste trabalho, foi utilizado outro modelo experimental, no qual ratos Wistar selvagens adultos (com 12 semanas de vida) pesando entre $230-250 \mathrm{~g}$, foram induzidos ao hipertireoidismo por 28 dias e/ou tratados simultaneamente com infusão contínua de Ang 1-7. A administração do heptapeptídeo foi realizada mediante utilização de minibombas osmóticas (Alzet, modelo 2004: 0,25 $\mu \mathrm{l} / \mathrm{h}, 28$ dias) implantadas no dorso dos animais, sendo a dose de Ang 1-7 correspondente a $24 \mu \mathrm{g} / \mathrm{Kg} / \mathrm{h}$ (LOOT et al., 2002). Após os 28 dias de tratamento, avaliamos o trofismo cardíaco mediante análise da massa cardíaca, bem como por quantificação do diâmetro do cadiomiócito em cortes histológicos do ventrículo esquerdo. A pressão caudal e a frequência cardíaca dos animais foram mensuradas semanalmente, durante os 28 dias de tratamento, por plestimografia caudal.

Em relação ao trofismo cardíaco, conforme apresentado na Figura 20, é possível verificar, apenas por avaliação visual, um aumento significativo do tamanho do coração nos animais tratados com T3. Esta hipertrofia é aparentemente concêntrica, uma vez que ocorre intenso espessamento da parede do ventrículo esquerdo, com aparente diminuição do volume da câmara ventricular, parâmetro que não parece ser alterado no grupo que recebeu concomitantemente Ang 1-7.

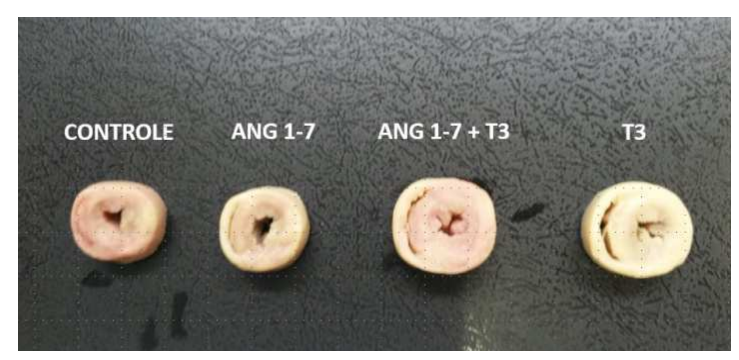

Figura 20 - Corte transversal do coração, em uma altura equidistante da base e do ápice; coletado logo após eutanásia. Da esquerda para a direita, grupos: controle, tratado apenas com Ang 1-7, tratado com Ang 1-7 e T3 e, por último, tratado apenas com T3. 
A hipertrofia cardíaca induzida por T3 foi confirmada pelo aumento da massa cardíaca nos animais induzidos ao hipertireoidismo (Figura 21), com aumento de 41,92 \% na massa cardíaca total em relação aos animais controles. Quando avaliadas as câmaras cardíacas separadamente, o hormônio tireoidiano foi responsável por promover um aumento de $27,37 \%$ da massa do VE e de $33,33 \%$ da massa do VD, em relação às respectivas massas do grupo controle (Figura 22). O tratamento com Ang 1-7 não promoveu qualquer efeito nestes parâmetros e tampouco preveniu ou atenuou os efeitos tróficos do T3, quando administrado concomitantemente a este (Figuras 21 e 22).

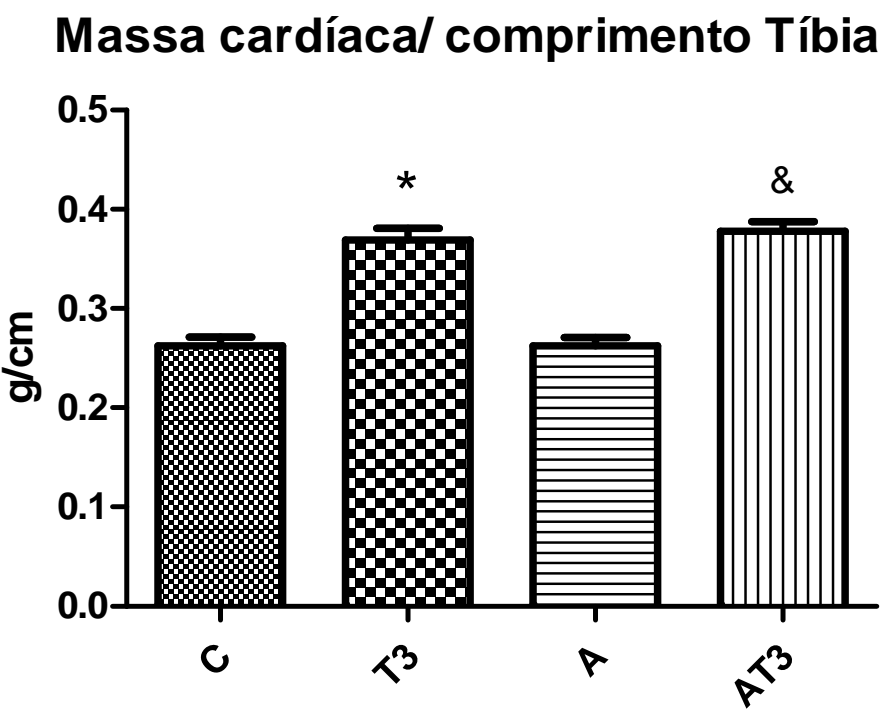

* vs. Controle $(p<0,001)$

\& vs. $\mathbf{A}(p<0,001)$

Figura 21 - Massa cardíaca (em g) normalizada pelo comprimento da tíbia (em $\mathrm{cm}$ ) nos diferentes grupos experimentais [C: Grupo controle ( $n=7)$; T3: Grupo hipertireoideo ( $n=7)$; A: Grupo tratado com Ang 1-7 ( $n=7)$; AT3: Grupo hipertireoideo tratado com Ang 1-7 $(n=7)]$. O teste estatístico utilizado foi ANOVA One Way, seguida de Pós-teste de Tukey. 
A

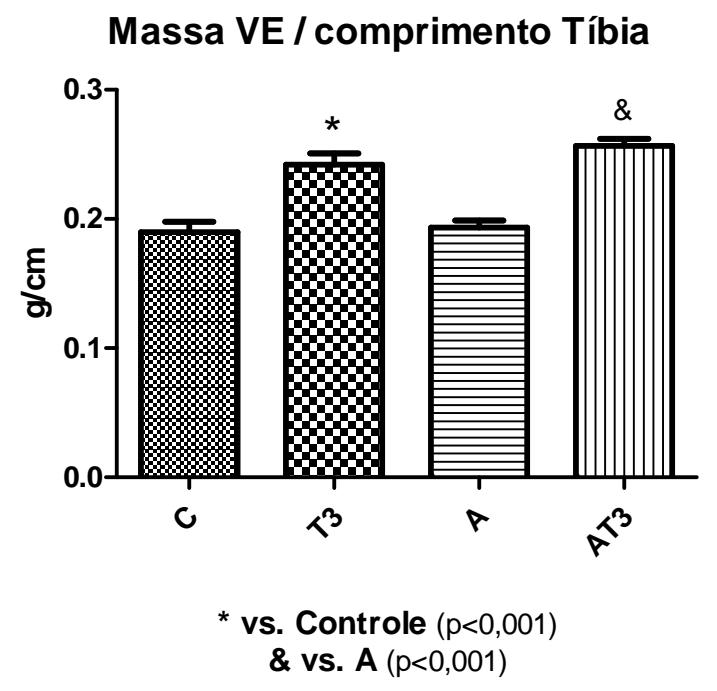

B

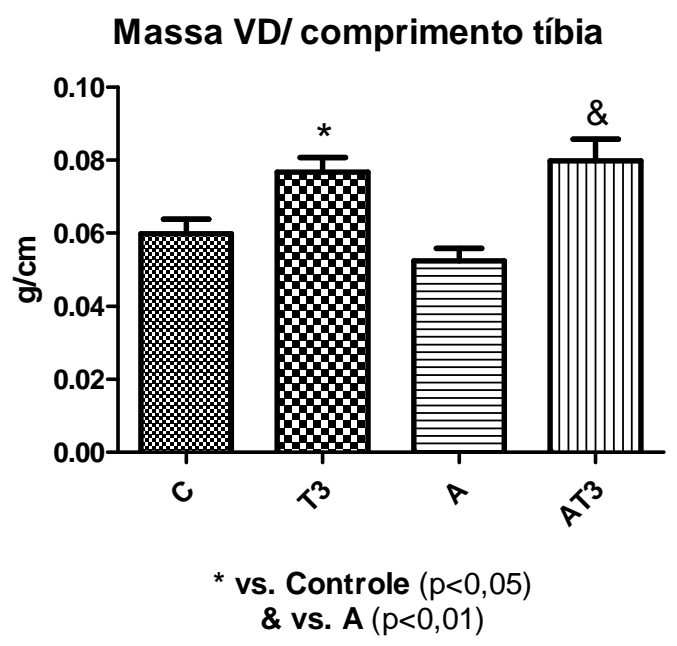

Figura 22 - Massa do VE e VD (em g), normalizadas pelo comprimento da tíbia, nos diferentes grupos experimentais. A - Massa do VE [C: Grupo controle ( $n=7)$; T3: Grupo hipertireoideo ( $n=7)$; A: Grupo tratado com Ang 1-7 (n=7); AT3: Grupo hipertireoideo tratado com Ang 1-7 $(n=7)]$. B - Massa do VD [C: Grupo controle ( $n=7)$; T3: Grupo hipertireoideo ( $n=7)$; A: Grupo tratado com Ang 1-7 $(n=7)$; AT3: Grupo hipertireoideo tratado com Ang 1-7 $(n=7)]$. O teste estatístico utilizado foi ANOVA One Way, seguida de Pós-teste Tukey. 
Ainda com o intuito de confirmarmos a presença da hipertrofia cardíaca nos animais hipertireoideos, bem como de verificarmos as possíveis ações antihipertróficas da Ang 1-7, avaliamos a organização do tecido cardíaco e o diâmetro transverso dos cardiomiócitos nos diferentes grupos experimentais (Figura 23).

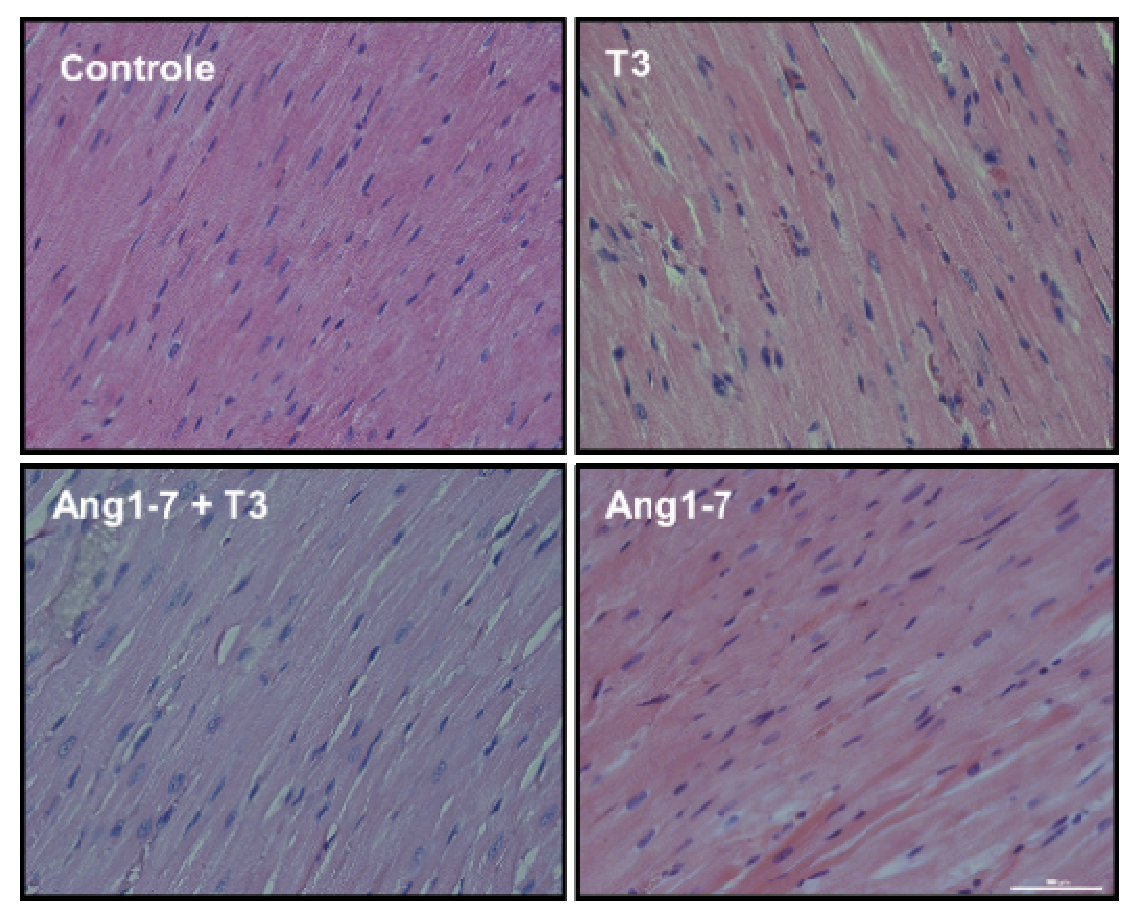

Figura 23: Corte histológico do VE corado com Hematoxilina e Eosina nos diferentes grupos experimentais, no aumento de $40 \mathrm{X}$.

O tratamento com HT promoveu um significativo aumento no diâmetro transverso dos cardiomiócitos da parede livre tanto do VE (C: $5,88 \pm 0,16$; T3: 8,88 $\pm 0,42$; A+T3: $8,01 \pm 0,28$; $A: 6,5 \pm 0,65$ micrometro) (Figura $24 \mathrm{~A}$ ) como no VD (C: 7,0 \pm 0,23; T3: 9,21 \pm 0,19; A+T3: 10,52 $\pm 0,57 ; A: ~ 7,15 \pm 0,19$ micrometro) (Figura $24 \mathrm{~B}$ ), o que caracteriza um efeito hipertrófico nessas câmaras. Entretanto, em mais um parâmetro avaliado, o tratamento concomitante com Ang 1-7 não foi capaz de prevenir ou atenuar esse efeito hipertrófico promovido pelo HT nas duas câmaras cardíacas. 
A

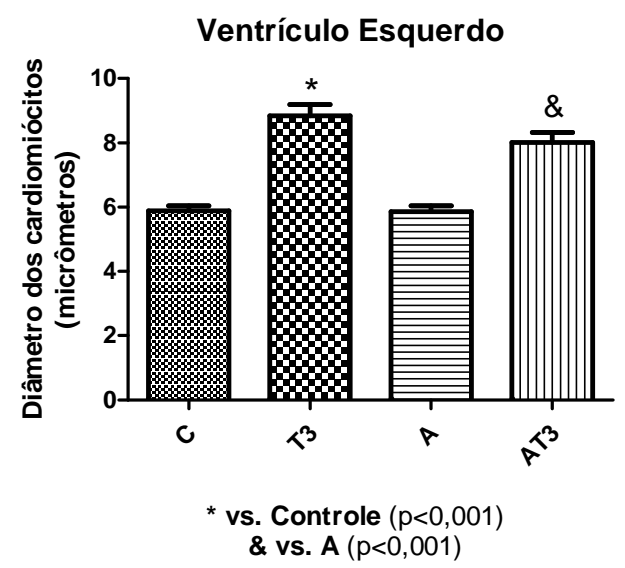

B

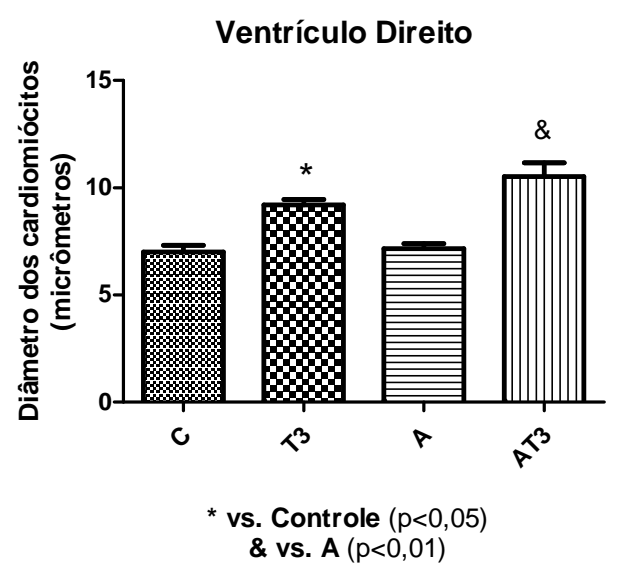

Figura 24 - Diâmetro transverso dos cardiomiócitos (em micrômetro) nos diferentes grupos experimentais. A - Diâmetro dos cardiomiócitos da parede livre do VE [C: Grupo controle $(n=7)$; T3: Grupo hipertireoideo ( $n=7)$; A: Grupo tratado com Ang 1-7 ( $n=7)$; AT3: Grupo hipertireoideo tratado com Ang 1-7 $(n=7)$ ]. B - Diâmetro dos cardiomiócitos da parede livre do VD [C: Grupo controle $(n=7)$; T3: Grupo hipertireoideo ( $n=7)$; A: Grupo tratado com Ang 1-7 $(n=7)$; AT3: Grupo hipertireoideo tratado com Ang 1-7 $(n=7)]$. O teste utilizado foi ANOVA One Way, seguida de Pós-teste Tukey.

Em relação às medidas de pressão caudal e frequência cardíaca, conforme pode ser observado na Figura 25, o tratamento com T3 induziu um significativo aumento na frequência cardíaca, a partir do sétimo dia, e este parâmetro não foi influenciado pelo tratamento concomitante com a Ang 1-7. Do mesmo modo, a pressão caudal, a qual dá ideia da PAS, apresentou um aumento significativo com o tratamento de $\mathrm{HT}$, a partir do $14^{\circ}$ dia, o qual também não foi praticamente influenciado pela infusão de Ang 1-7 (Figura 26). 


\section{Frequência Cardíaca}

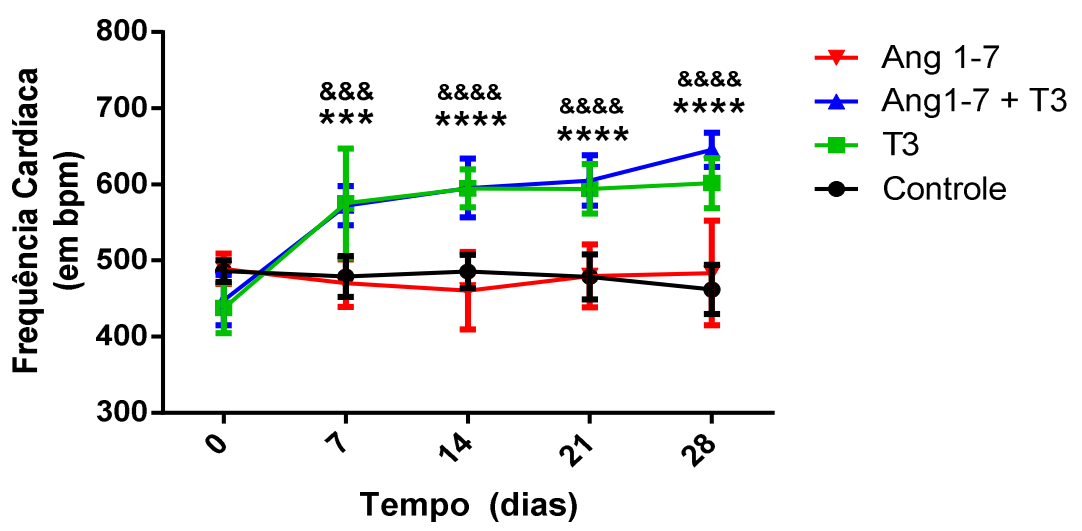

Figura 25 - Frequência cardíaca (em bpm) nos diferentes grupos experimentais [C: Grupo controle ( $n=7)$; T3: Grupo hipertireoideo ( $n=7)$; A: Grupo tratado com Ang 1-7 ( $n=7)$; AT3: Grupo hipertireoideo tratado com Ang 1-7 $(n=7)$ ]. As medidas foram realizadas no dia anterior ao início do tratamento (dia 0 ), no $7^{0}, 14^{0}, 21^{0}$ e $28^{0}$ dia de tratamento. O teste utilizado foi ANOVA One Way, seguida de Pósteste Tukey.

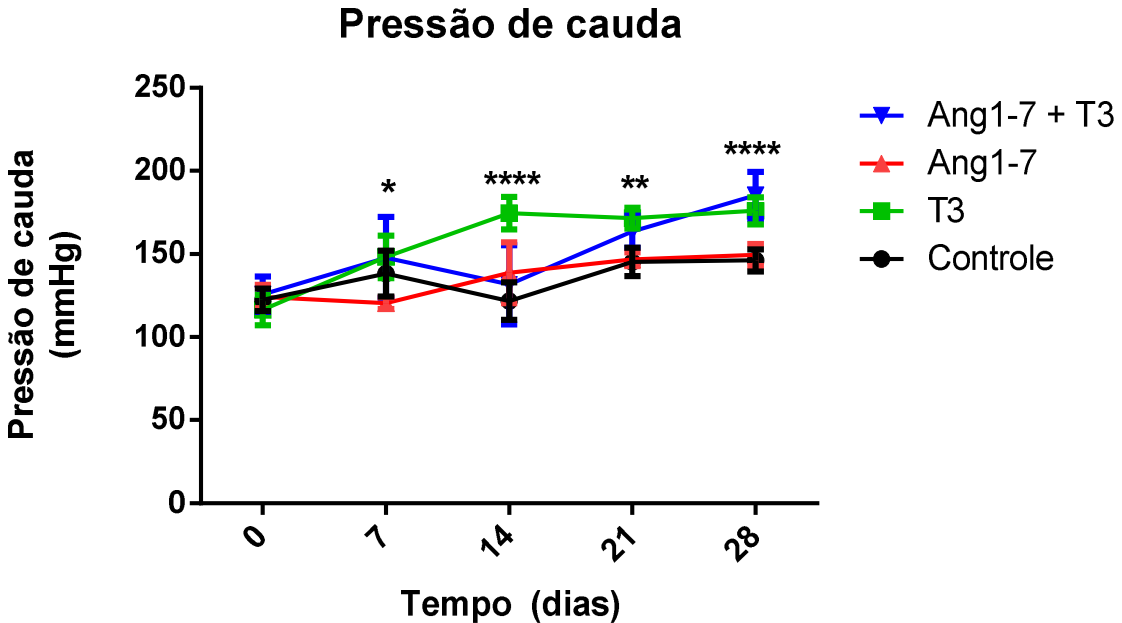

Figura 26 - Pressão de cauda (em $\mathrm{mmHg}$ ) nos diferentes grupos experimentais [C: Grupo controle ( $n=7)$; T3: Grupo hipertireoideo ( $n=7)$; A: Grupo tratado com Ang 1-7 ( $n=7)$; AT3: Grupo hipertireoideo tratado com Ang 1-7 $(n=7)]$. As medidas foram realizadas no dia anterior ao início do tratamento (dia 0), no $7^{0}, 14^{0}, 21^{0}$ e $28^{0}$ dia de tratamento. O teste utilizado foi ANOVA One Way, seguida de Pósteste Tukey. 
Portanto, diante dos resultados apresentados neste modelo experimental, pudemos verificar que o tratamento com Ang 1-7 não foi capaz de inibir ou atenuar a hipertrofia cardíaca induzida por T3 em ratos Wistar, assim como não apresentou efeito algum sobre os parâmetros de pressão caudal e frequência cardíaca.

Sendo assim, diante dos resultados obtidos em cultura de cardiomiócitos neonatos, confirmamos uma importante ação anti-hipertrófica da Ang 1-7 frente aos efeitos cardíacos do T3 e, portanto, nos questionamos a respeito da eficiência da liberação de Ang 1-7 pela bomba osmótica em nosso modelo experimental com ratos Wistar. Neste sentido, não apenas a liberação propriamente dita, mas a meiavida muito curta do peptídeo Ang 1-7 pode ter comprometido o seu efeito junto aos parâmetros avaliados. Em roedores, a meia-vida da Ang 1-7 é de aproximadamente 20 segundos, quando administrada por via intravenosa, a qual pode ser aumentada com o uso crônico de inibidor da ECA (lisopril) e antagonista do AT1 (losartan) (YAMADA et al., 1998). Em humanos, quando administrada por via intravenosa, a Ang 1-7 apresenta uma meia vida de aproximadamente 30 minutos (KONO et al., 1986). Portanto, decidimos então investir esforços novamente e testar um novo modelo experimental, utilizando animais transgênicos que apresentam superexpressão da Ang 1-7, animais TGR-L3292. Com a utilização deste novo modelo experimental pudemos então testar e comprovar a nossa hipótese inicial, conforme se observa ao longo da Dissertação.

B - Tabela com os parâmetros funcionais avaliados por ecocardiograma. 
Tabela 6 - Parâmetros funcionais avaliados por ecocardiograma nos diferentes grupos experimentais.

\begin{tabular}{|c|c|c|c|c|c|c|c|c|}
\hline & Razão E/A & $\begin{array}{c}\text { Tempo de } \\
\text { ejeção aórtico } \\
\text { (ms) }\end{array}$ & $\begin{array}{c}\text { Volume do VE } \\
\text { na diástole } \\
\text { (uL) }\end{array}$ & $\begin{array}{l}\text { Volume do } \\
\text { VE na sístole } \\
\text { (uL) }\end{array}$ & $\begin{array}{c}\text { Fração de } \\
\text { encurtamento } \\
(\%)\end{array}$ & $\begin{array}{l}\text { Fração de } \\
\text { ejeção (\%) }\end{array}$ & $\begin{array}{l}\text { Débito } \\
\text { cardíaco } \\
\text { (ml/mim) }\end{array}$ & $\begin{array}{c}\text { Frequência } \\
\text { cardíaca } \\
\text { (bpm) }\end{array}$ \\
\hline Controle & $1,48 \pm 0,9$ & $65,5 \pm 0,9$ & $336,3 \pm 8$ & $102,5 \pm 4,7$ & $40,2 \pm 1,1$ & $69,1 \pm 1,3$ & $68,9 \pm 1,5$ & $331,1 \pm 10,8$ \\
\hline T3 & $0,96 \pm 0,1$ * & $49,2 \pm 0,8$ * & $282,9 \pm 17,5$ & $44,2 \pm 5,2$ * & $55,2 \pm 1,5$ * & $84,5 \pm 1,3$ * & $120,9 \pm 5,9$ * & $468,8 \pm 12,7$ * \\
\hline A & $1,48 \pm 0,5$ & $74,6 \pm 2,0$ * & $381,9 \pm 28,9$ & $144,1 \pm 10$ * & $34,3 \pm 1,6$ & $61,2 \pm 2,1$ & $69,2 \pm 7,8$ & $307 \pm 5,4$ \\
\hline AT3 & $1,5 \pm 0,2^{\$}$ & $59,1 \pm 1,7^{\& \$}$ & $350,0 \pm 24,5^{\$}$ & $98,2 \pm 12,7^{\& \$}$ & $43,2 \pm 1,6^{\& \$}$ & $72,4 \pm 1,8$ \& \$ & $102,3 \pm 7,0^{\&}$ & $381,3 \pm 14,2$ \$ \& \\
\hline AT3A & $1,33 \pm 0,1$ & $57,8 \pm 2,0^{\&}$ & $247,7 \pm 15,7^{\text {\&\# }}$ & $47,1 \pm 7,4$ \&\# & $51,9 \pm 2,6^{\& \#}$ & $81,5 \pm 2,2^{\& \#}$ & $80,5 \pm 6,7$ & $405,0 \pm 16,6^{\text {\& }}$ \\
\hline [C: Grupo cc & le $(n=5) ;$ T3 & irupo hipertireoi & $0(n-6) \cdot A \cdot G$ & t̂nin & trole $(n=5)$ : $A 7$ & 2. Grung tro & înico hipertire & ideo $(n=6)$ \\
\hline AT3A: Grupo & ertireoideo tr & ado com A770 ( & $=6)] .0$ teste estati & ístico utilizado fo & i ANOVA One W & $y$, seguida de & ós-teste de Tuk & ey, sendo * \\
\hline
\end{tabular}

